\title{
Climate Change, Capitalism, and Citizen Science: Developing a dialectical framework for examining volunteer participation in climate change research
}

Joshua A. Wixom

Follow this and additional works at: https://researchrepository.wvu.edu/etd

\section{Recommended Citation}

Wixom, Joshua A., "Climate Change, Capitalism, and Citizen Science: Developing a dialectical framework for examining volunteer participation in climate change research" (2016). Graduate Theses, Dissertations, and Problem Reports. 6966.

https://researchrepository.wvu.edu/etd/6966

This Dissertation is protected by copyright and/or related rights. It has been brought to you by the The Research Repository @ WVU with permission from the rights-holder(s). You are free to use this Dissertation in any way that is permitted by the copyright and related rights legislation that applies to your use. For other uses you must obtain permission from the rights-holder(s) directly, unless additional rights are indicated by a Creative Commons license in the record and/ or on the work itself. This Dissertation has been accepted for inclusion in WVU Graduate Theses, Dissertations, and Problem Reports collection by an authorized administrator of The Research Repository @ WVU.

For more information, please contact researchrepository@mail.wvu.edu. 
Climate Change, Capitalism, and Citizen Science: Developing a dialectical framework for examining volunteer participation in climate change research

\author{
Joshua A Wixom
}

\author{
Dissertation submitted \\ to the Eberly College of Arts and Sciences \\ at West Virginia University \\ in partial fulfillment of the requirements for the degree of \\ Doctor of Philosophy in \\ Geography
}

\author{
Brent McCusker, Ph.D., Chair \\ Robert Behling, Ph.D. \\ Robert Hanham, Ph.D. \\ Phil O'Keefe, Ph.D. \\ Bradley Wilson, Ph.D. \\ Department of Geology and Geography
}

Morgantown, West Virginia

2016

Keywords: Citizen Science, Scientific Literacy, Climate Change, Consensus, SATELLITES, Dialectic, Media Discourses

Copyright 2016 Joshua A Wixom 


\begin{abstract}
Climate Change, Capitalism, and Citizen Science: Developing a dialectical framework for examining volunteer participation in climate change research
\end{abstract}

\title{
Joshua A Wixom
}

This dissertation discusses the complex social relations that link citizen science, scientific literacy, and the dissemination of information to the public. Scientific information is not produced in value-neutral settings by people removed from their social context. Instead, science is a social pursuit and the scientist's social context is embedded in the knowledge produced. Additionally, the dissemination of this information via numerous media outlets is filtered through institutional lenses and subject to journalistic norms. As a result, the general public must be able to recognize the inherent biases in this information. Yet, the rates of scientific literacy in the U.S. are quite low, which suggests that people may not be capable of fully understanding the biases present. Furthermore, people tend to seek out sources that reinforce their values and personal perspectives, thus reinforcing their own biases. Improving scientific literacy allows people to see past these biases and translate media narratives in order to comprehend the facts and evidence presented to them. Citizen science is both an epistemological tool used by scientists to collect and interpret scientific data and a means to improve the scientific literacy of participants. Citizen science programs have the ability to generate real knowledge and improve the critical thinking skills necessary for the general public to interpret scientific information. 


\section{ACKNOWLEDGEMENTS}

For Brent. Many thanks to my advisor Brent McCusker; without your help I would never have been able to realize my full potential. Your mentorship and friendship have guided me through this process and you will always have my respect and admiration. You taught me to be a better writer, a more vocal participant, and a proper scientist.

I would like to thank my committee: Drs. Behling, Hanham, O'Keefe, and Wilson. The guidance and support you have given me have proven invaluable as I conducted my dissertation work. Your collective wisdom has made me a better scholar and helped me realize that, no matter what obstacles lay before me, I can rise to the challenge.

What can I say about a person that has given me so much? Jessica, you deserve more thanks than there are stars in the sky. You stood by me through it all. You have made me a better person and helped me realize what I am capable of even when I doubt it myself. Your support has been so complete and for that I am truly grateful.

This work cannot be done in isolation. Ideas must be shared, critiqued, and refined. I was fortunate enough to be surrounded by people that shared my passion for learning and helped me along the way. Paul, Jenn, Maingi, Joyce, Derek, and Allyssa thank you for all that you have done.

Marx was right; there is no royal road to science. I have spent a great deal of time making the arduous climb. This is not the end of the journey, just another switchback to traverse. I will continue my pursuit and hopefully someday I will arrive at the summit.

Joshua A Wixom

Morgantown, West Virginia 2016 


\section{TABLE OF CONTENTS}

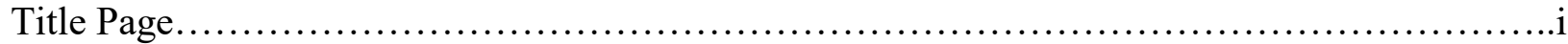

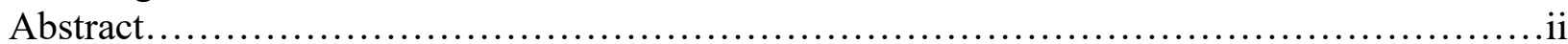

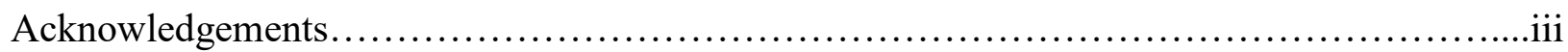

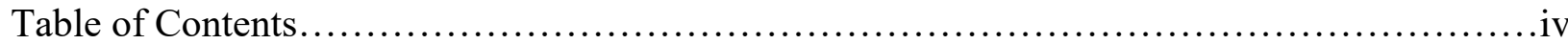

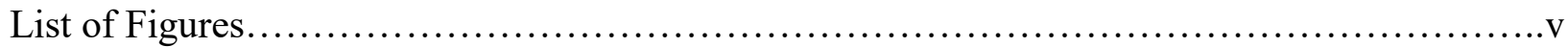

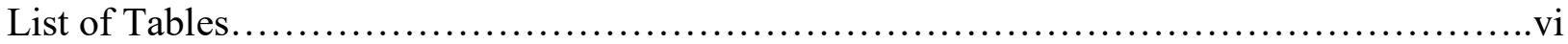

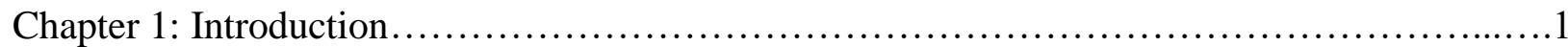

Chapter 2: Arguing over Agreement: Media Coverage of the Consensus on Anthropogenic Climate Change......................................................... 10

Chapter 3: Citizen Science and Environmental Learning: A Case Study of the SATELLITES

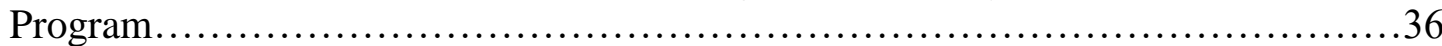

Chapter 4: A Brief Discussion of Marx's Dialectical Method...............................60

Chapter 5: Citizen Science as a Mode of Knowledge Production: Examining the Role of Volunteer Participation in Scientific Research............................... 74

Chapter 6: Conclusion................................................................. 106

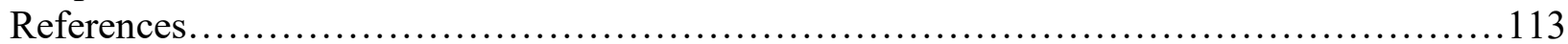




\section{LIST OF FIGURE}

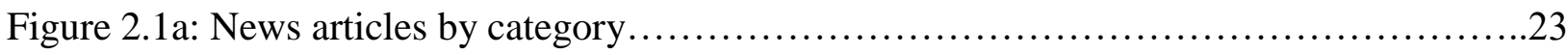

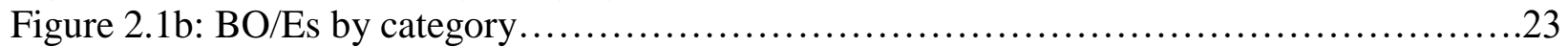

Figure 3.1: Respondent demographics by category.................................48-49

Figure 3.2: Diverging response rates for Likert-scale questions.............................55 


\section{LIST OF TABLE}

Table 2.1: Article sources for content analysis......................................19

Table 2.2: Major themes emerging from a content analysis of news stories related to the

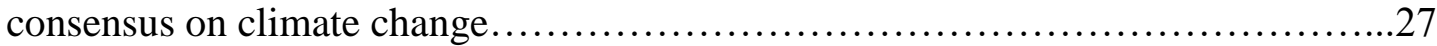

Table 2.3: Major themes emerging from a content analysis of blog posts and opinion/editorial

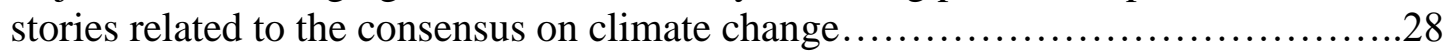

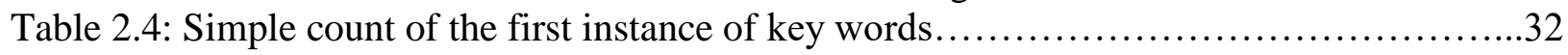

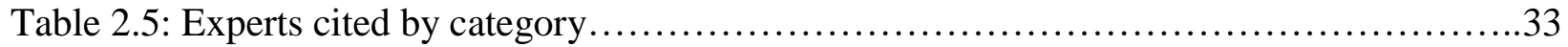

Table 3.1: Response rates for Likert-scale questions................................52-53 


\section{Chapter 1: Introduction}

"There is no royal road to science, and only those who do not dread the fatiguing climb of its steep paths have a chance of gaining its luminous summits.” (Marx, [1872] 1990)

This dissertation is about the complex dialectic that exists between the scientific enterprise, public participation in science, and the level of scientific literacy in the U.S. as it applies to topics related to climate change. Science has focused a great deal on the physical evidence of climate change and the direct links to human activity. Additionally, attention has been given to the way in which capitalism informs the socioeconomic and political actions of societies and the ways in which these activities influence climate change (Demerritt, 2001; O’Hara, 2009; Wainwright, 2010; Wainwright \& Mann 2012). Yet, there has not been a great deal of scholarship on the dialectic that links the production of scientific knowledge, for whom it is produced, and how the public in general interacts with this information. Thus, the main objective of this dissertation was to uncover these relations and determine how science and society interact to produce representations of complex issues and how society and science learn from one another. This dissertation examined how the media generated narratives discussing the consensus on anthropogenic climate change (ACC), how these narratives produced controversies, and created uncertainty within the U.S. public (Carvalho, 2007). This dissertation also assessed how citizen science projects impact scientific literacy among a group of volunteers participating in the Students and Teachers Exploring Local Landscapes to Interpret the Earth From Space (SATELLITES) program. Finally, Marx's dialectic was used to assess how the historical development of scientific thought has come to create citizen science programs, how volunteers can impact science in general, and how citizen science participation can improve literacy, thus offering a means for the public to better interpret media narratives that generate controversy (Ollman, 2003). The research goals of this dissertation were to: (i) understand how 
controversy is generated by media narratives on consensus, (ii) examine how these controversies impact the public's understanding of ACC, (iii) assess how the SATELLITES program impacts scientific learning, (iv) determine how scientific thought informs the development of citizen science programs, and (v) examine how citizen science programs can promote scientific literacy while challenging the authority of the scientific enterprise.

Marx's dialectic was of particular importance for this investigation due to its unique ability to examine phenomena from various perspectives (Marx, [1867] 1990; Ollman, 2003). For Marx, careful study and exposition of the underlying relations of phenomena can produce an accurate understanding of how surface appearances arise and how they are interpreted (Marx, [1867] 1990). Marx was critiquing modern science's logical positivist, empirical approach to producing knowledge, which is often overly reductionist and does not always capture the relations that give rise to the phenomena under observation (Levins \& Lewontin, 1985). Contrary to Marx's core assumption, empiricism implies that conclusions about the outward appearances of the concrete world can be drawn through repeated observations. This form of study has the potential to miss the interactions that occur between the subject of investigation and other phenomena leading to an incomplete understanding. This is particularly true when discussing topics like ACC, scientific literacy and the like. Adding to the complexity of investigation is the fact that productive forces in society, arising from the capitalist mode of production, influence the mode of exposition as well as the phenomena. As the history of capitalism unfolds, its influence penetrates more completely to inform the myriad elements that make up society (Peet, 2007). Marx's own analyses focused on the penetration of capitalism and its embeddedness within society (Bohm, 1983). Thus the use of moving windows of investigation can help researchers observe readily apparent forms, constructs, and social dynamics, which cannot be 
taken as objective truth but rather representations of more complex processes (Ollman, 1993; 2003). Viewed in this way, the production of knowledge is highly structured by the underlying relations that generate complex social interactions. When we frame complex issues such as climate change, citizen science, or the production of media narratives as arising from underlying social relations and not just surface appearances that can be study, we can begin to uncover the very essence of the problem.

Of course, a person's introduction to any issue is either through engaging with the science or, more often, through media representations of that topic. The media delivers translations of complex topics to the public that are shaped by professional norms and filtered through institutional lenses (Carvalho, 2007). These institutional lenses are strongly influenced by the values and socioeconomic perceptions of a given media outlet and can vary widely based on the source's ideological perspective (Demeritt, 2001). As a result, news about scientific issues, although presented as objective, tends to adopt the ideological constraints of the original source. This is particularly true will the coverage on ACC, which is continuously being delivered to the public through value-laden accounts (Lahsen, 2005). Media coverage on ACC demonstrates how an issue with nearly universal agreement among the scientific community can be presented to the general public as if there were substantive disagreements among experts (Antilla, 2005).

In their fifth assessment report for policymakers, the Intergovernmental Panel on Climate Change (IPCC) stated that "[W]arming of the climate system is unequivocal" and that it is "extremely likely that human influence has been the dominant cause of the observed warming since the mid-20th century" (Alexander et al., 2013: SPM-3; SPM-12). The case is being made, stronger than ever, that climate change is a direct result of human activity. There is a high 
probability that mean surface temperatures have increased by $0.5^{\circ} \mathrm{C}$ to $1.3^{\circ} \mathrm{C}$ from 1951 to 2010 and the cause of this has been increases in greenhouse gas emissions (GHGs). Additionally, it is predicted that warming will increase by $0.4^{\circ} \mathrm{C}$ to $4.8^{\circ} \mathrm{C}$ by the end of the 21 st century. Sea ice extent and Northern Hemisphere spring snow cover have shrunk along with Arctic and Antarctic ice sheet volumes. This has lead to a mean sea level rise of $0.19 \mathrm{~m}$ from 1901 to 2010 with a prediction of additional increases between $0.17 \mathrm{~m}$ to $0.82 \mathrm{~m}$ by 2100 . The world's oceans are acting as net sinks for increased energy accumulation, which has been increased by $3 \mathrm{~W} \mathrm{~m}^{-2}$ due to increases in GHG emissions. These emissions have reached levels that are unprecedented in at least 800,000 years of the proxy record. There will be a legacy of effects that persist for decades to centuries - even if GHG emissions become highly regulated over night - that result from complex interactions of atmospheric chemistry and global energy storage physics. Uncertainty, however, will always be present in any scientific data (Shackley \& Wynne, 1998). Unfortunately, there are numerous competing interests that have a stake in the outcomes of ACC, all of which are competing to privilege their own agenda. Groups that would be disadvantaged by solutions to ACC use this uncertainty to maintain the status quo. This process is anything but neutral with a great deal of socioeconomic and political leverage at stake (Peet, 2007; Peet \& Hartwick, 2009). When viewed through a Marxist lens, the discussion on global climate change becomes highly complex and brings to the foreground all of the underlying issues that are hidden by the construction of scientific facts, the formulation of dissent, and discussions of uncertainty. In short, it is impossible to separate the socio-political, biological, economic, and physical determinants of climate change from one another, thus transforming the science of climate change and its dissent into a dialectic of climate change (Harvey, 1996). For scientists, these controversies have the dual impact of forcing them to defend the science as valid and credible, 
while arguing that science is inherently social (Leiserowitz et al., 2013). Debates over controversies become deeply entrenched within the social and political arenas where they play out to whatever end, typified by intractable rhetoric. There must be a recognition that science cannot exist in a vacuum, it cannot be viewed as the pursuit and accumulation of facts; it must become more social and incorporate the implications of internal relations as subject matter, and the findings of this research must be made explicit and open to the public (Latour, 1986; Ollman, 2003).

There is, however, a growing consensus among scientists that the climate change is real, has concrete implications to humanity, and is, in large part, attributable to human activity (Cook et al., 2013). The science - the physical and empirical evidence for climate change-brings the implications of ACC up against economic norms that have, in many ways, led to this environmental crisis and forces scientists and academics to engage with the complex set of interactions at work. Indeed, the strategies required to address the implications of ACC will require massive changes in social and cultural norms, monumental shifts in the public's perception and understanding of science, and radical alterations in the manner in which the global economic infrastructure is managed (Wainwright, 2010; Wainwright \& Mann, 2012). One of the key metrics used to measure the magnitude of ACC has been the measuring of surface temperatures. Increasing surface temperatures are the direct result of higher levels of re-radiated infrared radiation from the lower atmosphere (Alexander et al., 2013). In turn, the increases in re-radiation are attributed to human-induced alterations of atmospheric chemistry through increases in GHG emissions. Increased terrestrial and marine surface temperatures are linked to a broad range of environmental issues including alteration in plant phenology (Parmesan \& Yohe 2003; Root et al., 2003); changes in the migration timing and patterns of birds (Bonter \& Cooper, 
2012); and the migration and distribution of plants (Iverson et al., 2011). Monitoring of surface temperatures has been accomplished in multiple ways from the use of satellites, weather stations, and volunteer data collections. The SATELLITES program was developed to get students involved in collecting scientific data as a tool, not only to develop a broadly distributed network of scientific data points, but also to help educate students as well (satellitesk12.org). SATELLITES students and teachers collect surface temperature recordings for Ohio, West Virginia, Pennsylvania, and Maryland (Hedley et al., 2008).

Public understanding of scientific issues is paramount for a democratic society whose continued development is predicated on scientific and technological expertise (Miller, 1983). Scientific literacy can be defined as the understanding of fundamental scientific concepts (Durant, 1993). As has been suggested, most people garner information about science through the media and not through direct involvement in the scientific process (Corbet \& Durfee, 2004). To be scientifically literate, however, does not imply that people become experts in a given scientific field, instead they need to be able to effectively process scientific information in order to make decisions that impact themselves as well as society as a whole (Thomas \& Durant, 1987). Scientific literacy and the public understanding of science thus depends on the availability of quality information. This has as much to do with the acquisition of knowledge by the public as the presentation of scientific representations by the media (Einsiedel, 1992). Additionally, understanding the ways in which literacy is improved and the mechanisms by which literacy is promoted are critical for increasing public awareness and acceptance of ACC. Media coverage is one such mechanism by which the public receives information about scientific issues (Nelkin, 1987). The public must be able to understand how science influences society and how scientific thinking can help solve complex problems. Unfortunately, there are much broader 
socioeconomic issues that seldom get addressed in discussions on scientific literacy. Western science tends to be privileged above other forms of knowledge production, which, in turn, reinforces the status quo that exists within the scientific enterprise (Aikenhead, 1996; Dos Santos, 2008). As a result, minorities, poor students, and females are marginalized and tend to be underrepresented in science (Eisenhart, Finkel, \& Marion, 1996). Scientific knowledge has the power to shape and transform society, and when people couch their critical thinking in the broader social context they may be more likely to fully understand how some decision privilege one group of people over another (Dos Santos, 2008). The application of a more communal mode of thinking may lead to a more inclusive frame for scientific literacy and promote the equality of educational outcomes (Eisenhart, Finkel, \& Marion, 1996).

Taken together, the need for increased scientific understanding among the public and the reliance on communal thinking suggests that citizen science programs can function as a bridge to narrow that gap that exists between scientific and public understanding on a given topic (Brossard, Lewenstein, \& Bonney, 2005). When considering ACC in particular a citizen science approach appears well-suited to promoting increased understanding of climate science and enhancing public acceptance. Citizen science is a methodology employed by scholars that uses volunteer labor to collect data (Bonney, Cooper, Dickinson et al., 2009). Citizen science is capable of being adapted to the evolution of modern scientific enquiry by allowing both scientists and volunteers to interact and engage with both the objects of investigation as well as the fundamental tenets of science in general (Bonney, Cooper, Dickinson et al., 2009). As Silvertown (2009) points out, there are three factors that explain the rise in citizen science programs: (1) technology has made it easier to disseminate information about projects and transfer data; (2) citizens represent a large pool of cheap labor possessing skills such as computer 
literacy; and (3) funding agencies such as the NSF have requirements that all funded programs have an outreach component. There is a complex set of relations guiding the development and implementation of citizen science projects on the one hand and the choice made by volunteers to participate on the other.

As research questions become more complex, the need for data that transcends one study at one particular time becomes a prerequisite (Field et al. 2003). Since, these large-scale projects-spanning multiple temporal and spatial scales-are becoming more commonplace scientists are turning to citizens to help with data collection, which, as Cohn (2008) suggests would be extremely difficult and expensive if it were not for the volunteers. And, as Galloway, Tudor, and Vander Haegen (2006) point out agencies with small budgets are finding it difficult to collect the necessary data to make informed management decisions without volunteer help. Researchers are increasingly asking their volunteers to handle greater responsibility as researchers push the boundaries of citizen science projects and expand the scope of data collection and monitoring of sample populations over larger geographic scales and longer periods of time. As the pace of scientific knowledge production quickens and expectations for high quality scientific products increase scientists are finding it necessary to let some of these challenges fall to citizen science programs and volunteer labor (Fitzpatrick et al., 2009). Working across multiple scales, citizen science projects have pushed the boundaries of traditional research to expand the scope, diversity, and complexity of what volunteers can achieve (Jordan et al., 2011). This can give volunteers a tremendous amount of power and shift authority away from traditional centers of knowledge production. What is ultimately needed is a highly democratized form of citizen science where researchers and community members share the responsibility for scientific outcomes by implementing projects that incorporate economic, social, and political 
factors into the framework in addition to purely empirical research objectives (Pandya, 2012). Citizen science can become a lever of change that improves community cooperation, promotes scientific literacy, and allows people to better interpret the information that is packaged and disseminated via media narratives. 
Chapter 2: Arguing over Agreement: Media Coverage of the Consensus on Anthropogenic Climate Change

Paper to be submitted to: Science Communication

\begin{abstract}
This paper examines media representations of the scientific consensus on Anthropogenic Climate Change (ACC). Content analysis was performed on print and online media stories covering the consensus in order to better understand how debate is prolonged in the public arena, in spite of overwhelming scientific evidence that human activity is driving ACC. The analysis uncovered core themes used by both oppositional and supporting authors to frame their stories. Analysis also showed that each group of authors relied on a small set of key words to cue their audiences and a core group of experts to lend credibility to their arguments. Online and editorial spaces provided authors with greater leeway to attack the consensus and misrepresent climate science. News stories had mixed coverage of the consensus demonstrating the lack of a consistent message on climate change.
\end{abstract}

Key words: Anthropogenic climate change; consensus; content analysis; media representations

\title{
Introduction
}

Anthropogenic climate change $\left(\mathrm{ACC}^{1}\right)$ is a complex environmental and social issue that is surrounded in controversy. This controversy is a product of a persistent and effective campaign to mislead the public led by powerful financial elites opposed to addressing the consequences of ACC (Demeritt, 2006). Climate change science, however, continues to solidify as new studies are published that support the notion of human-driven change. In the mid- to late$19^{\text {th }}$ century, scientists John Tyndall and Svante Arrhenius made the first attempts to examine the impact of the earth's chemical composition on surface temperatures. Arrhenius expanded on Tyndall's work and demonstrated that energy in the form of heat was partially absorbed by atmospheric gases (Arrhenius \& Holden, 1897). Roughly 60 years later Charles D. Keeling began tracking atmospheric $\mathrm{CO}_{2}$ concentrations at Mauna Loa Observatory. In 1958, concentrations were measured at 317 parts per million (ppm) and now measure over $400 \mathrm{ppm}$

\footnotetext{
${ }^{1}$ For this study climate change refers to a broad range of long-term changes to the Earth's climate system (NASA, 2015). Anthropogenic Climate Change (a term I use synonymously with Anthropogenic Global Warming) refers to the enhanced warming trend observed globally from the 1950s to present driven primarily by human activity (IPCC, 2014).
} 
(Monroe, 2015). The continuous increase in atmospheric $\mathrm{CO}_{2}$ is driven by the burning of fossil fuels, which presents a fundamental problem. Scientists know that fossil fuels contribute to the enhanced absorption of reradiated heat energy, which increases surface temperatures globally. Yet, the modern global economic system is based, in large part, on the continuous consumption of fossils fuels (Harvey, 2003). Addressing ACC poses a direct challenge to the global economic system (Dunlap \& McCright, 2011).

Numerous stakeholders rely on unfettered economic development, which, in turn, means they have a vested interest in discrediting climate science (Lahsen, 2005). The social relations of ACC make it difficult to uncover the interactions between scientific inquiry and skepticism. The science, in particular, has received the most scrutiny from those interest groups that have the most to lose (Demeritt, 2006). The Intergovernmental Panel on Climate Change (IPCC) represents a multi-national attempt to synthesize the current state of climate change science. When the IPCC releases a report, however, oppositional voices are mobilized to challenge the science and scientists to prevent action (Agrawala, 1998). The denialist message has gained traction and has led to decreased public acceptance of ACC even though the evidence continues to mount (Nisbet \& Myers, 2007). Despite these efforts, a strong consensus ${ }^{2}$ has emerged within the scientific community that human activity is largely responsible for the increased warming over the past 60 years. With the publication of its Fifth Assessment Report (AR5), the IPCC finds it 'extremely likely' that humans have caused a majority of the warming that has occurred since the 1950s (IPCC, 2014). The consensus has existed for more than a decade now (Oreskes, 2004), but the number of Americans that acknowledge the consensus remains stagnant (Funk \&

2 The consensus on climate change has emerged over the last 30 years and suggests that human activity is largely responsible for unprecedented warming (IPCC, 2014). 
Rainie, 2015). Each time an attempt is made to quantify the consensus a small group of wellfunded deniers mobilizes to discredit the research (Dunlap \& McCright, 2011).

The public remains unconvinced because interests groups knowingly use contrary science and spread misinformation to undermine the consensus (Carvalho, 2007). Print and online media representations of climate change science provide competing perspectives that fuel the debate on ACC (Boykoff, 2007b). With few exceptions, Americans rely on the mass media for information about science (Nelkin, 1987). The media constructs stories to align with their organizational values and attitudes. The construction of stories is informed by a complex set of social relations that influence the reporting of facts, the framing of complex issues, and even the reception of news by the consumers (Demeritt, 2001). These relations are influenced by economic, social, and political forces, and the resulting information is not completely free of value judgments (Antilla, 2005). To overcome institutional bias the media relies on professional standards that attempt to add objectivity. These professional standards, however, are influenced strongly by corporate ownership and socioeconomic values. The ideological underpinnings of a media outlet inform its professional standards and shape the narratives being delivered to the public (Carvalho, 2007). Examining media coverage of ACC can uncover the contradictions embedded in stories and provide insights into why the scientific consensus on ACC remains surrounded in controversy (Krippendorff, 1989). This paper seeks to understand how print and online accounts of the consensus prolong public debate. The paper addresses the major themes, experts, and key words proponents and opponents of the consensus use to strengthen their arguments.

The debate over consensus demonstrates how a controversy can arise in the public arena when values and political motivations encounter scientific evidence. People willingly accept scientific evidence if it aligns with their beliefs and ideas (Feldman, et al., 2014). Conservative- 
owned media outlets circulate misleading information on the consensus precisely to keep the public from calling for action on ACC (Antilla, 2005). The purpose of this paper is to analyze how print and online media coverage of the consensus portrays supporting and opposition view points on climate change and how this dichotomy perpetuates debates within the U.S. Next, I will assess how media coverage of the consensus differs between print, online, and editorial sources. I will conclude by arguing that the major themes, key words, and experts embedded in competing news stories continue to prolong the debate over consensus.

\section{Background}

\section{Establishing Consensus}

Scientific consensus on ACC began to emerge toward the end of the 1980s. The collective research of the IPCC has demonstrated an increasing certainty that human activity is directly responsible for Earth's changing climate. With AR5 there was a fundamental acknowledgement within the scientific literature that humans are unequivocally responsible for the increased warming scientists have been observing for more than five decades (Oppenheimer et al., 2007; IPCC, 2014). Oreskes (2004) represented an early attempt to quantify the consensus within the scientific community. She collected and analyzed the abstracts of 928 papers for the time period of $1993-2003$. Oreskes' analysis found that $75 \%$ of abstracts directly or indirectly supported an acknowledgement that humans were driving warming. The analysis also found that $25 \%$ of abstracts focused solely on the science and took no position. No abstracts directly rejected the consensus on climate change.

In a follow-up paper Oreskes (2007) found that within the climate change literature there is no longer a debate over the causes of climate change, but recognized the persistence of strong anti-consensus voices. In 2009, Doran and Zimmerman conducted a survey of 3,146 earth 
scientists and asked the question: "Do you think human activity is a significant contributing factor in changing mean global temperature" (22). The survey generated a response rate of $30.7 \%$ (965 responses). Their overall results suggest that $82 \%$ of respondents thought that humans were contributing to global warming. Self-identified climatologists responded 'yes' at a rate of $97.5 \%$ compared to a 'yes' response rate of $77 \%$ among non-climatologists. Anderegg et al. (2010) conducted a survey among climate scientists that found almost $98 \%$ respondents supported the consensus view. Finally, Rosenberg, et al. (2010) distributed a survey to 883 physical climate scientists, receiving a response rate of 53\% (468 participants), they found that only $9.47 \%$ of participants disagreed and $2.08 \%$ strongly disagreed that humans were accelerating global warming. The authors go on to note that much of the disagreement among scientists, however, centered on the extent and magnitude of change, the rate of change, and the consequences of change on local and regional scales.

\section{Solidifying Consensus}

On May 15, 2013 Environmental Research Letters published a pivotal, if not controversial, paper on the consensus entitled 'Quantifying the consensus on anthropogenic global warming in the scientific literature' (C2013) lead by John Cook. The authors extended Oreskes' (2004) paper in frame and scope to capture the current literature on climate change. They analyzed 11,994 papers over a 20-year period from 1991-2011 using the search terms 'global climate change' and 'global warming'. The authors grouped each abstract into one of six categories $^{3}$. C2013 found that $32.6 \%$ of all abstracts (3,896 papers) endorsed a position on anthropogenic global warming (AGW) and represented $97.1 \%$ of those papers with an AGW position. Those abstracts that took no position on AGW accounted for $66.4 \%$ (7,930 papers) of

\footnotetext{
${ }^{3}$ Refer to Cook, J. et al. (2013). Quantifying the consensus on anthropogenic global warming in the scientific literature. Environmental Research Letters, 8, 1-7 for more detail.
} 
the sample. Finally, papers rejecting AGW or expressed uncertainty accounted for $0.7 \%$ (78 papers) and $0.3 \%$ (40 papers) of the sample respectively.

Additionally, the authors of C2013 emailed a sample of 8,547 authors who had papers in the analysis and asked them classify their own work. The results of this secondary analysis captured 2,142 papers receiving self-ratings from 1,189 authors. When analyzed using the above criteria, $62.7 \%$ of (1,342 papers) endorsed AGW and represented $97.2 \%$ of those papers with an AGW position. Only 35.5\% (761 papers) took no position and 1.8\% (39 papers) rejected an AGW position. The authors also addressed the limitations and shortcomings of their study in the paper's discussion. Often the abstracts contained ambiguous language that made categorization difficult. Additionally, the rating process is subjective because raters may themselves accept the consensus biasing them to classify papers with no position as endorsing AGW, or, conversely, raters may choose to limit the amount of contention in the process by classifying papers as having no position. Finally papers that took no position on AGW may have been written by authors that either accept or reject the consensus view, but their points of view may not have been captured by the study.

\section{Challenging Consensus}

The challenges to the consensus stem from persistent skepticism by external groups and media outlets that have a vested interest in creating a contentious debate over climate change (Boykoff, 2007b). One of the first challenges to the consensus was a study undertaken by KlausMartin Schulte (2008). He recreated Oreskes' 2004 paper by searching the ISI Web of Science database using the same search terms. Schulte found that the percentage of papers rejecting consensus rose from zero to six percent since 2004. Additionally, the proportion endorsing consensus also dropped from $75 \%$ to $45 \%$. Legates et al. (2013) responded to C2013 by 
suggesting that the search for scientific consensus was inherently political and the underlying bias is not readily apparent to the public. The authors go on to state that people do not overwhelmingly support the consensus view because they do not share the scientific view that ACC can completely explained the observed variability in the Earth's climate system. Finally, Richard Tol (2014) wrote a rejoinder to the findings of C2013 challenging the methodological rigor with which the study was conducted. Tol did not question the conclusions of the paper, but suggested the mathematical errors in analysis did not support the findings. Tol recreated C2013's

analysis to highlight these errors and found what he considered signs of bias, which rendered the paper irrelevant. While consensus exists among scientists, skepticism is firmly entrenched within the denialist community.

\section{Media Coverage}

The media has a profound effect on the way citizens receive and interpret the news on issues such as the consensus on ACC (Nelkin, 1987). Print and online media are intended to reach specific audiences and their content is often translated through editorial and ideological filters that result in multiple perspectives on the consensus (Boykoff, 2007b). Media ownership is concentrated to a few corporations and ideology often becomes embedded in media content (Edwards, 2000). A democratic society relies on the free flow of high quality information among its citizenry, yet ideology often undermines this core tenet (Dispensa \& Brulle, 2003). The agenda set by the news agency and the frame through which the content is organized allows the media to influence what people should think about and how they think about it (Einsiedel, 1992). As the issue of climate change has moved from the academic realm into the public arena, media outlets have maneuvered to either reinforce the science or challenge its credibility. Ideology strongly underpins the agenda of a media outlet and has implications for the way the public 
consumes information on ACC (Dunlap, Xiao, and McCright, 2001; Boykoff \& Boykoff, 2007). The embedded ideology cues perspective consumers that a particular media outlet shares the same values and ideals (Hmielowski, et al., 2014). This is not a trivial point; the public will be more willing to accept an offered interpretation of reality when it aligns with their values.

Selective exposure to media outlets leads to a reinforcement of person's previously held beliefs and, even when a person opts to obtain their news from an opposing outlet, it often leads to disconfirmation bias (Feldman et al., 2011). Additionally, media coverage of the consensus, as well as climate change, is subjected to the norm of 'balanced reporting', which often presents competing voices on a controversial topic in an attempt to maintain objectivity (Gelbspan, 1998). Structurally, however, this norm is negotiated through a complex set of social relations that skews the stories perspective to align with the source (Gans, 1979). Furthermore, balanced reporting is often substituted for content verification when journalists do not have either the time or the understanding to corroborate a story (Dunwoody \& Peters, 1992). Journalists tend to identify the most prevalent positions and present both sides of the debate (Gans, 1979). This leads to a situation where 'dueling experts' compete over truth claims in an apparent attempt at transparency by the media outlet (Nelkin, 1987).

Accuracy in Reporting \& Communicating CC

The current debate surrounding the consensus is largely the result of competing interests as they compete in the public arena. The mass media wields tremendous power as a translator of climate science; as a result, these interpretations become moving windows through which the public comes to understand the science (Antilla, 2005). The lack of public acceptance of the consensus stands as an example of what happens when ideologically motivated points of view are challenged by robust scientific evidence in an arena where rhetoric can act as the sole arbiter 
(Dispensa \& Brulle, 2003). A recent Pew survey (Funk \& Rainie, 2015) shows that the number of people that believe there is no rigorous evidence that human activity influences global warming has increased from $11 \%$ in 2009 to $25 \%$ in 2014 . The percentage of people attributing global warming to human activity has stayed the same from $49 \%$ in 2009 to $50 \%$ in 2014. While there are certainly other causes for this increase in public skepticism, print and online media inform the way people think about climate change. Even those media outlets who accept the consensus face structural constraints that obscure the reporting of facts. With the proliferation of online platforms media outlets can reach a broader population, but they must adopt more extreme positions to distinguish their own brand (Hmielowski et al., 2014). The drawback is that online media escalates competing narratives and increases public confusion.

Finally, controversies are constructed by using an amalgam of evidence, values and preferences, and blind spots, which get broadcast to a general public who often does not have the requisite training to interpret the evidence (Freudenburg \& Muselli, 2010). Denialist media outlets use these controversies to weaken the credibility of the science as well as the experts in an attempt to influence the public into thinking climate change does not pose a serious threat (Jacques, Dunlap, \& Freeman, 2008). As people seek out media sources that share their values and perspectives there is an entrenchment of skepticism and an internalization of the news as truth despite being given evidence to the contrary (Feldman et al., 2014). Denialist media outlets reaffirm these truths by relying on a core group of dissenting experts to bolster the notion of uncertainty (Antilla, 2005). The effectiveness of these counterclaims is dependent upon convincing the public that ACC is a hoax that threatens individual freedom (Demeritt, 2001).

\section{Methods}

\section{Data Collection}


The establishment of the $97 \%$ consensus by C2013 has been central to the current debate surrounding ACC. The window of investigation for this study was set at 15 May 2013 through 15 May 2015. The four target news papers were the New York Times, Wall Street Journal, The Washington Post, and The Guardian. News articles and Opinion/Editorial pieces were collected through a database search using LexisNexis and ABI/Inform using 'climate change consensus' as the search term. The Guardian was included in this analysis because of its coverage of ACC and its extensive reporting on U.S. environmental issues. Additionally, The Guardian hosts both online print media and blog posts dedicated to climate change. A snowball sampling was used to collect articles from additional sources $(n=100$; Table 2.1).

\begin{tabular}{|c|c|}
\hline News Article & BO/E Articles \\
\hline Corporate Knights & JunkScience.com \\
\hline Scientific American & Financial Post - Opinion \\
\hline The Guardian & Watts Up With That? \\
\hline New York Times & New York Times - Opinion \\
\hline Los Angeles Times & Climate Depot \\
\hline The Washington Post & realsceptic.com \\
\hline National Review & Wall St. Journal - Opinion \\
\hline National Geographic & Forbes - Opinion \\
\hline Forbes & The Guardian - Environment Blog \\
\hline Wall St. Journal & The Washington Post - Opinion \\
\hline The Atlantic & realclearscience.com \\
\hline The Economist & thinkprogress.com \\
\hline Salon.com & Science 2.0 \\
\hline Newsweek & Climate Etc. \\
\hline Washington Times & planetexperts.com \\
\hline Fox Business & TIME - Opinion \\
\hline The Heartland Institute & climatecrocks.com \\
\hline$N P R$ & planetexperts.com \\
\hline \multirow[t]{12}{*}{ The New American } & Breibart \\
\hline & Arstechnica.com \\
\hline & The Conversation \\
\hline & Carbon Brief \\
\hline & Desmog Blog \\
\hline & disinfo.com \\
\hline & SFGATE \\
\hline & PRWeb \\
\hline & Scientific American - Blog \\
\hline & Joanne Nova \\
\hline & PopularTechnology.net \\
\hline & businessspectator.com \\
\hline
\end{tabular}

Table 2.1: Article sources for content analysis. 
Blog sources were selected first by accessing the website Skeptical Science. Skeptical Science, created by John Cook, is an interactive website that was designed specifically to respond to the misleading information published by denialist sources in order to promote the public understanding of climate science. The website maintains profiles of key denialists and links to prominent dissenting websites and blogs. Additionally, the website maintains links to supporting blogs. Opposing and supporting blogs were visited and the same search parameters and investigation window used for news stories was used to collect blog posts. While searching each blog, posts linked from other blogs were noted and later visited. Snowball sampling was used to collect additional blog posts. Posts were omitted if they did not contain direct reference to the scientific consensus or contained violent or conspiratorial language. Blogs tend to repost material from other sites, so duplicate articles were removed from the final sample. For this analysis Opinion/Editorials were grouped with blog posts. The final sample contained $124 \mathrm{blog}$ and Opinion/Editorial pieces (BO/Es; Table 2.1).

\section{Data Analysis}

This study relied on a content analysis of news articles and BO/Es to objectively quantify the position taken by each article (Berelson, 1952; Kerlinger 1986). The analysis of textual or written material offers a way to produce testable data (Krippendorff, 1989) and allows the researcher to draw inferences by identifying specific elements of messages through a highly organized methodological approach (Holsti, 1969; Weber, 1985). Content analysis moves beyond simple textual description in order to assess the level at which cultural influences, attitudes, or specific themes become embedded in a given text (Fairclough, 2003). Content analysis can uncover the differing kinds of values and preferences held on a particular issue by 
the author and, in turn, allows for the direct comparison of a given message across texts addressing the same or similar issues (Babbie, 1992).

For this study, the debate surrounding ACC has become heavily reliant on discourse and written texts to either directly challenge or support the evidence for scientific consensus. The individual newspaper article or BO/E served as the unit of analysis. After each set of articles had been collected a subset was selected for a pilot study (McMillan, 2000). The articles and BO/Es were placed in chronological order and every sixth article was extracted to include in the pilot study (Boykoff, 2007a). The pilot study began with a review of each text to gain an understanding of context and tone (Tesch, 1990). Next, each text was reread to begin the coding process. Keywords and phrases were recorded that captured the thoughts of the author and their perspective (Miles \& Huberman, 1994). To reduce the ambiguity of the keyword search, the frequency of words was recorded for both sets of articles in the pilot study (Stemler, 2001). If a word appeared in three or more of the articles it was included for the final analysis. Because there was not a second analyst to conduct a parallel pilot study all data were from the initial pilot study was set aside for a period of one month. A second pilot phase was conducted following the same approach as the initial pilot study (Krippendorff, 1989). The results of both pilot studies were compared against one another and the areas of commonality were retained for the final analysis. Classification was reserved until after each article had been read in its entirety, keywords identified, and the content had been compared to the results of the pilot studies (Krippendorff, 1989).

Each article was first categorized by their reference to C2013: (1) explicit reference, (2) implicit reference, and (3) no reference. The scientific consensus on ACC was captured by some articles that did not necessarily reference C2013 in their writing and some sources made an 
indirect reference to a 'new paper' or a 'new report' on consensus in their writing. Next, each article was categorized on their acceptance or rejection of the underlying premise of the consensus, which is that humans are the primary drivers of climate change. The categories were similar to those used by Dispensa and Brulle (2003): (1) explicit acceptance, (2) implicit acceptance, (3) explicit rejection, (4) implicit rejection, and (5) no position. During analysis key themes were uncovered and written in a coding log along with quotations that highlighted the author's perspective. Additionally, the key words highlighted in the pilot study were tracked and the first instance of each was tallied for all articles and entered in the coding log. Finally, a list of experts cited by each article was tracked and entered into the coding log.

\section{Results \& Discussion}

\section{Variations in Reporting}

C2013 renewed the debate over consensus that has existed since Oreskes published her first analysis. This study highlights the variations in reporting between traditional news stories and $\mathrm{BO} / \mathrm{Es}$ and how these differences perpetuate debate. Results show that two-thirds of news stories accept the scientific consensus (Figure 2.1a), while 15\% of news stories reject the consensus. The remaining articles take no position. There is a lack of balanced coverage within the sample of news articles. Boykoff's (2007b) study revealed a persistent trend in media coverage to portray climate change science as contentious even though the scientific consensus began to emerge in the mid-1990s. This study shows that fewer news articles rejected the consensus, but one-third still do not support the consensus. In general, news stories were more passive about the consensus: "But for now, it's simplistic and misleading to conflate the impressive level of agreement that warming is manmade with more subjective judgments about what that signifies" (Anonymous, 9/25/13). 


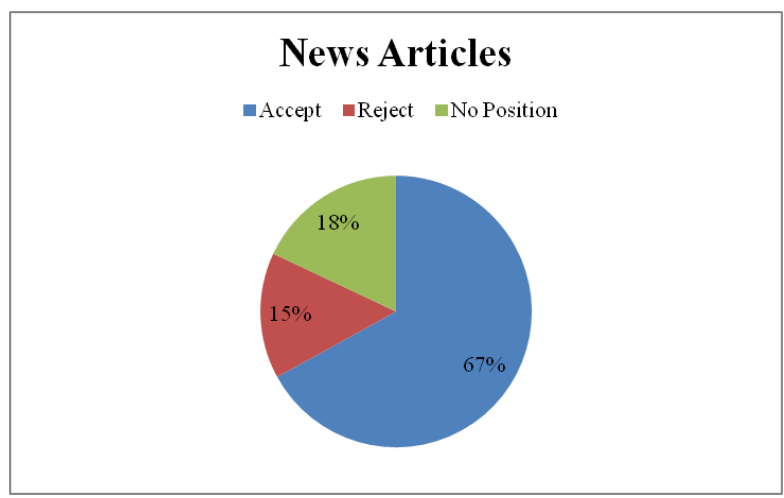

Figure 2.1a: News articles by category.

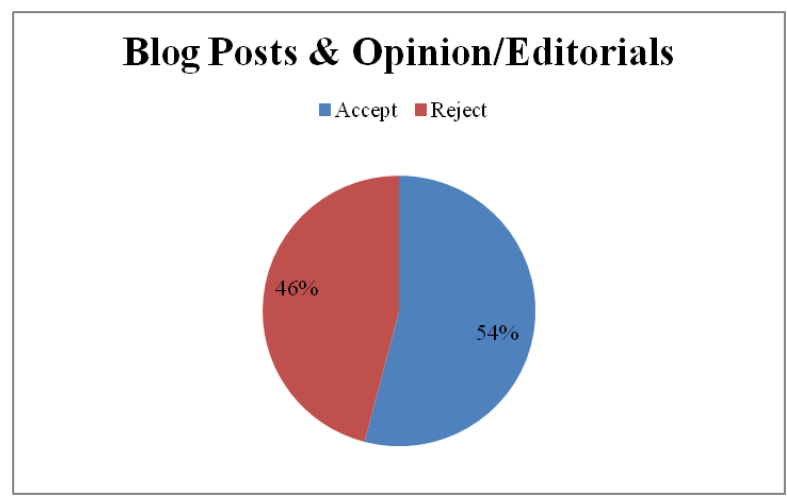

Figure 2.1b: BO/Es by category.

In stark contrast, there were no $\mathrm{BO} /$ Es that took a 'no position' stance on the consensus.

The break down between acceptance and rejection was also more balanced (Figure 2.1b).

Additionally, BO/Es were unequivocal in their support or rejection of the consensus:

This remarkable agreement exists because a scientific consensus is reached on the weight and amount of research that is available in the literature. It's also this scientific evidence that led to the scientific consensus of for example evolution, plate tectonics, the big bang, germ theory, and so on. Such a consensus only arises through meticulous study and hard work by scientists (Maessen, 5/19/14).

This is post-modern science at its worst. Critics and outside 'experts' rather than the authors themselves have the final say over what an author or team of researchers are truly saying in their own paper. The original authors are simply offering one opinion, not necessarily the definitive one, concerning what their research shows (Burnett, 4/6/15).

Online platforms and editorial pages give the author a great deal of freedom to express their perspective, which expands the scope of the debate (Tremayne, 2012) while avoiding the norms associated with traditional print media (Johnson \& Kaye, 2004). Online media also allows authors to respond to opposing perspectives in almost real time as new content is produced. Social norms often breakdown when readers and writers engage online because they are separated by space and time (McCluskey \& Hmielowski, 2012). While communicating online can foster a sense of community it can also generate conflict (Tremayne, 2012). Both of these relations exist within the context of climate change communications. This analysis highlights a 
particularly important example based on discussions of C2013. Christopher Monckton of Brenchley (9/9/13), an adamant denialist, wrote a blog post for Watts Up With That criticizing C2013:

Cook et al., paid schoolboy interns in propaganda studies at Queensland Kindergarten, are not pleased with Legates et al. (2013), written by grown-ups, which demonstrated that the kids, surveying the abstracts of 11,944 papers on global climate change published from 1991-2012, had marked only 64 abstracts out of 11,944 as explicitly endorsing the IPCC's version of consensus.

The kids themselves had gone to great lengths to contrive not to reveal that devastating fact in their headcount paper, which on that and many other grounds would not have passed peer review in a real scientific journal instead of a comic.

In response, Collin Maessen (9/16/13) wrote a piece on his own site, Real Sceptic, responding to Monckton's criticism:

These attacks aimed at the Cook et al. paper aren't about honestly discussing the results and raising legitimate criticism. Like I said in my previous blog post on the Cook et al. paper it's more about discrediting a paper that gives a result that is easy to communicate to the public; a result that is also very easy to understand. Which is probably the reason this paper has struck a nerve among climate science deniers.

Blogs and online media had a greater range of variability in their reporting of the consensus compared to news stories. Denialist perspectives coalesced around a wide variety of key themes and amplified a particularly vehement opposition to the consensus. This is particularly important because the collective reinforcement of a perspective relies on highly idiosyncratic means of conveying a message (Wilkins, 2008). Readers are drawn to a familiar point of view and this selective exposure tends to lend legitimacy to the source (Feldman et al., 2014). The persistence in the debate over the consensus is due, in large part, to continued publication of oppositional B/OEs.

Discussing C2013 
Few news stories $(n=24)$ referenced C2013 when discussing the consensus. Opposition articles, like the one published by the Heartland Institute, cited C2013 and focused on core denialist themes (Bast \& Smith, 5/14/14). The authors suggested that C2013 was driven by a political agenda and conducted by activist scientists in order to misinform the public about climate change. Another article used Tol's personal and statistical critique to show that C2013 had statistical inconsistencies that discredited C2013's findings (Jasper, 6/5/13). Finally, Fox News published an article using Legates et al.'s (2013) unequivocal dismantling of C2013's methods and findings to demonstrate that a consensus does not exist (Lewis, 10/16/13).

A number of news articles accepting the consensus and referencing C2013, on the other hand, wrote about the consensus gap. While $97 \%$ of scientists agree the majority of warming since the 1950s has been caused by human activity, only 50\% of Americans share this position (Funk \& Rainie, 2015). The articles focusing on the consensus gap attempted to use the findings of C2013 to demonstrate that there is near-unanimous agreement within the scientific community. Many authors suggest that in order to close the gap the public needs to hear the consensus message repeated through multiple sources. Repeating the consensus message may increase overall acceptance by the America people, but it is contingent upon overcoming competing oppositional messages (Lewandowsky, Gignac, \& Vaughn, 2012). Additionally, the news coverage attempted to highlight the increasing level of certainty that ACC is occurring and happening a lot faster than previously predicted (Nuccitelli, 1/6/15).

Most of the coverage of C2013, however, was confined to BO/Es. There were $57 \mathrm{BO} / \mathrm{Es}$ that referenced C2013 with an almost even split of 28 that accepted and 29 that rejected the consensus. The majority of papers rejecting C2013's findings attempted to deconstruct the methods and statistics of the paper. A blog post from Watts Up With That? used Tol's reanalysis 
citing it as definitive proof that the consensus is false (Tisdale, 3/26/15). An opinion piece in Forbes suggested that C2013 deliberately mislead the public by manipulating data (Taylor, 5/30/13). The author claims that C2013 knowingly altered the classification of research articles to inflate the supporting numbers. One of the most interesting critiques leveled by denialists is that supporting scientists are guilty of conflating consensus with truth. These scientists are engaged in post-modern science where negotiated findings stand in for scientific truth arrived at by rigorous analysis (Howard, 8/13/14). Post-modern science does not rely on testability and thus consensus is arrived at through political maneuvering to garner support for an activist cause. Consensus in science, however, has never been a stopping point of examination; rather it represents the current understanding of a given issue. Finally, deniers discuss the financial costs of addressing climate change. A post from Watts Up With That? suggests that reducing carbon in the atmosphere would cost trillions of dollars and hurt economic development (Beisner, 7/16/14).

The most basic finding of C2013 tells us that an overwhelming majority of scientists agree that the climate is changing and human activity is the primary driver. A post from Bad Astronomy reiterates this finding (Plait, 9/9/14). A supporting article from the Desmog Blog highlights the financial backing of denialist sources by the fossil fuel industry (Redfearn, 6/6/13). A recent study by Farrell (2016) found that corporate funding was more likely to influence the thematic content of recipient organizations and that the content was meant to polarize the climate change issue. The overriding reason that a small group of dissenting voices can garner such support is due to this financial backing of the fossil fuel lobby (Lahsen, 2005). Limiting the public's understanding of climate change reduces the amount of pressure people can exert on the government to act, which prolongs the existence of a fossil fuel-driven economy.

\section{Emergent Themes}


A number of themes were embedded within news stories and BO/Es (Tables 2.2 and 2.3). News articles had a broader range of themes supporting the consensus on climate change than oppositional articles. The consensus gap was discussed by many of the news stories. Stressing the level of agreement among scientists can be an effective strategy to reach people who are doubtful about climate change (Lewandowsky, Gignac, \& Vaughan, 2012). Additionally, supporting news articles focused on the evidence compiled by the IPCC and presented at professional organizations. Focusing the argument on the evidence highlights the academic rigor that underlies climate change science. Finally, some supporting news articles were geared toward responding to denialist arguments and debunking myths. These authors dedicated their pieces to stronger confrontational themes by challenging opposition articles that misrepresent the science and pointing out the strong financial ties linking denialist voices with the fossil fuel industry. Lobbying money finds its way to denialist scientists and conservative media outlets that promote skepticism of the consensus by generating misleading research and news stories (Lahsen, 2005; Dunlap \& MCCright, 2010). Nowhere is this more readily apparent than when Exxon prevented their own scientists from publishing evidence of climate change in the 1980s (Banerjee, Song, \& Hasemyer, 2015). The financing of a small, but powerful group of dissenting voices continues to prolong the debate over climate change within the media.

\section{Proponents of Consensus}

\begin{tabular}{l|l|l}
\hline Closing the Consensus Gap & Critiquing Mainstream Science & Science Education Standards \\
\hline Debunking Myths & Criticism of IPCC & Politics of Climate Change \\
\hline Highlighting Funding for Denial & Addressing Climate Change & Discussion of Risks \\
\hline Economics of Climate Change Action & Attacks by Alarmists & \\
\hline Presenting the Science & Economics of Climate Change & \\
\hline Media Coverage & & \\
\hline
\end{tabular}

Table 2.2: Major themes emerging from a content analysis of news stories related to the consensus on climate change. 
Proponents of Consensus

\begin{tabular}{l|l|l}
\hline Consensus & Consensus & Psychology \\
\hline Support C2013 & Critiquing Consensus & Discussing the Science \\
\hline Addressing Denialism & Skeptical Science Perspectives & \\
\hline Motivating Politicians & Attack C2013 Methodology & \\
\hline Biased Media Coverage & Attacking C2013 & \\
\hline & Attacking Scientific Institutions & \\
\hline & Climate Change Economics & \\
\hline
\end{tabular}

Table 2.3: Major themes emerging from a content analysis of blog posts and opinion/editorial stories related to the consensus on climate change.

Oppositional news articles, on the other hand, sought to redefine the narratives of climate change. One strategy was to call for more evidence; while this seems to align with the goals of the scientific enterprise it hides a clever theme popular with denialists. When a person calls for more evidence it says to the reader that the scientific community cannot draw sound conclusions from the data that already exists. Eroding the scientific foundations of climate science opens the door for a debate about climate change validates denialist positions. Self-styled skeptics continue to reiterate that consensus is not proof of climate change, but merely opinion. "But for now, it's simplistic and misleading to conflate the impressive level of agreement that warming is manmade with more subjective judgments about what that signifies" (Samenow, 9/25/13). From this, readers are supposed to think that consensus studies are not actually relevant and denialist perspectives are just as valid. Another key theme was the persistent criticism of scientific organizations, specifically the IPCC and the American Geophysical Union. Opposition authors painted these institutions as activist organizations that had political agendas. The activist scientists that make up these institutions are accused of corrupted the scientific process and peddling misleading science (Anonymous, 4/5/14).

Both supporting and oppositional news articles focused on climate change economics. Supporting articles discussed topics such as carbon pricing strategies, green energy initiatives, and divestment. Divestment refers to the removal of fossil fuel-related investments from portfolios and would seriously weaken the financial and political influence the fossil fuel 
industry could wield. Conversely, opposition writers tend to promote free market strategies to address climate change. The argument against cutting emissions and divestment is simple: economic growth is more important than addressing climate change and any solution would have harmful economic impacts in the long-term (W.W., 6/20/13). Climate hawks see prosperity as progress and they only way to maintain U.S. standing globally is continue to grow an economy based on fossil fuels (Harvey, 2003).

Themes from neutral, or 'no position', news stories focused on education standards and the teaching of climate change science. A prime example is the 'Truth in Texas Textbooks' coalition, which is pushing for the removal of definitive language on climate change from textbooks. "Truth in Texas Textbooks formed last year to shape how climate change and scores of other topics are taught. It has no political or religious affiliations but organizers recruit volunteers through Tea-Party networks and church groups" (Foran, 12/8/14). The manipulation of textbooks is not a new phenomenon, but it does pose a serious challenge to teaching climate change science. Texas has the second largest market for textbooks in the U.S. and, as a result, publishers often sell the same texts in other states as well. These changes would expose millions of children to misleading information on ACC. A Similar debate over the teaching standards has occurred in West Virginia; a state with deep times to the coal and natural gas industry. The Board of Education made changes to the "Next Generation Science Standards" to make the language on climate change more ambiguous. This sparked an outcry from some board members and educators within the state. As a result of the pressure, the Board of Education withdrew the alterations to the standards and passed them in their original form (Schwartz, 1/14/15). The controversy over educational standards reiterates the gulf between opponents and proponents of ACC. 
Blog posts and opinion pieces also used a broad range of themes to discuss ACC and the consensus. One of the primary themes of supporting BO/Es was the unequivocal support for C2013. As Timmer (9/4/14) points out: "[T]he consensus forms precisely because reproducible evidence is generated". Consensus in science is not a simple counting exercise; it represents the culmination of rigorous academic study. Supporting writers continued to reiterate that the consensus was not 'truth' but rather a clear indication of the state of climate change research. Directly tied to this theme was the acknowledgement of the consensus gap. There are complex social barriers that need to be overcome in order to raise public awareness. Selective exposure to media sources and motivated reasoning complicates the public's understanding of climate change precisely because they may never be exposed to a different perspective (Hmielowski et al, 2013; Feldman et al., 2014).

Opposition writers directly challenged the very notion of consensus. The most consistent theme in opposition $\mathrm{BO} /$ Es is that truth can neither be negotiated nor established by consensus (Tamny, 3/15/15). This 'postmodern science' subjects truth to interpretation and does not necessarily require evidence to be accepted. This argument is successful because it resonates with a segment of the population that is already skeptical of academia. Opposition writers bolster this position by offering up their own brand of climate science. Denialist voices suggest that human activity has negligible impacts, climate change is caused by natural variability, or is not even occurring. Some writers suggest that increased $\mathrm{CO}_{2}$ may actually be beneficial for the planet. Dr. Judith Curry is perhaps one of the most well-respected denialist scientists. In an interview she said: "humans do influence climate to some extent, what we do with land-use changes and what we put into the atmosphere. But I don't think it's a large enough impact to dominate over natural climate variability" (Morano, 4/17/15). 
The majority of supporting BO/Es focused on discussing the science of climate change, the methods of C2013, and challenging the positions taken by climate deniers. One strategy was to catalog and respond directly to the myths used to disseminate disinformation. Deniers use a number of strategies to counter climate science: (1) cherry picking data, (2) creating straw man arguments, (3) using skeptical experts, (4) downplaying risks, and (5) attacking expert credibility. Supporting writers must respond to these strategies so they do not gain traction. The tone of these posts and articles is meant to counteract the hyperbolic rhetoric of opposition authors without engaging in similar tactics (Maessen, 4/6/15).

The themes of oppositional BO/Es tended to be more aggressive overall. Writing for his site, Watts (9/4/14) states: "[C]onsensus is the business of politics. Science, on the contrary, requires only one investigator who happens to be right, which means that he or she has results that are verifiable by reference to the real world". As with oppositional news articles there is a conflation of causation with outcomes. They also fail to acknowledge that the authors of C2013 recognized the limitations of consensus. Additionally, BO/Es addressing climate change economics were mostly written by opposition authors. The overwhelming sentiment is any effort to curb greenhouse gas emissions would be too costly for American enterprise and lead to an economic downturn (Beisner, 7/16/14). The positions taken in BO/Es discussing economics hints at the influence of the fossil fuel industry on media content and its entrenchment in U.S. political and social affairs (Farrell, 2015).

Key Word Analysis

A key word analysis of the articles revealed a set of overlapping words that supporting and opposition authors used to convey meaning within their pieces (Stemler, 2001). The analysis revealed ten common key words used in both news articles and BO/Es (Table 2.4). Overall, the 
most used words were 'denial/denier'. Supporting authors used these words as a label for scientists, organizations, and authors that rejected the consensus. Opposition authors respond to this label and suggest they are being ostracized by the establishment for challenging misleading climate science. The next most frequent key word was 'alarmist' and was meant as a label for supporting scientists, organizations, and other authors that accepted the consensus. Alarmist was used predominantly by opposition writers to convey a meaning of activism. Next, both supporting and opposition authors in both sets of articles used the word 'misleading'. Supporting authors used it to refer to the tactics opposition voices used in their stories. Opposition authors used it to suggest that supporting voices were deliberately trying to mislead the public on the consensus. Finally, the phrase 'consensus gap' was used mainly in supporting BO/Es to

\begin{tabular}{lr|lr}
\multicolumn{2}{c}{ News Articles } & BO/E Articles \\
\hline Denial/Denier & 36 & Denial/Denier & 36 \\
Ideology & 6 & Ideology & 11 \\
Settled Science & 5 & Settled Science & 10 \\
Balanced & 7 & Alarmist & 20 \\
Hoax & 12 & Hoax & 4 \\
Uncertainty & 6 & Uncertainty & 10 \\
Misinformation/Misleading/Misconduct & 24 & Misinformation/Misleading/Misconduct & 20 \\
Debate & 22 & Debate & 23 \\
Consensus Gap & 13 & Consensus Gap & 23 \\
Contrarian & 15 & Contrarian & 6 \\
Myth & 6 & & \\
\hline
\end{tabular}

Table 2.4: Simple count of the first instance of key words. comment on the lack of public awareness for the consensus.

Cited Experts

The last analysis focused on the experts used by each article category (Table 2.5). Dueling experts are used by competing perspectives the public must be the final arbiter on the validity of a given argument (Nelkin, 1987). This analysis found that of the news articles accepting the consensus 34 reference at least one expert. Only nine news articles rejecting the consensus cited any experts. BO/Es accepting the consensus had 34 articles referencing at least 
one expert and $\mathrm{BO} /$ Es rejecting the consensus had 37 articles citing at least one expert. The two most cited experts were Dr. Naomi Oreskes and Dr. Richard Tol. Oreskes' work was cited in a number of different contexts because supporting voices view her work on ACC as pivotal for moving the discussion forward. Opposition voices critiqued her work in the same way they did for C2013. Tol's rebuttal to C2013 was used in a similar manner by opposition voices to deconstruct the consensus. Finally, BO/Es rejecting the consensus consistently cited Tol, Judith Curry, Willie Soon, and David Legates. These scholars are adamant denialists and their notoriety is leveraged to attack the consensus.

\begin{tabular}{l|l|l|l}
\multicolumn{1}{c}{ News-Accepting } & \multicolumn{1}{c}{ News-Rejecting } & \multicolumn{1}{c}{ BO/Es-Accepting } & BO/Es-Rejecting \\
\hline Naomi Oreskes & Richard Tol & Naomi Oreskes & Richard Tol \\
Richard Tol & Peter Doran & Richard Tol & David Legates \\
Roy Spencer & Maggie Zimmerman & Daniel Kahan & Judith Curry \\
Michael Mann & David Legates & Peter Doran & Roger Pielke \\
Daniel Kahan & Dennis Bray & Maggie Zimmerman & Richard Lindzen \\
John Christy & Hans von Storch & & Willie Soon \\
Richard Alley & William Anderegg & & Roy Spencer \\
Benjamin Santer & & Naomi Oreskes \\
\hline
\end{tabular}

Table 2.5: Experts cited by category.

\section{Conclusions}

This study produced a robust analysis of the themes, key words, and experts used by news articles and BO/Es. The confrontation of opposing voices in the media leads to a prolonged debate over the scientific consensus on climate change. Numerous studies have attempted to quantify this consensus and raise awareness among the U.S. populace. Consensus on any topic only comes about through meticulous study and validation. For climate science, consensus is not the end of the story, but rather the beginning. Acknowledging that there is a problem and human activity is causing unprecedented warming is only the first step toward a complex strategy address climate change. As Oreskes (2007) pointed out, the scientific consensus on ACC may be 
proven wrong in the future, but the likelihood diminishes as the body of evidence continues to mount.

There remains, however, such a high degree of polarization over the consensus that public acceptance of the problem poses significant challenges to the implementation of any serious changes. The results of this study show that the news coverage of the consensus is moving away from 'balanced' reporting, but this has not translated in broader public awareness. The results from $\mathrm{BO} / \mathrm{E}$ reporting were more complex. There is almost an even split between supporting and denialist coverage. The nature of online spaces makes the perpetuation of competing perspectives easier. Also, online spaces often rely on hyperbolic rhetoric to prolong debates (Tremayne, 2012).

Selective exposure to media sources ensures that some people will never accept the consensus despite overwhelming scientific evidence (Feldman et al., 2014). These sources, in turn, are responsible for publishing the most robust challenges to the consensus. The emergent themes from oppositional coverage target vulnerabilities in social perception. The scientific enterprise is well-respected in the U.S. and denialists play on public fears that its integrity could be corrupted by a political agenda. Additionally, fossil fuels have been a cornerstone of the U.S. economy for so long that challenging their dominance runs contrary American thinking. Supporting pieces understand the deeply rooted ties to fossil fuel consumption and the social barriers that must be overcome to combat climate change. These pieces spoke directly of overcoming the consensus gap in order to help people acknowledge the consensus. Once people recognize the problems solutions become easier to implement.

Key word analysis showed that authors used specific words to convey meaning in their work. Key words such as 'denialist' versus 'alarmist ', 'myth or 'misinformation' are used as 
signifiers for an author's perspective. The audience internalizes these words thus reinforcing their assumptions. The analysis of experts cited by the media reveals that authors rely on a small group of scientists to reinforce the validity of their arguments. The use of dueling experts makes judging the validity of an argument difficult to determine. Finally, this analysis found that C2013 became less of a focal point over the duration of the analysis window as emergent themes generated new avenues of debate. 
Chapter 3: Citizen Science and Environmental Learning: A Case Study of the SATELLITES Program

Paper to be submitted to: Frontiers in Ecology and the Environment

\begin{abstract}
Citizen science is a mode of knowledge production that employs volunteers to collect data for scientific studies (Bonney, Cooper, Dickinson et al., 2009). Programs designed to use volunteers cover a range of disciplines and seek to answer complex social and environmental problems. A fundamental element of citizen science programs is their goal to enhance scientific learning among the public (Brossard, Lewenstein, \& Bonney, 2005). By improving scientific literacy people are better able to understand complex topics that impact the way policy is created and problems are resolved (Miller, 2004). The SATELLITES program is part of the GLOBE initiative and seeks to engage K-12 students in hands-on scientific research. Educators were surveyed and results suggest that they thought the program was improving their students' scientific understanding. When asked whether or not the SATELLITES program better equipped the educators and the students to deal with complex issues outside of the classroom, results were less conclusive. While the program is effective at engaging students in scientific research it makes less of an impact in getting participants to understand why science is important and how scientific thinking can apply to their daily lives. This is a broader issue that all citizen science programs must address in order to meet their larger programmatic goals.
\end{abstract}

Key Words: Citizen Science, SATELLITES, Scientific Literacy, Online Surveys

\title{
Introduction
}

The modern notion of citizen science represents a relatively recent development by the scientific enterprise to bring together scientists and the public to answer complex questions. Most citizen science projects tend to focus on scientific outcomes with little consideration for the impacts on participants' scientific learning (Bonney, Cooper, Dickinson et al., 2009). As a result, there are few scientific studies examining the impacts these programs have on their participants' overall scientific understanding (Jordan, Ballard, \& Phillips, 2012). Citizen science programs allow people to develop their own views on the project while working within a program's guidelines. Even though participants work as part of a larger group they are allowed leeway to form their own thoughts and opinions about the program (Roth \& Barton, 2004). This 'personalcuriosity science' fully immerses a person in a program and may even lead to a higher level of scientific literacy and civic engagement (Aikenhead, 2005). In some cases, citizen science 
programs have no direct ties to a formal classroom setting, but they can be a useful tool at the K12 level to enhance student learning. The reliance on personal curiosity and individual connection are crucial elements for the overall success of scientific literacy efforts on a national scale (Aikenhead, 2005). This analysis relied focused on The Students and Teachers Exploring Local Landscapes to Interpret the Earth From Space (SATELLITES) in order to examine how citizen science programs can improve students' overall scientific learning.

Scholars studying citizen science programs hold scientific literacy as a fundamental element of this research paradigm because it promotes critical thinking that people can apply to their daily lives (Bonney, Cooper, Dickinson et al., 2009). Citizen science programs also situate scientific literacy in a broader context by decentralizing of formal environments and using the home and communal areas as research settings. This notion of a more democratic science promotes a sense of community that links literacy with local issues, which engages more people than traditional laboratory science (Roth \& Barton, 2004; Price \& Lee, 2013). Decentralizing and democratizing science and scientific knowledge will become increasingly important as complex issues like global climate change begin to affect social, environmental, and political outcomes. Indeed, the strategies required to address the implications of global climate change will require massive changes in social and cultural norms, and monumental shifts in the public's perception and understanding of science both at the global and local levels (Demerritt, 2001). Global climate change is just one topic that will require the collective learning of experts and amateurs alike. A person's exposure to any given scientific topic is varied, but often includes primary and secondary education, natural curiosity, media representations, or a combination of all three. As the $21^{\text {st }}$ century progresses, a greater understanding of climate change, as well as other complex scientific issues, will be necessary for policy development. These complex issues will have far 
reaching social and environmental impacts that will require a society to have the scientific intellect to address these problems. Citizen science can be used to help communities understand and respond to the changes they will experience in the coming decades.

Scientific literacy is a broad term that has come to encompass many different aspects of scientific education and has evolved over time in response to dominant social forces (DeBoer, 2000). In its simplest form scientific literacy "stands for what the general public ought to know about science" (Durant, 1993: 129). This narrow definition implies that the public recognizes the goals of scientific study, the methods employed, and its limitations. Additionally, it suggests that the public has a basic understanding of the fundamental scientific ideas (Hurd, 1958; Laugksch, 2000). Thus, scientific literacy is a mechanism by which the public comes to understand the scientific enterprise and it role in a productive society (DeBoer, 2000). Scientific literacy must then transcend the mere knowing of facts and methods in order to understand why scientists ask the questions they do, how science is pressed into service for society, and how science and social change mutually shape one another. The true measure of scientific literacy is the public's ability to evaluate what constitutes credible science in the context of addressing social issues (Lewenstein, 2011). This is certainly the case with an issue such as climate change that continues to divide public opinion despite overwhelming scientific evidence.

Citizen science can serve as a mechanism to bring science and the public together for collaboration. Yet, most of the participation in citizen science programs comes from people that are already well educated and have generally positive attitudes toward the STEM fields (Brossard, Lewenstein, \& Bonney, 2005). This simultaneously challenges and offers insight into the application and extension of citizen science projects to complex environmental issues. What does it take to engage those who would not normally participate? There is a push within 
community-based citizen science programs to turn the model on its head and formulate a grassroots, bottom-up management approach (Cooper et al., 2007). Grassroots engagement and scientific literacy depend on the availability of quality information. This has as much to do with the production of knowledge as it does with the acquisition of knowledge by the public via media representations of science (Einsiedel, 1992). The need for increased scientific understanding among the public and the reliance on shared communication suggests that citizen science programs can function as a bridge to narrow that gap that exists between scientific and public understanding on a given topic (Brossard, Lewenstein, \& Bonney, 2005). The goals of this research project are to: (i) examine what role the SATELLITES citizen science program plays in improving the literacy of its students and (ii) analyze how SATELLITES' educators view the effectiveness of the program overall.

\section{Research Questions}

1. Is project-based learning and citizen participation in the SATELLITES program an effective way to improve student learning?

2. How do teachers, volunteering with SATELLITES, view the effectiveness of this program?

\section{Background}

Citizen science is a research technique that uses volunteers to perform scientific research (Cohn, 2008; Bonney, Cooper, Dickinson et al., 2009). In other words, citizen science projects seek, to a higher degree, to engage non-professionals in 'authentic' scientific research (Dickinson et al., 2012). There is an implicit assumption that those choosing to participate in these projects are freely donating their time to a project of their choosing. It has been suggested that this model is capable of adapting to the evolution of modern scientific enquiry through its use of volunteers to capture large amounts of data, at low cost, over broad geographic areas (Bonney, Cooper, Dickinson et al., 2009). SATELLITES program was developed as a collaborative project to 
collect a broad distribution of data points for environmental scientists and to foster science education (Hedley et al., 2008). Over the last 20 years citizen science has undergone an additional transformation; its role and conceptualization has shifted to increase the responsibility of participants (Cohn, 2008), to focus on the social implications of the projects themselves (Becker et al., 2005), and to incorporate goals that directly impact the volunteers and their communities (Jordan, Ballard, \& Phillips, 2012; Dickinson et al., 2012; Shirk et al., 2012). There is now an assumption that these projects are available to potentially everyone who wants to participate and the outcomes can have a positive effect at the community level. There is a complex set of relations guiding how projects are developed and the choice made by volunteers to participate.

The proliferation of citizen science programs is partially a response to the expanding scale of human activity and its impacts on social and environmental issues (Cooper et al., 2007). As scientific research has become more complex and focused on more involved questions, the need for large amounts of data has become a necessity (Field et al., 2003; Dickinson et al., 2012). Citizen science programs offer researchers a means to address these large-scale, multi-temporal issues by addressing these needs (Cohn, 2008). Moreover, such projects are budget-friendly and allow researchers at small agencies the opportunity to conduct high quality field work at low cost (Galloway, Tudor, \& Vander Haegen, 2006). The ability of citizen science programs to adapt to the evolving needs of researchers, and to link people, places, and research questions across broad geographic areas makes it a powerful mechanism to answers questions that have been beyond the scope of traditional science (Dickinson et al., 2012). Increasingly, researchers are asking their volunteers to shoulder greater responsibility in expanding the scope, extent, and duration of data collection (Bonney, Cooper, Dickinson et al., 2009). Working across multiple geographic and 
temporal scales, citizen science projects allow scientists to observe ongoing changes as well as develop baseline indicators and aid management programs. Importantly, there is an acknowledgement that the kinds of projects that use volunteers must be carefully planned in order to produce high quality data (Jordan, Ballard, \& Phillips, 2012). Adequate training is essential for the continued success of citizen science projects. Project managers must perform quality control checks on the data to ensure continuity (Trumbull et al., 2000; Cohn, 2008). However, there is an increasing acceptance that collaborative learning and 'collective intelligence' improves overall project performance (Williams Woolley et al., 2010).

Because citizen science programs rely heavily on collaborative learning they are uniquely positioned to greatly expand scientific literacy nationally (Kahan et al., 2011; Leiserowitz et al., 2013). These programs can be used as an effective tool in advancing scientific knowledge and educating the public (Bonney, Cooper, Dickinson et al., 2009), and promoting citizen participation in decision-making and policy formation (Jordan, Ballard, \& Phillips, 2012). Thus, recruitment of volunteers becomes a major issue for program managers since they now need to attract people from excluded populations that would never volunteer on their own (Trumbull et al., 2000; Pandya, 2012). Engaging the public allows researchers and community members to arrive at local solutions while also achieving larger programmatic goals (Jordan, Ballard, \& Phillips, 2012). Citizen science projects such as the SATELLITES' surface temperature study relies on a large number of volunteers to collect and report data, and thus reaches many communities and cultivates a sense of local pride (Dickinson et al., 2012; Shirk et al., 2012). What is ultimately needed is an inclusive form of citizen science where researchers and community members share responsibility for scientific outcomes by implementing projects that incorporate economic, social, and political factors into the framework in addition to purely 
empirical research objectives (Pandya, 2012). Citizen science has the potential to decentralize conventional knowledge away from traditional institutions, but it must also be seen as a mechanism to reengage the public, which have been largely alienated from the process of knowledge production (Shirk et al., 2012).

The first challenge is to highlight the relatively low level of collective literacy in the Unites States. Estimates suggest that nearly $80 \%$ of adults do not possess the basic knowledge that would qualify them as scientifically literate (Miller, 2004). This poses serious challenges to the ability of people to make informed decisions. Science and technology have always been fundamental elements for progress and economic prosperity and their historical development must be understood by the general populace. Scientific literacy thus becomes a tool to create a citizenry that is more likely to understand complex issues social, political, and environmental issues (Hurd, 1998). To be scientifically literate means a person must be able to "read about, comprehend, and express an opinion on scientific matters" (Miller, 1983: 30). The role of science in society has shifted throughout history and after WWII scientific literacy became a core competency necessary for the public to resolve issues and larger challenges they may have throughout their lifetime (Hurd, 1998). Because scientific advancement plays such a critical role in society, the public must be able to understand how science influences society and how scientific thinking can help solve complex problems (Eisenhart, Finkel, \& Marion, 1996).

This new understanding of science led to the development of new modes of education and redefined learning objectives. During the 1980s, science education was placed in the social context in an attempt to get the public to apply scientific thinking to everyday decisions (DeBoer, 2000). At present, however, science educators are made responsible for student learning with little or no regard for how that knowledge can or will be applied in the future. Attributing 
scientific learning to quantifiable metrics fails to capture the multifaceted nature of how this knowledge is employed (Eisenhart, Finkel, \& Marion, 1996). Additionally, this form of education carries with it some structural deficiencies and inequalities that directly challenge the basic principles of science. Western science tends to be privileged above other forms of knowledge production (Dos Santos, 2008). As a result, minorities, poor students, immigrants and females are marginalized and tend to be underrepresented in scientific literacy proposals (Eisenhart, Finkel, \& Marion, 1996). Further, underrepresented groups are forced into an educational framework that does not share similar vocabularies, social norms, or educational goals. These groups are at a disadvantage since they must overcome structural barriers in order to reach the same educational attainment as their White, male, middle class counterparts (Dos Santos, 2008).

While scientific knowledge has the power to transform societies, continuing to promote privileged positions limits the efficacy of this power and reinforces systematic inequalities (Dos Santos, 2008). Placing scientific literacy back in its social context allows educators to promote a more communal mode of instruction and to increase critical thinking skills among all students. This improves equality in educational outcomes and produces a populace that is equipped to participate in the decision-making process (Eisenhart, Finkel, \& Marion, 1996). When people are capable of comprehending and processing technical information they can make well-informed decisions. There is also an assumption that a scientifically literate society can better understand the consequences of policy decisions leading to more thoughtful legislation (Miller, 1983). In spite of this assumption, no person can completely understand all of the political issues and their associated technical requirements. Instead, they must choose to focus on specific issues (Miller, 1983). 
Under this scenario, members of the public choose what topic they wish to learn more about leading to groups with specialized knowledge. Thus the public has to rely on informational sources they trust (media outlets, public officials, or popular scientists) to gain an understanding of a topic. This selective exposure to facts and evidence is biased toward a person's values and political views, which can lead to blind spots on a given issue (Feldman et al., 2014). It can be argued that some of these blind spots can be offset by providing the public with a basic scientific vocabulary and training in foundational scientific knowledge, which could potentially reduce informational bias (Thomas \& Durant, 1987; Miller, 1983). However the acceptance of information is often governed by a person's values and lived experiences, and is compounded by the intentional selection of media sources that align with their beliefs. This leads to a cyclical pattern of information acceptance or rejection based on individual bias (Feldman et al., 2014) and poses a fundamental issue for scientific literacy as education must overcome the sociohistoric and cultural contexts of individuals in order to improve understanding.

\section{Study Group}

I partnered with the SATELLITES program, managed by Dr. Kevin Czajkowski at the University of Toledo to better understand how educators viewed the role of participatory research in science education. SATELLITES is part of the Global Learning and Observations to Benefit the Environment (GLOBE) Program. Both programs aim to engage K-12 students and teachers in hands-on science as a way to promote scientific literacy and learning. SATELLITES guides educators and students in Ohio, West Virginia, Pennsylvania, and Maryland to collect surface temperature measurements at designated locations during every program cycle. The SATELLITES program mission is to participate in GLOBE's Surface Temperature Campaign through the compilation and sharing of data. GLOBE is a network of scientists, teachers, and 
students that operates globally with the aim of collecting a variety of environmental data (globe.gov). The program was founded as an effort to use scientific investigations as a way to engage young students in scientific research to enhance learning and understanding of the scientific process.

Teachers participating in both programs are encouraged to use the data, techniques, and students' own innate curiosity to reinforce learning. Trainings and programmatic materials are available to all participants, and highly structured protocols for conducting investigations, collecting data, and submitting information are provided to ensure consistency across collectors and collection times. The program also prioritizes that students learn not only what the data show, but how science is conducted as well. By structuring science learning in this way SATELLITES addresses the need of all citizen science programs to ensure participant learning through defined objectives, methods, and quality standards (Bonney, Cooper, Dickinson et al., 2009). This research will assess how effective the SATELLITES program has been in enhancing student learning. A combined qualitative and quantitative data analysis approach was used in order to gain a better understanding of how educators view and interpret the goals of the SATELLITES program and gauge its effectiveness in improving scientific literacy among the participants.

\section{Methods}

The qualitative-quantitative $\left(\mathrm{Q}^{2}\right)$ methodological approach extends the analytical power of both techniques in order to critically examine the role of volunteers in complex participatory research (Place, Adato, \& Hebinck, 2007). In particular, the utility of the $\mathrm{Q}^{2}$ approach offers a complementary set of methodological tools that compensates for the short-comings of both quantitative and qualitative data while increasing the reliability of the findings (White, 2002; 
Place, Adato, \& Hebinck, 2007). Quantitative data analysis is well-suited for identifying trends and patterns in the data whereas qualitative data allow the research to gain a more robust insight into how these patterns come about and what they potentially mean. To achieve these goals, this research used in-depth surveys of SATELLITES educators.

Web-based surveys are an effective tool for collecting data from a non-contiguous population to which the researcher has limited access (Mansvelt \& Berg, 2005; Ritter \& Sue, 2007) and were selected over ground-based mailings or blind phone calls, because of cost and the relative decline in efficacy of cold calls (Evans \& Mathur, 2005; Duffy et al., 2005). Prior to the dissemination of the online survey, a letter of introduction was emailed individually to each participant to make sure they understood that there were protocols in place to ensure their participation in this survey was anonymous. In this letter I identified myself as a $\mathrm{PhD}$ candidate and gave my university affiliation so that respondents had a way to determine the validity of the research project (McGuirk \& O’Neill, 2005; Archer, 2008). The letter of introduction also included an Institutional Review Board certified 'Informed Consent' statement so the participants were assured their anonymity (Ritter \& Sue, 2007). The online surveys were designed to collect a range of demographic, educational attainment, and attitude-based data. The proposed survey entailed four parts: (i) demographic information, (ii) educational attainment data, (iii) Likert-scale attitude questions, and (iv) open-ended questions (reserved for future analysis).

The survey was distributed by email to a population of 166 past and current SATELLITES participants. The data collected from the survey allowed me to develop a profile of the educators participating in the SATELLITES program and gauge the overall learning of their students. The data provided basic metrics for background development, as well as in-depth 
information on the program as a whole (Place, Adato, \& Hebinck, 2007). For this analysis Likert scores generated from the participants' responses to each attitude-based question were treated as non-continuous ordinal data. That is, the Likert scales have an ordered rank, but the magnitude between each interval is not assumed to be the same (Blaikie, 2003). The resulting scores were transformed into a contingency table of response frequencies for analysis (Agresti \& Kateri, 2011). The resulting contingency table helped to highlight statistical relationships that exist within ordinal data types. These relationships are important for this research project since the data generated is nonparametric and not based on interval data (Gliem \& Gliem, 2003; Jamieson, 2004). Measures of variance and similarity/difference between the categories were scrutinized closely for qualitative differences between and among the sampled population (Lynch, 2013). Ordinal logistical regression (logistic regression) was used to analyze the relationship between the Likert scores and the independent variables. Likert scale responses were compared against demographic variables (Hosmer \& Lemeshow, 2000). During analysis, the tests were shown not to be statistically significant due to the small sample size.

\section{Results \& Discussion}

\section{Demographics}

Of the population of participants included in the initial distribution, 62 email addresses were returned as undeliverable. An attempt was made to check the validity of email addresses and three were updated successfully. This left a sample of 107 participants. The survey was left open online for a period of one year and the participants were sent reminder emails every month. After the survey was closed a total of 35 respondents $(32.7 \%)$ completed the survey. The demographic breakdown of the respondents was quite diverse in some respects and homogenous in others. At final count there were 22 female educators and 13 male educators included in the 
sample. Interestingly, however, 34 of the respondents self-identified as White with one respondent choosing not to answer.

The homogeneity among the race/ethnicity of the educators suggests that the SATELLITES program is similar to other citizen science programs with respect to demographics (Brossard, Lewenstein, \& Bonney, 2005; Pandya 2012). The age distribution of respondents was clustered in two ranges (Figure 3.1a; 41-50 and 51-60) with $81 \%$ of female educators and $54 \%$ of male educators accounting for responses from these age groups. This suggests that as educators progress through their careers they may see citizen science programs as a new teaching technique (Bonney, et al., 2009). Additionally, there is a large percentage of respondents (Figure 3.1b; female $=59 \% ;$ male $=92 \%$ ) that are tenured educators either at public or private schools. Most educators came from a middle-class background; the income range $\$ 50,001-100,000$ captured $45.5 \%$ of female participants and $38.5 \%$ of male participants; and the income range over

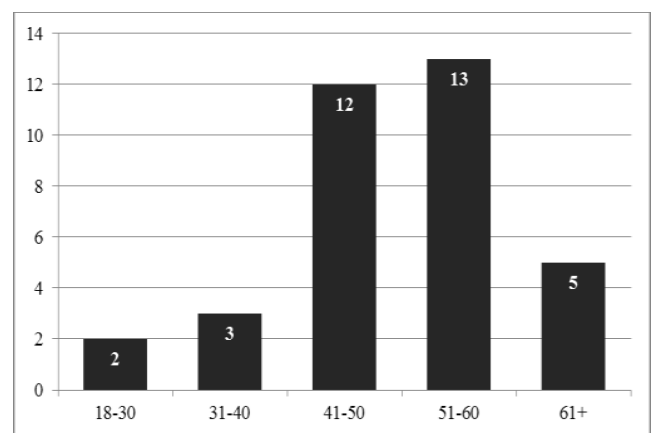

a: Age breakdown.

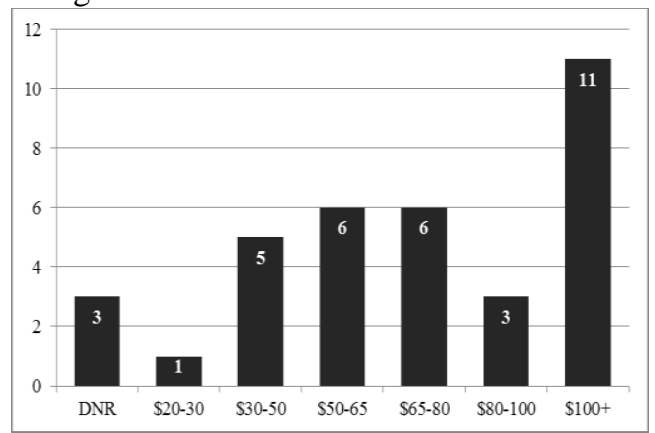

c: Participant income (x1000).

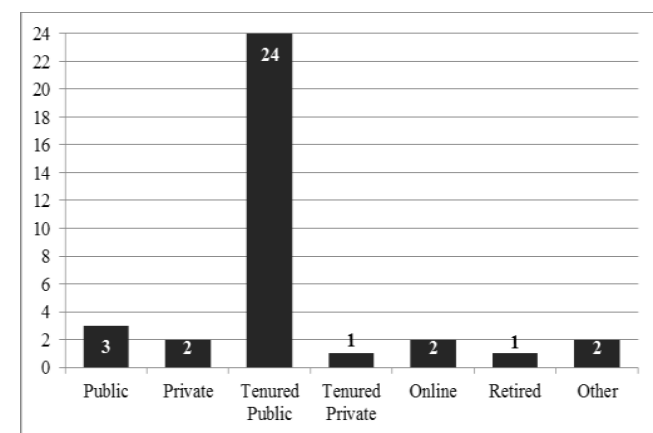

b: Occupation.

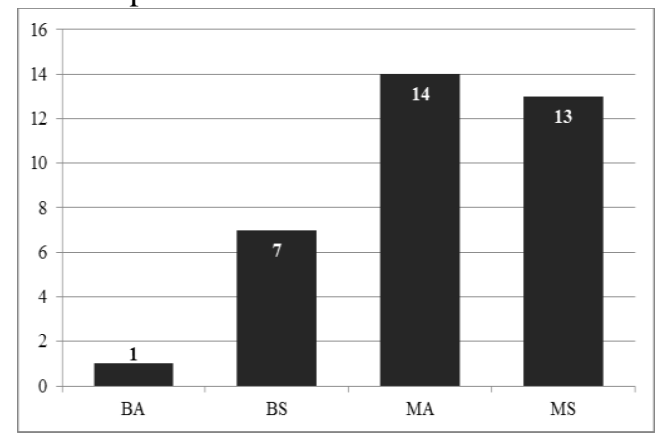

d: Educational Attainment. 


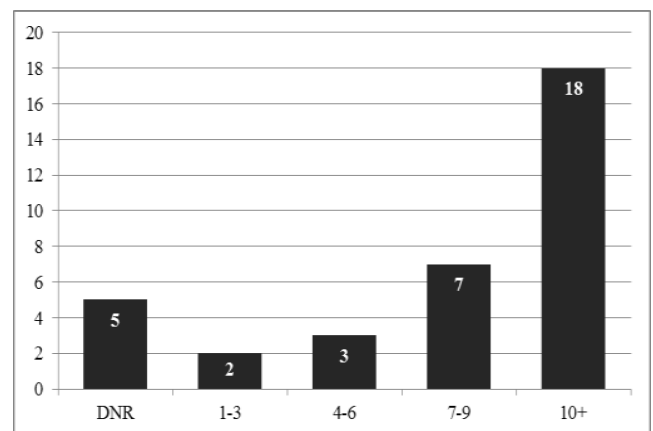

e: Number of science courses taken.

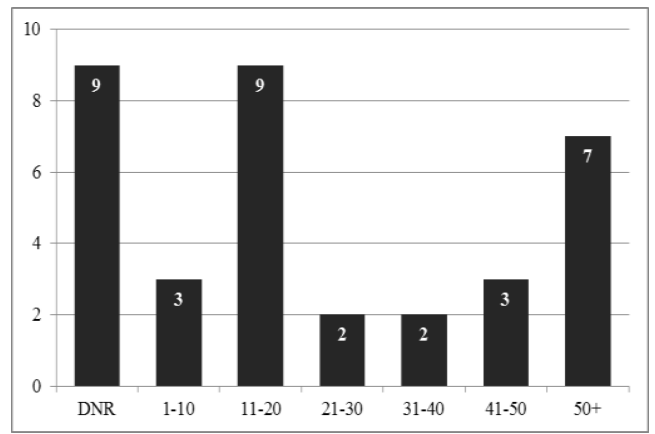

g: Number of students let during each mission.

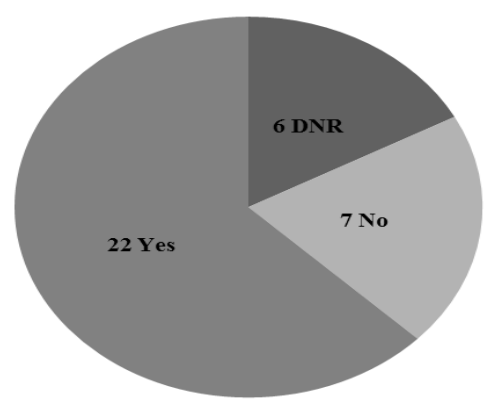

i: Led a citizen science mission before SATELLITES.

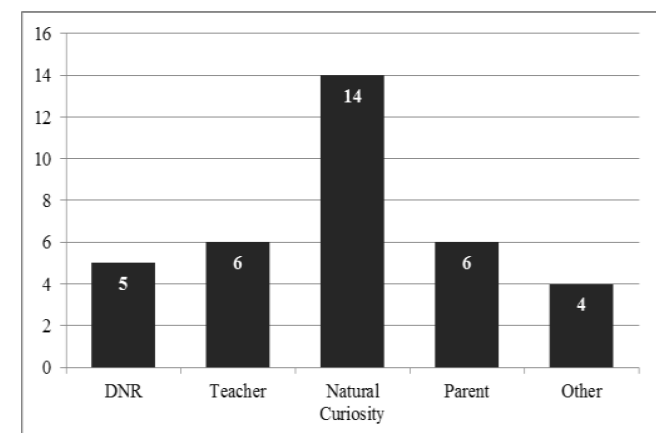

f: Who first interested respondent in science.

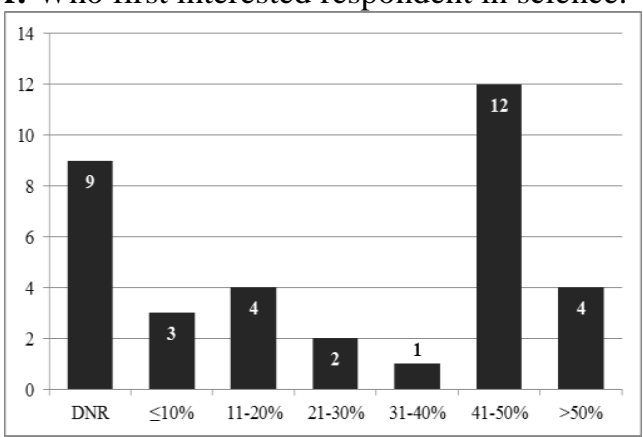

h: Percent female students instructed during each mission.

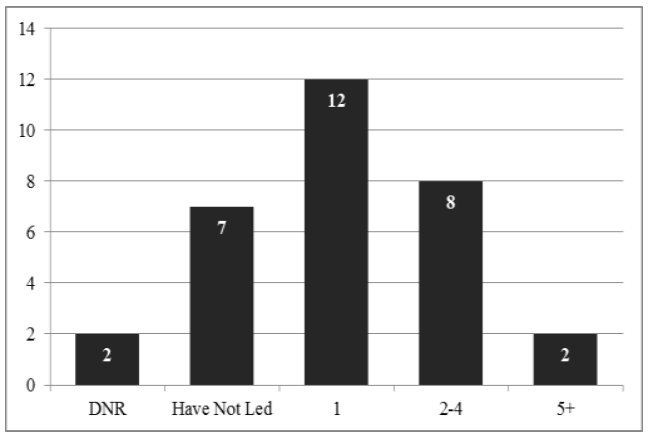

j: Number of SATELLITES missions led.

Figure 3.1: Respondent demographics by category.

$\$ 100,000$ captured $32 \%$ of female participants and $31 \%$ of male participants (Figure 3.1c). This is not altogether surprising given the high percentage of respondents that are tenured faculty members. In addition to a relatively high household income, $73 \%$ of female respondents and $85 \%$ of male respondents hold either an M.A. or M.S. degree (Figure 3.1d). The respondents were not asked whether holding a Master's degree was a prerequisite for their job, but it does suggest that educational attainment plays a role in educators deciding to participate in citizen science programs (Brossard, Lewenstein, \& Bonney, 2005). Related to their educational 
attainment, $86 \%$ of female participants and $46 \%$ of male participants reported completing seven or more science courses during their academic career; with $72 \%$ of female respondents having had formal training in environmental and climate science (Figure 3.1e; only $38 \%$ of male respondents had such training). Following the questions about training and educational attainment, the respondents were also asked who or what first got them interested in science. The survey found that $45.5 \%$ of female participants and $31 \%$ of male participants were inspired by natural curiosity (Figure 3.1f). Surprisingly, no male respondents stated that a teacher got them interested in science, whereas $27 \%$ of female respondents stated the affirmative. A Chi square test revealed that the results of this breakdown between gender and interest in science were statistically significant $(p<0.05)$, which may suggest, at least anecdotally, that these female educators were encouraged to participate in STEM fields and could be transferred to their female students.

An interesting point was uncovered when participants were asked about the average number of students led during a SATELLITES mission. Respondents (Figure 3.1g; 32\% female and $38 \%$ male) said they taught over 30 students for each data collection cycle. For such a small citizen science program, the number of students included in the data collection is quite remarkable. The participants were also asked what percentage of female students made up each group during a data collection cycle. This question was included, because women are still underrepresented in the STEM field and citizen science may offer a strategy to reverse that trend (Ceci \& Williams, 2011). The survey found that $43 \%$ of all respondents led groups that consisted of $30 \%$ or more female students and more than $10 \%$ of respondents led groups with over $50 \%$ female representation (Figure 3.1h). When asked if any of the participants had instructed students in a citizen science program before SATELLITES 68\% of female respondents and 54\% 
of male respondents said yes (Figure 3.1i). Over 50\% of the entire sample is actively incorporating citizen science programs in their pedagogy, which means that more and more students will get a chance to participate. Additionally, $28.5 \%$ of the entire sample has led more than one SATELLITES data collection mission with $17 \%$ of all respondents having participated in five or more cycles (Figure 3.1j). There is a strong indication that the SATELLITES program has been an effective tool for educators as they continue to engage new groups of students. When asked how they heard about the SATELLITES program 17\% of respondents were informed while participating in self-enrolled classes, $8.5 \%$ from community workshops, and $28.5 \%$ from internet research. That means that $54 \%$ of participants actively sought out additional programs that were of interest to them and could be used in their teaching strategies.

\section{Attitudes Toward SATELLITES Program}

The respondents were asked to answer a series of 27 Likert-scale questions and statements ranging from 1 - Strongly Disagree to 5 - Strongly Agree. The questions were designed to better understand how participating educators felt about the SATELLITES program, its effectiveness as a STEM educational tool, and gauge the student's overall satisfaction. While over $70 \%$ of all participants responded to the demographic questions, this response rate did not follow for the Likert-scale responses; 10 participants $(28.5 \%)$ chose not to answer any of the attitude-based questions. I will refer to these participants as chronic non-responders (CNRs). Surprisingly, however, four of the 10 respondents who chose not to answer the attitude-based questions did go on to answer the open-ended questions. These four respondents were all female educators with Master's degrees. They were all tenured faculty at public schools and they fell into the upper-middle or high income brackets. Half of the CNRs chose only to answer the first six demographic questions and then ceased answering any additional questions. There is no 
consistent pattern among these CNRs, but four out of five were male educators. They came from varying age and income ranges. Their occupations varied from being tenured teachers at public schools to retired educators. Because they did not answer any additional demographic questions it is unclear whether or not this subset of educators had any previous experience with citizen science projects before SATELLITES or a way to measure the degree to which they have participated in the SATELLITES project. One participant, Respondent 18 chose to answer all attitude-based questions as Strongly Disagree. There is no indication as to whether or not respondent 18 actually disagreed with the content of the questions or not. The assumption can be made that respondent 18 chose to answer the questions all the same in order to rapidly complete the survey because she did not answer any of the open-ended questions. A comments section was not included in the survey, so no explanation was given as to why the CNRs and Respondent 18 chose not to answers the Likert-scale questions at all.

\begin{tabular}{|c|c|c|c|c|}
\hline \multicolumn{2}{|r|}{ Likert-Scale Questions } & \multicolumn{3}{|c|}{ Frequency } \\
\hline & & $\begin{array}{l}\text { Strongly } \\
\text { Disagree }\end{array}$ & $\begin{array}{l}\text { Strongly } \\
\text { Agree }\end{array}$ & $\begin{array}{c}\text { No } \\
\text { Response }\end{array}$ \\
\hline $\mathrm{Q} 1^{\wedge}$ & $\begin{array}{l}\text { While working with SATELLITES you discussed with your students why data are being } \\
\text { collected and why it is important. }\end{array}$ & 1 & 16 & 7 \\
\hline $\mathrm{Q}^{\wedge}{ }^{\wedge}$ & $\begin{array}{l}\text { The experience of collecting data is used within the classroom to reinforce key scientific } \\
\text { concepts. }\end{array}$ & -- & 13 & 11 \\
\hline Q3* & Before working with SATELLITES the topic of participatory research was important to me. & -- & 8 & 16 \\
\hline Q4* & SATELLITES has improved my overall understanding of the scientific process. & -- & 12 & 12 \\
\hline $\mathrm{Q}^{\wedge}$ & SATELLITES has improved my student's overall understanding of the scientific process. & -- & 12 & 12 \\
\hline Q6* & $\begin{array}{l}\text { SATELLITES helped me to better communicate with my students about science-related } \\
\text { debates. }\end{array}$ & -- & 10 & 14 \\
\hline $\mathrm{Q7}^{\wedge}$ & Working with SATELLITES has improved the student's overall opinion of science. & -- & 12 & 12 \\
\hline Q8 & $\begin{array}{l}\text { The topic of climate change was discussed within the classroom in conjunction with } \\
\text { participation in SATELLITES events. }\end{array}$ & -- & 14 & 10 \\
\hline $\mathrm{Q}^{\wedge}$ & SATELLITES has encouraged my students to learn more about environmental issues. & -- & 10 & 14 \\
\hline Q10* & Working with SATELLITES has increased my knowledge of environmental issues. & -- & 12 & 12 \\
\hline Q11^ & $\begin{array}{l}\text { While working with the SATELLITES program the students felt a sense of importance with } \\
\text { the work they were doing. }\end{array}$ & -- & 13 & 11 \\
\hline${\mathrm{Q} 12^{\wedge}}^{\wedge}$ & The students understood why they were collecting data for SATELLITES. & -- & 13 & 11 \\
\hline $\mathrm{Q}^{1} 3^{\wedge}$ & $\begin{array}{l}\text { Volunteering with the SATELLITES program made the students realize the importance of } \\
\text { scientific knowledge as a complex problem solving tool. }\end{array}$ & -- & 6 & 18 \\
\hline Q14* & $\begin{array}{l}\text { Volunteering with the SATELLITES program made me motivated to encourage others to } \\
\text { participate in community science projects. }\end{array}$ & -- & 5 & 19 \\
\hline Q15* & $\begin{array}{l}\text { My appreciation of scientific research increased as a result of my participation with } \\
\text { SATELLITES. }\end{array}$ & -- & 6 & 18 \\
\hline Q16* & $\begin{array}{l}\text { Working with SATELLITES has encouraged me to be more politically active when it comes } \\
\text { to environmental issues. }\end{array}$ & 2 & 6 & 16 \\
\hline Q17* & After working with SATELLITES, I actively sought to engage in public and private & 2 & 6 & 16 \\
\hline
\end{tabular}




\begin{tabular}{|c|c|c|c|c|}
\hline & discussions with others about what my students and I have learned. & & & \\
\hline Q18* & I will continue to help students participate in future SATELLITES activities. & -- & 4 & 20 \\
\hline Q19^ & Working with SATELLITES has strengthened my students' communication skills. & -- & 4 & 20 \\
\hline $\mathrm{Q} 20^{\wedge}$ & $\begin{array}{l}\text { After working with SATELLITES, students learned how to work in groups and divide tasks } \\
\text { between each other. }\end{array}$ & -- & 3 & 21 \\
\hline $\mathrm{Q} 21^{\wedge}$ & Volunteering with SATELLITES has increased my students' critical problem solving skills. & -- & 4 & 20 \\
\hline $\mathrm{Q} 22^{\wedge}$ & $\begin{array}{l}\text { Volunteering with SATELLITES has increased my students' attendance and participation in } \\
\text { science and math groups and/or extracurricular activities. }\end{array}$ & 1 & 2 & 21 \\
\hline Q23* & $\begin{array}{l}\text { Working with SATELLITES has encouraged me to participate in discussions surrounding } \\
\text { environmental and science-related issues. }\end{array}$ & -- & 5 & 19 \\
\hline Q24* & $\begin{array}{l}\text { Participating with SATELLITES has improved my overall opinion of the role of science in } \\
\text { society. }\end{array}$ & -- & 6 & 18 \\
\hline $\mathrm{Q} 25^{*}$ & $\begin{array}{l}\text { By participating with SATELLITES my opinion of scientific education as a way to engage } \\
\text { students in complex issues has improved. }\end{array}$ & -- & 7 & 17 \\
\hline Q26 & $\begin{array}{l}\text { Students participating in scientific research have the ability to improve the overall quality and } \\
\text { understanding of the research findings. }\end{array}$ & -- & 6 & 18 \\
\hline Q27 & $\begin{array}{l}\text { In your opinion, project-based learning can improve the overall learning of individual } \\
\text { students. }\end{array}$ & -- & 17 & 7 \\
\hline
\end{tabular}

The responses to the attitude-based questions resulted in a distinct set of values as participants eschewed the more moderate responses (i.e. 2, 3, or 4) in favor of the extreme values of option 1 - Strongly Disagree and option 5 - Strongly Agree (Figure 3.2; Robbins \& Heiberger, 2011). Additionally, participants chose not to answer the attitude-based questions at a high rate. By looking at the responses question-by-question there is no clear pattern to the No Response category. If participants suffered from survey burnout, then the percentage of no response answers should have increased from the first question to the last (Fan \& Yan, 2010). This, however, is not the case; both Q1 (While working with SATELLITES you discussed with your students why data are being collected and why it is important.) and Q27 (In your opinion, project-based learning can improve the overall learning of individual students.) have No Response rates under $50 \%$, which is the lowest for all questions. This might be expected if participants chose to focus on the first and last questions, but the frequency of responses fluctuates from Q2 to Q26. Questions 1 through 12 and 27 all had response rates above 30\%. For questions 13 through 26 the response rates dropped to a low of $10.5 \%$ to a high of $23 \%$. 
Questions 1, 16, 17, and 22 also, had the highest Strongly Disagree response rates for the entire set of questions (Table 3.1; Figure 3.2). These, rates, however, are quite low when compared to the Strongly Agree and No Response rates. For Q16 (Working with SATELLITES has encouraged me to be more politically active when it comes to environmental issues.) two respondents answered in the negative, 6 participants responded in the affirmative, and fully twothird of respondents chose not to answer these questions. Questions 16 and 17 focused on the participants' willingness to engage in public debates and get involved in political movements that deal with environmental issues. Again, educators are using the SATELLITES program only as a teaching tool that does not extend past the boundaries of the classroom. Whatever the reason, it is important to note the implications of these respondents' attitudes. As political divisiveness over complex scientific issues (i.e. global climate change) grows, increased public understanding of the underlying science will become more important in determine truth versus misinformation (Carvalho, 2007). Questions 1 and 22 only saw one person respond in the negative respectively. These two questions asked about the students understanding of program goals and their willingness to participate in other STEM activities. These responses indicate that one participant feels strongly that their students are not fully engaging with the program and that it is not getting them excited about science. 


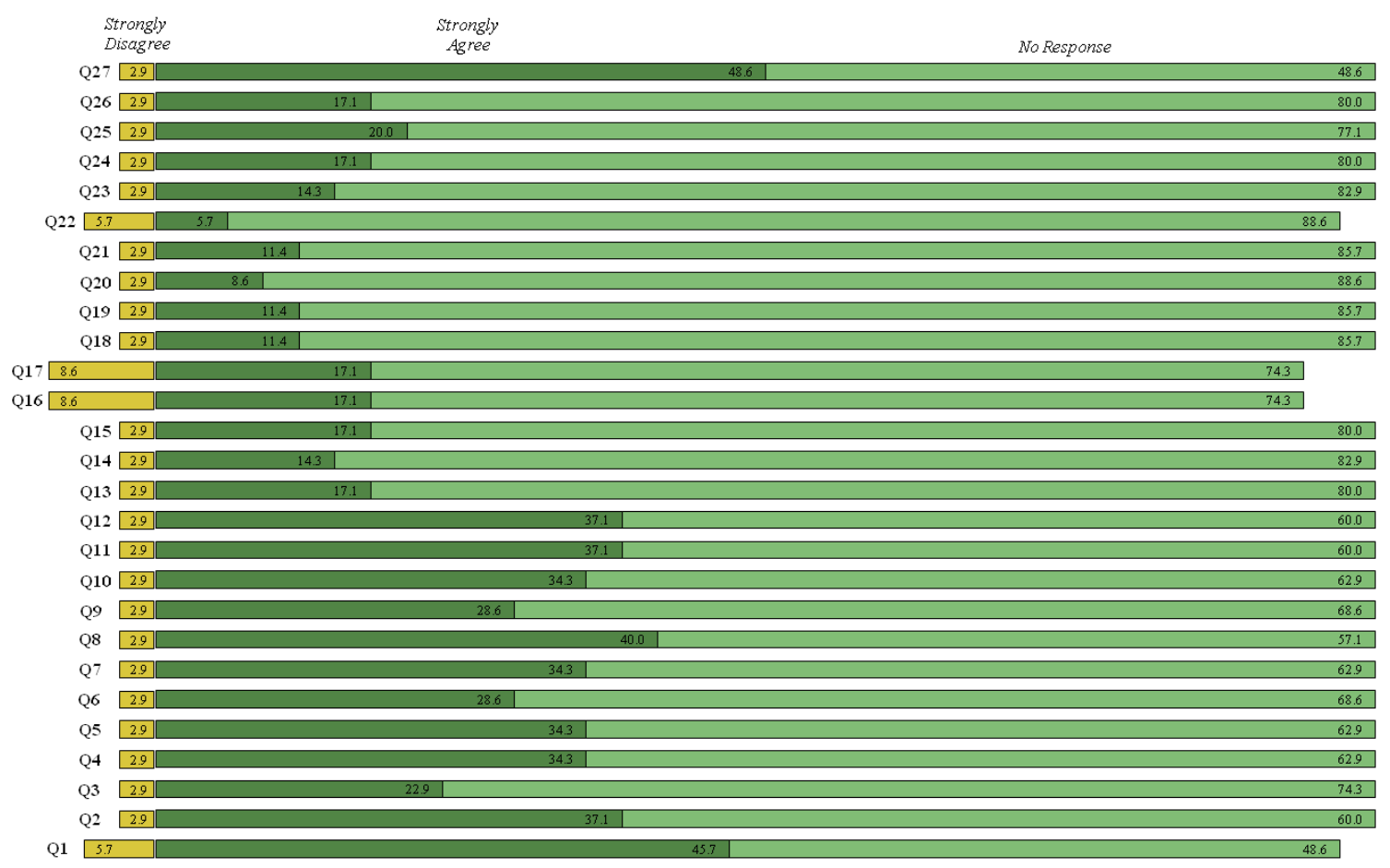

Figure 3.2: Diverging response rates for Likert-scale questions.

A subset of questions (Table 3.1) were used to gauge how effective the SATELLITES program was in improving the students' overall learning and understanding of scientific topics. Responses to these questions were mixed, but most were answered Strongly Agree at a high rate. Questions 13 (Volunteering with the SATELLITES program made the students realize the importance of scientific knowledge as a complex problem solving tool.), however, had a low affirmative response rate. There seems to be a disconnect between program objectives and practical outcomes. The sustainability of citizen science programs depends on many factors, not the least of which includes providing participants with clear and consistent objectives (Dickinson et al., 2012). For instance, Q1 asked whether the participants explained to their students why they were collecting these data. While Q13 only had six participants answered with any level of certainty, 16 participants answered Strongly Agree for Q1. When we discuss the level of scientific literacy within society we are really concerned with how people receive, ingest, and 
use scientific information to inform their daily lives (Miller, 1983). This suggests that there may be a gap in instruction among the participants or some participants are choosing to frame the objectives of the SATELLITES program in a narrow perspective. For Q11 (While working with the SATELLITES program the students felt a sense of importance with the work they were doing.) there was a higher than expected No Response rate; educators may not have discussed with their students why they were collecting data, instead opting to treat it like a class exercise, which dovetails with Q12 (The students understood why they were collecting data for SATELLITES.). If students are not made aware that their teachers are using the SATELLITES program to augment their science education then the students may never fully grasp the larger programmatic goals. Questions 19-22 also had low affirmative response rates, which is surprising since they dealt with scientific learning of the students. The low response rates demonstrate that the students, while participating in large numbers, are not becoming more interested in scientific topics.

A subset of questions (Table 3.1) was used to assess the attitudes and opinions of the respondents themselves. These questions had a much higher rate of No Response than the questions regarding the students. The response to Q3 (Before working with SATELLITES the topic of participatory research was important to me.) was low with over $60 \%$ of respondents choosing not to answer the question. This is of particular interest, because the group of respondents has a high level of scientific training and stressed the overall importance of projectbased learning for their students. In fact, Q27 had a Strongly Agree response rate of 68\%. While the respondents were well trained in the scientific method, they were not necessarily aware of the impacts citizen science programs could have on student learning. Many respondents may have chosen not to answer when asked about their opinion on outcomes because they felt that the 
SATELLITES program did not impart any new knowledge. Low response rates overall indicate that their teaching goals and programmatic goals do not necessarily align. Some educators led groups at lower grade levels and they are just introducing the students to scientific methods, with the goal of teaching students how to conduct a scientific experiment. Questions 14-18 and 23-25 had the highest No Response rates in this subset. These questions primarily asked whether or not participants were likely to discuss scientific topics or become actively involved in public discussions after working with SATELLITES.

Finally, questions 1,26 , and 27 were used to gauge how important the respondents felt citizen science projects were to overall scientific literacy. Question 1 dealt specifically with discussing the goals of the SATELLITES program with the students. This is important because it leads students to understand that the work they are doing is not just another exercise, but part of a larger project. Two-thirds of respondents answered in the affirmative. Additionally, there was a high No Response to Q26. Nearly three-quarters (72\%) of participants chose not to answer this question in any way, which may suggest that this was not necessarily a program objective. If this is the case, as with other citizen science programs, objectives may need to shift to include outcomes that can be used in peer-reviewed scientific research (Bonney, Cooper, Dickinson et al., 2009). Citizen science projects could be redesigned in the future to include these downstream strategies, not only focusing on teaching science, but also as a means to develop a more grassroots science. Expanding the scope of citizen science projects to train people to become amateur scientists or to incorporate hard-to-reach groups may be an effective strategy to improve scientific understanding (Pandya, 2012). Lastly, roughly 70\% of respondents answered in the affirmative for Q27. The participants had positive views of SATELLITES as a learning tool, 
which suggests that as citizen science programs gain in popularity, scope, and distribution more educators with incorporate project-based learning into their curriculum (Dickinson et al., 2012).

\section{Conclusions}

Citizen science is a relatively novel form of scientific research that has many applications to scientific education (Zoellick, Nelson, \& Schauffler, 2012). However, there are concerns that citizen science programs do not meet the educational needs of all communities. The SATELLITES program has a high rate of participation from a White, middle-class population, which has been observed with other citizen science programs (Brossard, Lewenstein, \& Bonney, 2005). The lack of diversity poses some concern that citizen science programs in general are missing at-risk minority groups, which could also potentially benefit from participatory education (Pandya, 2012). Citizen science programs could be used to promote equality in science education, thus improving scientific literacy, but participation has to be better distributed among all populations. Programs like GLOBE and SATELLITES are using similar teaching techniques to reach at-risk groups around the world. The organizers of these programs recognize the need to be inclusive in order to achieve programmatic aims, which suggests that outreach efforts will continue to address the lack of diversity. Additionally, the creation of more localized neighborhood projects broadens the focus from solely education to include community-based engagement (Jordan, Ballard, \& Phillips, 2012). The SATELLITES program is effective at engaging students in academic research. Respondents regarded the program as a useful teaching tool and acknowledged improvement their students' overall learning through their participation.

Next, an assumption can be made that educators possessing a great deal of scientific training would opt to incorporate experiential science-based education in their curriculum, but I do not think this point is a simple tautology. Citizen science programs provide a unique 
opportunity for educators to offer a hands-on educational experience for their students (Zoellick, Nelson \& Schauffler, 2012). However, science educators do not necessarily seek out citizen science programs to incorporate into their lesson plans. They have to be motivated to go beyond standard classroom-based instruction in order to introduce their students to hands-on application of scientific practices. This takes coordination with program sponsors, other teachers, and parents and requires additional resources to implement (Jordan, Ballard, \& Phillips, 2012). Additionally, there is a concern that STEM education reaches male students at a disproportionate rate translates to fewer female students receiving science-based degrees (Ceci \& Williams, 2011), but the SATELLITES program has a high rate of female student involvement.

Raising the awareness of the participatory opportunities citizen science programs offer may increase their use both in the classroom and communities. The research project found mixed results in terms of the respondents' attitudes toward the SATELLITES program, but their overall opinion of its efficacy as a teaching tool was high. Students did not receive program objectives equally and some respondents viewed the program as just another part of their curriculum. Thus, some students were not made aware that the science they learn in and out of the classroom could have a greater impact on their lives. Citizen science programs need to continue to stress the importance of the learning objectives so participants will develop a deeper connection and understanding of scientific inquiry in general (Dickinson, et al., 2012). This will have the added benefit of promoting scientific literacy and creating generations of people that feel connected to science on a deeper level (Miller, 2004). 


\section{Chapter 4: A Brief Discussion of Marx's Dialectical Method}

For Marx, careful examination and exposition of the underlying relations can yield a more accurate explanation of how the outward appearances that are the subject of inquiry came to be (Marx, [1867] 1990). Modern scientific thought, which is antagonistic to Marx's program, has come to be dominated by a logically positivist, highly empirical approach to producing knowledge. When critiqued through a Marxist lens, this approach is seen as overly reductionist and misses the relationships between phenomena and only captures surface appearances (Levins \& Lewontin, 1985). In short, a strictly empirical approach to science produces limited insights into the key elements that produce the object of study (Ollman, 2003). Marx emphasized the role of capitalism because his analyses suggested that the complex functioning of capitalism transcended the economic sphere and produced key contradictions and determinants that ultimately became embedded within the social and political superstructure (Marx, [1867] 1990). Contrary to Marx's core assumption, empiricism implies that conclusions about the outward appearances of the concrete world can be drawn from a calculus of observations without ever fully understanding how they came into being. Thus, manifestations of socioeconomic, environmental, or political change result from individual or group dynamics rather than being informed by complex interactions.

Even more challenging to our critique of capitalism is the reinforcing narrative that has accompanied its development. As the history of capitalism unfolded, its influence has been disregarded by scholars who come to see the mode of production as a universalizing natural element of society (Peet, 2007). Marx's own analyses were predicated on the assumption that capitalism was not natural but highly ideological and he emphasized that any notion, concept, or thought of or about reality resulted from the influence of capitalism (Bohm, 1983). "[C]hanges in 
the productive forces dictate the course of human history, including the evolution of social relations, mental conceptions, the relation to nature, and the like" (Harvey 2008: 28). Thus readily apparent forms, constructs, and social dynamics cannot be taken as objective truth but rather representations of more complex processes (Ollman 1993: 2003). Viewed in this way, the production of knowledge is highly structured by the underlying relations that generate complex social interactions. When we frame citizen science as arising, not only from the evolution of modern scientific thought, but shifts in socioeconomic and political norms as well, we can begin to uncover its very essence. Thus, the focus paid to citizen science and the research conducted is the result, not only of scientific curiosity, but complex social relations that have developed over time.

\section{Historical Materialism}

Marx's subject of study was capitalism and by extension how capitalism influenced all aspects of society. In order to understand the way in which Marx examined and came to conceive of capitalism one must come to appreciate the underlying scientific and philosophical framework Marx employed to move beyond outward appearances and uncover the true essence of his observations (Ollman 1976: 63). Marx's philosophical framework was constructed around the notion of historical materialism, which reinforced his view on human consciousness (Morrison, 1995). Additionally, Marx adapted Hegel's dialectic as a scientific methodological tool so that he could analyze the qualitative - as well as quantitative — changes that took place within society as capitalism unfolded (Ollman 1993; 2003). The dialectic is an anti-reductionist mode of thought that stresses change and contradiction as the drivers of historical moments. The "fluidity and historicity" of Marx's dialectic comes from the view that readily apparent social structures and formations are linked together through a series of internal relations that create, react, and 
feedback to give rise to dynamic moments in the historical development of society (Levins \& Lewontin, 1985: 267). Thus, there is an inherent link between historical materialism and the dialectic since it is through the evolution of the material basis of society (i.e. the dominant mode of production) where we see the origins, alterations, and contradictions of social relations that further influence the historical development of a society (Ollman, 2003). In order to present Marx's dialectic as scientific rather than metaphysical ideology we have to demonstrate how its theoretical underpinnings are informed by a critical rationality.

Marx developed his materialist view of history over the course of his early professional life. His theory crystallized with the publication of the Grundrisse and Capital Vol. I. As a young man, Marx had a critical appreciation for theses laid out by Hegel and Feuerbach. Responding to the events of the French Revolution, Hegel outlined a rigidly idealistic philosophy that informed his social theory (Marcuse, 1954; Morrison, 1995). For Hegel, individual thought-not material existence-is the vehicle through which knowledge can arise. "Knowledge begins when philosophy destroys the experience of daily life" (Marcuse 1954: 103). Hegelian idealism calls for a higher form of philosophy, one in which the observer transcends a sense-based approach to knowledge production. Because the material existence is always changing it is impossible to gain an understanding of the world (Morrison 1995). Marx sees this as a fundamental error in critical social thought and challenges the notion of Hegelian idealism with his own materialist critique. For Marx, everyday experience must form the basis of investigation (Marx \& Engels, [1845] 1947).

From materialism we get the concept of the generalized structure of society, which discusses the differing modes for producing the material basis of life throughout history (Peet, 1979). Modern scientific thought must take as its object of study human existence, social 
relations, and economic necessities, since they drive daily life and shape consciousness. The repetitive daily activities of people shape how they interact with nature to fulfill their basic material needs (Morrison, 1995). A materialist theory of history focuses on studying the concrete conditions that reproduce human existence, which are realized through productive activities (Marx \& Engels, [1845] 1947). Every period of history had its own mode of production that shaped society and these productive forces transform the socioeconomic and political structures of that particular society (Marx, [1867] 1990). By reframing the manner in which we think about societies Marx produced a radical social theory that interpreted societal development through the lens of productive forces. These productive forces express themselves in modern society through complex interactions between capital and labor and become cemented in practice by laws, economic activity, and societal norms (Peet, 1979). A structured division of labor that produces ever-increasing specialization further refines the relations that develop between capital and labor (Durkheim, 1893). This division of labor comes to include the modern scientific enterprise whereby the production of scientific knowledge employed by capital for its own expansion and reproduction (Peet, 2007; Smith, 2008).

\section{Philosophy of Internal Relations}

Fundamental to our understanding of Marx's dialectic and closely allied with a materialist theory of history is the philosophy of internal relations. Marx owes an intellectual debt to Hegel, Leibniz, and Spinoza for their earlier conceptualization of the philosophy. Each attempted to search "for the meanings of things and/or of the terms that characterize them in their relations inside the whole" (Ollman, 2003: 39). The search for an internally coherent structure of relations suggests that a theoretical whole is not "just the sum of its qualities, but through the links these qualities (individually or together in the thing) have with the rest of nature, it is also a 
particular expression of the whole" (Ollman, 2003: 40). Within reality things cannot exist independently from one another and thus are not reducible to ontologically different parts and wholes (Levins \& Lewontin, 1985). The philosophic notion of 'relation' becomes a means to which we can analyze and interpret how seemingly unconnected things or systems act and react with respect to one another. Here we begin to see the foundation of Marx's dialectic and a movement away from viewing the world as 'subject' existing externally from people as 'observer' to a view of inherent inseparability (Morrison, 1995). The inherent link between Marx's historical materialism and the philosophy of internal relations leads to an epistemological view that knowledge can only be produced by centering any analysis on the productive forces at work in a given society (Harvey, 1996). The material basis that is responsible for guiding the processes of reproduction also generates the myriad of complex forms and structures people encounter every day. This, in turn, shapes peoples ways of thinking about the world and what gets produced and recorded as knowledge. This forms a complex assemblage of relations that cannot be isolated, or reduced, from one another. When we think about citizen science is this way we can begin to appreciate how tightly coupled the implementation and reception are with its epistemological roots.

The common sense view of the world, applied predominantly to positivist reductionist research, suggests that processes are external to things, acting on them to produce changes (Harvey, 1996). This leads to the alienation of the object by the observer, and when the observer assumes as reality, this isolation, the knowledge produced will always be incomplete. Indeed, the view that the individual becomes the key actor in a society has its origins in Enlightenment thought whereby society becomes a collection of individual actions, which are influenced by dominant productive forces. "The alienated world is both ideological and real," which means that 
predominant social order appears to be a natural consequence of historical development while, at the same time, it is a reflection of the reality that has been erected through the complex interactions of individual actors (Levins \& Lewontin, 1985: 270). This sets up a dichotomy in which change is ascribed to cause-effect relationships where reality is separate from both the observer and causality. The alienation between object and observer not only occurs when discussing society, but when observing the physical world as well. Modern scientific thought adopts this practice by decomposing nature into systems, or 'parts' and 'wholes' as a method to produce knowledge. This practice often leads to reductionist conclusions where the analysis of a system or whole becomes the aggregation of accumulated facts resulting from the examination of isolated parts (Levins \& Lewontin, 1985). In order to overcome reductionism we must subscribe to the notion that parts and wholes are not ontologically divisible, but "evolve in consequence of their relationship, and the relationship itself evolves" (Levins \& Lewontin, 1985: 3). Internal relations both alter and can be altered by complex feedback and change that are inherent to the observable world. Marx's dialectic is a methodological tool that we can use to understand how internal relations give rise to surface appearances and generate real insight about the concrete world without reducing our analysis to parts and wholes.

Hegel's Dialectic

Marx's dialectic was informed by Hegel's own conceptualization of the dialectic. It is readily apparent that Marx's dialectic evolved from Hegel's own mode of inquiry yet represents a radical departure as well. Hegel's dialectic was influence by the French Revolution, which represented the culmination of a complex arrangement of social relations that shook modern society to its very core and (Morrison, 1995). The primary contribution Hegel made during this 
period is the notion that history is in 'motion'. As Morrison (1995: 2) points out, there are four distinct theoretical concepts that drove the development of Hegel's philosophy:

1. History is in motion and any one social or political structure can be replaced,

2. Economics and politics are inherently linked in society,

3. Historical changes assume the outward appearance of changes in social formation; these changes represent distinct periods of development, and

4. Individual experiences must form the subject matter of any analysis of these changes.

The notion that history is in motion, or that there is a flux to historical development is central to both Hegel's and Marx's dialectic (Harvey, 1996; Levins \& Lewontin, 1985; Ollman, 1976, 1993, 2003). The appearance of stability in society becomes associated with positive representations of historical development, but in reality stability is only a moment in time when change is not readily apparent (Levins \& Lewontin, 1985). When we begin from the position that change is inherent to all social formations then we can accept the dialectic as the mode of thought that captures and internalizes this logic of motion. In his introduction to Capital Volume I, Mandel (1976) draws the link between the Hegelian dialectic and the materialist Marxist dialectic by recognizing that each internalize a search for the general forms of motion that are inherent to society. With Hegel's dialectic the source of motion comes from the 'Absolute Idea,' which is responsible for producing an original unity out of which direct knowledge of reality can be developed (Smith, 2008; Marcuse, 1954). Ideas - abstracted through the use of the dialecticrepresent the final stage of knowledge (Collinge, 2008). General laws of motion generate the readily apparent features, which are observable by humans. For Hegel, knowledge is not the accumulation of observable facts, but the uncovering of essence through ideas. Hegel's dialectic began with the negation, and indeed was called a negative philosophy. The reality of any object 
contained both what it is and what it is not (Marcuse, 1954). The dialectic represents a philosophical challenge to positivism since the dialectician must challenge the very existence of observable facts on which the latter mode of thought is predicated. The beginning of truth thus becomes the acceptance that appearance does not necessarily equal truth and one must "pierce farther and farther through successive layers of phenomena" to arrive at facts (Mandel, 1976: 19 in Marx, [1967] 1990). As a result, thought arises out of all the possible contradictions a human can experience. Contradiction arises from contentions relationships between people, social structures, economic relationships, and things. These relationships result from the historical development of societies (Marcuse, 1954; Morrison, 1995). Hegel's contradiction produced immediate forms that were readily observable yet incomplete because they represented the partiality or incompleteness of what things could be (Marcuse, 1954).

\section{Marx's Materialist Dialectic}

Marx inverts Hegel's dialectic by unequivocally stating that abstract ideas cannot produce 'truth' about reality. Instead, abstraction is a means through which real, substantive observations about the material essence of reality can be made (Ollman, 2003). Broadly speaking the dialectic is the pursuit of the unity of opposites. Capitalism creates contradictions and tension within modern society that need to be resolved (Ollman, 2003). The dialectical method is designed to examine the totality of all phenomena in order to uncover the true essence of the underlying movements (Mandel, 1976, in Marx, [1867] 1990). Contradiction arises from the internal movements of the dominant mode of production and that these movements give rise to what people conceive of as reality. Marx's dialectic provides a method to move beyond appearance to essence (Ollman, 2003). Appearances are mistaken as reality, but Marx tells us that not only do surface appearances get produced from the motion of capitalism, but ideas are 
filtered through the dominant mode of production as well. Thus, the dialectic comes to represent a mode of thought that directly challenges bourgeois science. "The value of the dialectic is as a conscious challenge to the major sources of error of the present" (Levins \& Lewontin, 1985: 268). There is a fundamental bias by scientists to privilege positivist research programs that treat observations about reality as fact, ignoring the underlying socioeconomic and political drivers of observable phenomena.

From a dialectical perspective, phenomena are temporary appearances of interrelated parts that are not ontologically separable from the observed whole (Levins \& Lewontin, 1985). What this implies is that reality is not reducible to individual parts that have an internally consistent logic when viewed in isolation. Rather, there is an inherent irreducibility to reality and the epistemic roots of the very essence of apparent forms and social relations must be grounded on the knowledge that the culmination of internally related characteristics gives rise to what is readily apparent. This makes the job of dialectical science difficult since observable moments are ephemeral—although they may persist for decades or centuries — and the constant flux of internal relations can and will produce new moments. The dialectician must be able to recognize that the totality of all relations makes up reality (Morrison, 1995) and the understanding of these relations comes from the resolution of contradictions while acknowledging that the knowledge produced is both temporary and necessarily incomplete. In reality, both Marx and Harvey were unequivocal on this role of the dialectic. It is capable of generating knowledge about the world of appearances while being transitory and temporary (Ollman, 2003). Dialectical thought internalizes the notions of incomplete knowledge and fallibility.

Dialectical investigations rely on a very specific and intellectual rigorous set of methodological tools, which include: (i) the philosophy of internal relations; (ii) the process of 
abstraction that occurs through three interrelated modes-extension, level of generality, and vantage point; and (iii) the concept of relations. As we have already seen, Marx's investigation of capitalism is underpinned by the theory of internal relations and a materialist theory of history. These two aspects of Marx's and Marxist thought inform the dialectic and act as a guide for any mental reconstruction of the world. As Harvey (1996: 54) points out, "the interdigitation of parts and wholes entails the interchangeability of subject and object, of cause and effect". Viewed in this manner, the intellectual products of the dialectic can be seen as dynamic and force the observer to engage with reality repeatedly. This mode of enquiry-one that challenges the observer to continuously engage reality in though—produces "permanences such as concepts, abstractions, theories, and institutionalized structures of knowledge which stand to be supported or undermined by continuing processes of enquiry" (Harvey, 1996: 55). By searching for the internal relations that give rise to social formations, behaviors, institutions, and the like the dialectic internalizes the stated objectives of the bourgeois scientific method, but goes further to demand a level of continued examination that embodies openness and precludes the closure of any investigation with the pronouncement that indeed immutable facts and laws have been discovered (Harvey, 1996; Levins \& Lewontin, 1985). Although rarely discussed by Marxist theorists, the dialectic is a modernist mode of enquiry that attempts to generate universal laws about the role of capitalism - the dominant mode of production, or base - in shaping the concrete world of social norms, ideology, thought, laws, and economics (superstructure). Caution is necessary when employing the full intellectual depth and breadth of the dialectic, since if we do not follow the dialectic to its logical conclusion then it will be seen as mere description fraught with teleological outcomes of deterministic relationships (Harvey, 1996). By continuously interacting with reality and thinking through the internal relations, an investigator can avoid 
producing deterministic conclusions. We begin to understand that, although the interconnected web of internal relations is complex and requires a great deal of thought, there are dominant social formations and phenomena that can guide our enquiry. We can use the other methodological tools Marx (via Ollman) has given us to achieve our goals.

First among these tools is the process of abstraction. Because the subject matter of the dialectic is change and interaction we must attempt to analyze reality by accounting for what gives rise to it, but we must also break reality down into manageable units. Through the process of abstraction we can set temporary boundaries to determine where our investigation will begin and guide us through our thought experiment. All thought proceeds through similar lines, but the dialectic is the only mode of enquiry that consciously recognizes the links between abstracts, the historical process contained within abstracts, and the need to join abstracts together to obtain an adequate analysis (Ollman, 2003). The process of abstraction begins with the 'real concrete'the world as it is laid out before us; flows through abstraction itself, or the "intellectual activity of breaking this whole down into the mental units with which we think about it"; and arrives at the 'thought concrete', which is the reconstruction, in the mind, of the reconstituted totality (Ollman, 2003: 60). During the process of abstraction the observer will focus of the relations that are contained within each mental unit. What is truly difficult to grasp is that thought has to be understood as dialectical as well, so that the thought concrete also is connected to the underlying relations and is shaped by human experiences within the superstructure.

There are three modes of abstraction that any observer must confront throughout the dialectic: extension, level of generality, and vantage point. These modes of abstraction represent three very real ways of enabling and altering an observer's perspective and the way they relate and engage with the whole. "Knowledge is socially constructed because our minds are socially 
constructed and because individual thought only becomes knowledge by a process of being accepted into social currency" (Levins \& Lewontin, 1985: 268). The manner in which the observer engages with the totality and attempts to formulate conceptual units is inherently social. The dominant mode of thought has its roots in the scientific revolution of the Enlightenment and stresses observation, reduction, and empiricism. Marx's process of abstraction is an attempt to combat surficial reductionism. Extension sets spatial and temporal boundaries around Marx's abstracts. This gives us multiple scales and time periods from which we can examine the underlying processes of an abstraction. When we abstract in time, we set boundaries around the historical context that was at work. When we abstract in space, we set boundaries on the process and other abstractions that can be studied. We can classify things and organize our thoughts into categories, but we must be able to move between different scales and times so that the processes and apparent forms can be observed fully. As we move between different abstractions of extension the appearance and qualities of a 'thing' can change. In a traditional positivist framework the qualities ascribed to a thing always remain intact so that it always remains the same. For Marx, however, as he moves through different levels of extension things can be radically different or they can appear to have the same identity, by which Marx means "a different expression of the same fact" (Ollman, 2003: 77). Thus, the notion of 'fact' will always be relational. The second mode of abstraction is the level of generality, or a movement from the specific to the general and vice versa. As you move to a more general level of abstraction you expand your focus and broaden the time span, which allow you to capture more aspects of nature (Ollman, 2003). 
Taking the level of generality into account, we can now see how Marx can move so adeptly through his dialectic, observing multiple social formations and always bringing the observations back to a discussion on internal relations. Each level of generality sets the conditions of possibility for what can occur at each successively specific level. The third mode of abstraction is vantage point. "A vantage point sets up a perspective that colors everything that falls into it, establishing order, hierarchy, and priorities, distributing values, meanings and degrees of relevance, and asserting a distinctive coherence between the part" (Ollman, 2003: 100). What is interesting about altering the various modes of abstraction is that an observer can uncover seemingly different contradictions in their analyses simply by constraining a moment by time, space, or perspective. This is one of the fundamental reasons that reality must be encountered over and over, so that these constraints are not taken for 'truth'. Additionally, within a certain vantage point some processes will be privileged over others, some will be obscured, and some will be invisible. This also changes between observers, since it is the grounding in classconsciousness that inform people's perception of reality. Thus, people can and most likely will reach different conclusions while viewing the same relations.

Next we come to concept of relations as a methodological tool. By this we mean how the abstracted categories and mental units function and interact together throughout the analysis. Marx identifies four types of relations: (i) identity/difference, (ii) interpenetration of opposites, (iii) quantity/quality, and (iv) contradiction. Each of these are highly reliant the philosophy of internal relations. First, identity/difference is an attempt to discover how abstracts can come to be viewed as the same and different. As we go through the process of abstraction, identity/difference is geared to helping us obtain a more complete understanding of the appearance of 'things'. Second, interpenetration of opposites "is based on the recognition that to 
a very large degree how anything appears and functions is due to its surrounding conditions. These conditioning factors apply to both objects and the persons perceiving them" (Ollman, 2003: 16). By examining the interpenetration of opposites, we attempt to understand any social formation, event, institution, etc. is situated within a specific set of conditions at any given time. Third, quantity/quality describes how two seemingly distinct movements occur within the same process. At first, the movement takes on a "quantitative change" that can be measured and then, later on, the movement undergoes a "qualitative transformation", which is accompanied by a "change in its appearance and/or function" (Ollman, 2003: 16-17). Fourth, contradiction is the most important relation and is "understood here as the incompatible development of different elements within the same relation, which is to say between elements that are also dependent on one another" (Ollman, 2003: 17). Contradiction is inherent in the flux of internal relations (see above) and produces tensions that are not easily resolved. To a certain extent, the goal of the dialectic is the resolution of contradiction and the unity of opposites. As Ollman (2003: 129) points out, "[T]o know anything is to know its relations". As we pierce through the veil of surface appearances and uncover the internal relations that give rise to superstructural elements, we come to understand the very essence of how reality has been shaped. 
Paper to be submitted to: Human Geography

Chapter 5: Citizen Science as a Mode of Knowledge Production: Examining the Role of Volunteer Participation in Scientific Research

\begin{abstract}
Citizen science is both a mode of knowledge production and a tool that can be used to increase scientific literacy among participants. A complex dialectic exists linking program developers and participants and the underlying social relations are responsible for generating nuanced outcomes for both groups. This research projects attempts to uncover these relations in order to better understand how citizen science is embedded within the modern scientific enterprise as well as how program managers and volunteers interact to influence each other. Marx's dialectic and content analysis were used to interpret the positions taken by program developers and participants. Each vantage point supplies a unique perspective on citizen science programs and offers a way to compare competing outcomes. Results show that there is some overlap between the goals of program developers and participants as well as competing priorities. Program managers, however, seem to be further removed from the scientific enterprise than previously thought and their priorities align with those of volunteers to a greater extent than was predicted.

Key Words: Social Relations, Dialectic, Citizen Science, SATELLITES, Scientific Thought
\end{abstract}

\title{
Introduction
}

A great deal of thought has been given to the way in which science has been transformed throughout modern history (Peet \& Hartwick, 2009). Yet, little attention has been given to the multifaceted ways in which social relations interact and become embedded within the scientific process regarding citizen science. As the scientific enterprise evolves it searches out new modes of inquiry and exposition in order to meet its structural requirements. A new form of scientific knowledge production is being employed at present known as citizen science where volunteers are recruited to aid scientists in the scientific process (Dickinson \& Bonney, 2012). Citizen science represents a complex dialectic that is both created by the scientific enterprise and informs the continued development of science in general. As scientists search for techniques to meet new academic requirements they turn to citizen science with the recognition that outcomes must benefit society as well as scholarship (Brossard, Lewenstein, \& Bonney, 2005). 
The objective of this project was to develop a dialectical analysis of citizen science in order to understand how modern scientific thought has evolved and to uncover the core similarities and contradictions that have promoted this form of knowledge production. Science has increasingly become influenced by capitalism as a means to generate technological innovation in the name of efficiency and to promote knowledge as a commodity (Peet, 2007). Broadly speaking, capitalism is a specific mode of production that brings together and aggregates labor and capital for the goal of producing commodities for exchange and profit (Marx, [1867] 1990). Capitalism is a complex social relation that has permeated socioeconomic, political, and cultural foundations of modern society. It is important to understand how this penetration has come to embed science as part of a capitalist society. The goals of this research project were to: (i) develop a dialectical framework for the investigation of citizen science; (ii) examine what role citizen science plays within the scientific enterprise and how it can be used as a tool to radically respond to the dominant mode of knowledge production; and (iii) compare how researchers and volunteers understand and engage with citizen science projects. When bent to a Marxist analysis, the discussion of science, in general, and citizen science, specifically, becomes highly complex and brings to the foreground all of the underlying relations that are hidden.

There are many different approaches that can be employed in order to better understand the role of citizen science programs within the scientific enterprise as well as their contributions to society. This investigation focused on one specific program: the Students and Teachers Exploring Local Landscapes to Interpret the Earth From Space (SATELLITES). The SATELLITES program was developed to get students involved in collecting scientific data to aid in student learning (satellitesk12.org). SATELLITES participants collect surface temperature recordings for Ohio, West Virginia, Pennsylvania, and Maryland. The impetus for project is to 
provide additional data sources for environmental scientists all while getting students interested in conducting scientific research (Hedley et al., 2008).

Citizen science is a research technique that employs volunteers to participate in scientific research (Bonney, Cooper, Dickinson et al., 2009; Dickinson \& Bonney 2012). Simply put, citizen scientists are volunteers that actively seek out research projects or are recruited by various intermediaries. The implementation of citizen science projects is particularly suited to large-scale projects that span multiple temporal and spatial scales. Citizen science has been offered as a model that is capable of being adapted to the evolution of modern scientific enquiry by allowing both scientists and volunteers to interact and engage with both the objects of investigation as well as the fundamental tenets of science in general (Bonney, Cooper, Dickinson et al., 2009; Henderson et al., 2012). Additionally, this model can produce excellent results and actually encourage scientists to design more complex studies as participants become more scientifically literate (Shirk et al., 2012).

The implementation of citizen science projects can be conceptualized in such a way that recognizes the political nature of science, transcends issues of experts versus non-experts, and yields knowledge that is recognized as both useful and partial in order to resolve the duality. As Bhaskar (1989: 68) wrote, "Marx viewed knowledge as being capable of generating real insights about the world, while being both fallible and partial, and always non-identical with the world". This epistemological stance is crucial, since it is the cornerstone upon which we develop our dialectical analysis of volunteer participation in scientific research. To resolve this duality, not only must citizen science be used as a lever to wrest conventional knowledge away from traditional practices, but it must also be seen as a mechanism to reengage society, which have been alienated from the process of knowledge production. Citizen science programs can become 
that lever for change when implemented with concern for the complex social relations governing the scientific enterprise (Trumbull, et al. 2000).

\section{Research Questions}

1. What role do citizen science programs play in the larger context of the scientific enterprise?

2. How do SATELLITES volunteers view participatory research?

3. How do volunteer views on citizen science projects compare with those of program developers?

\section{Background}

What we conceptualize as modern scientific thought actually results from the manner in which societies have interacted with nature throughout their historical development (Smith, 2008). The collected body of knowledge generated from these interactions has become concentrated at institutions that claim a monopoly on its production. These institutions are indebted to the capitalist mode of production and the knowledge being generated holds a tremendous amount of power and influence over social decision-making (Greenberg, 2001; Peet, 2007). This leads to a scientific enterprise that is tied directly to the political formation of a society, and both are beholden to the expanding influence of capitalism.

The historical development of scientific thought has culminated in the current model of bourgeois knowledge production. By examining this historical development we can see that the modern scientific enterprise has its roots in ancient Greek scholarship. The Greeks developed a highly philosophical approach to science, attempting to describe nature in terms of ideals systems (Barber, 1952). For the Greeks, philosophy and science were not separate disciplines, rather epistemology and logic were directly tied the production of knowledge (Hutten, 1962). Their mode of inquiry maintained its highly logical approach to inform their metaphysics and conceptualization of nature (Hutten, 1962; Vernant, 1988). As the Roman Empire emerges as the 
center of culture, science, and governance, the Romans internalized Greek scholarship and extend the scope of rational thought (Barber, 1952). The fall of the Roman Empire ushered in the Dark (Early Middle) Ages, so called for its apparent reactionary movement away from logic and common sense toward a theologically determined world view. Scholars, scientists, and priests alike were trying to understand the world in terms of divinity, seeking worldly analogs for a Divine plan (Price, 1965). Churches and monasteries became the most important centers of learning with an overall retraction of learning within the broader society (Whitehead, 1925). Yet, to suggest that this period was completely regressive and devoid of scientific thought is to greatly diminish the contributions of individuals such as St. Thomas Aquinas, the entire body of knowledge produced by Arab scholars (Barber, 1952; Huff, 2003), or the preservation of ancient texts within monastic libraries. While scientific thought during the Early Middle Ages was concerned more with understanding societies and hierarchy according to the will of God, which offered a distorted view of scientific knowledge and suggest a lack of progress (Barber, 1952). The influence of religious ideals during this time period had the unintended consequence of further aligning the notion that God's divine plan can be rationally understood with modern conceptions of science (Whitehead, 1925).

Emerging from the isolation of the Early Middle Ages is the philosophy of humanism. Humanism was an attempt to use logic and rational thought to bring humanity closer to God while not necessarily ascribing nature to some divine plan (Hubner, 1983). The rise of humanism brought with it a movement toward secularism and challenged the notion that the Church was the formal locus of knowledge and power (Hutten, 1962). The introduction of the printing press led to an unprecedented expansion in literacy and national societies, guilds, and universities were organized as centers of learning and repositories of knowledge (Barber, 1952). The erosion of 
Church authority and increased access to knowledge ushered in the Enlightenment era in Europe around the turn of the $18^{\text {th }}$ century (Price, 1965). As history unfolds we can begin to see how the key elements for the production of knowledge in the past have come to be embedded in more recent scholarship. As The Enlightenment dawned in Europe mathematics and the physical sciences came to dominate modern thought while, at the same time, there was a distinct push for the development of critical philosophy, political economy, and early sociology. These disciplines were founded on the same principles as their hard science counterparts: individualism and logic (Peet \& Hartwick, 2009). Descartes' induction was adopted as a means of examination (Levins \& Lewontin, 1985), Hume and Kant pressed for a highly empiricist tradition based on repeatable measurements (Hubner, 1983), and Comte introduced logical positivism and pushed for the use a scientific method within the social sciences (Peet \& Hartwick, 2009). The guiding influence of these scholars reinforced the notion of individualism as the focus of critical philosophy and science and moved scholarship toward a worldview that sees humans and nature as separable. Thus, the behavior of individuals within society was seen as highly rational and could be studied with the rigorous application of scientific principles. The causes of social change were attributed not to the underlying shifts in the relations that gave rise to societies in the first place, but instead to the ideas and behaviors of individuals (Morrison, 1995; Peet \& Hartwick, 2009).

This line of thought migrated into the political economics of the day and, with the publication of The Wealth of Nations in 1776, Smith provided a treatise that would fundamentally change social, political, and economic relations forever. For Smith, the individual was viewed as an autonomous actor operating within a larger society, acting in his or her own self-interest (Smith, [1776] 1910). The unity of society rested on the common goal of overall economic prosperity (Morrison, 1995; Peet \& Hartwick, 2009). As a result, the general function 
of the political structures of society was reduced to protecting the individual rights of people to pursue economic gain. Rational and moral economic philosophies penetrate the very core of contemporary history and are bound to the socioeconomic and political elements of society (Peet, 2007). As a result, the accumulated body of knowledge during this period was intimately linked with the development of society, the customs and norms that are embraced, and the dominant mode of production that dictates how and why commodities should be produced (Marx, [1867] 1990). Science, in essence, was pressed into the service of capitalism. At the turn of the $19^{\text {th }}$ century, the Industrial Revolution began the complete transition into the capitalist mode of production. As capitalism went in search of new innovations and technology to increase surplus value extraction there was a fundamental shift in how the scientific enterprise was utilized. Instead of producing knowledge in order to satisfy human being's innate curiosity, science was employed to solve technical and social problems arising from the functioning of capitalism. Capitalism seized control of the social relations and shaped them in order to maintain its own reproduction. As a social activity, science was co-opted to reinforce these social relations as natural and universal and to solve crises that developed from the functioning of capitalism. As a result, the scientific enterprise that has developed since the mid-1800s owes its existence to capitalism and the knowledge produced by extension can have no claims on objective neutrality (Peet, 2007).

As a result of this dynamism, contemporary thought has continued to change with transitions in social and economic relations (Morrison, 1995). Comte (1908) called for a more sense-based, empirical philosophy whereby people could come to know the world through observation. Positivism was based on the acceptance of a generalized method of investigation and posited that human development can only be assessed based on collected facts (Morrison, 
1995). Because positivism and capitalism developed at the same time there is a profound merging of ideology that remains to this day (Morrison, 1995). The development and reproduction of capitalism has come to be viewed as natural and universal, which means that any positivist attempt to study capitalism will reinforce its 'naturalness' and reify the universality of the dominant mode of production. The apparently 'independent' edification of capitalism by science is a relic of capitalism's co-option of the general functioning of society (Peet, 2007; Peet \& Hartwick, 2009).

Marx, however, set out to understand what processes may be responsible for such dynamism is social and political transitions and how the impacts have affected the various classes of society (Morrison, 1995). Human consciousness played an important role in how knowledge came to be produced in either the positivist tradition or the Marxist tradition. For Marx, everyday experiences and concrete reality formed the basis for investigation (Morrison, 1995). Marx's theory of historical materialism was one of social existence that stressed the importance of improvements to human well-being. First and foremost, Marx recognized the need for people to meet their basic needs of existence and reproduction through the consumption of necessities. The materialist theory of history then assumes three things: (1) humans must meet basic needs, (2) humans are different from other animals because they can develop a mode of production to meet these needs, and (3) the manner of production is based on what can be found in nature (Morrison, 1995). When there are social disadvantages in the procurement of these necessities inequalities arise and, as a result, inequality gives way to a struggle between the disadvantaged and the privileged (Morrison, 1995; Peet \& Hartwick, 2009). Thus, the real world actions and the material conditions of people inform their own consciousness. Ideas and theories of reality are the source of social dynamism and they have a material basis. Marx radically 
inverts the positivist view of consciousness and directly challenges the traditional way in which knowledge is produced (Marx, [1867] 1990; Peet, 2007).

Durkheim and Weber rejected Marx's claims that the world could come to be known through the analysis of material life and reinforced an empirical, positivist science. For Durkheim ([1895] 1982), theory must be grounded in science, by which we mean direct empirical research. Durkheim's research program called for the discovery of laws that govern progress, social development, and economic transformations and was directly influenced by Comte's positivism. He thought that through observation, description, and classification scientists could come to understand nature (Morrison, 1995). Durkheim suggested that sociological phenomena were external to individual consciousness and society was theoretically prior to the individual throughout history (Peet \& Hartwick, 2009). Durkheim borrowed the concept of 'division of labor' from classical political economy to argue that modern society has developed a complex and highly organized structure of duties. This collective system of values included a legal structure designed to maintain the proper working of society, which as Peet and Hartwick (2009) pointed out means the maintenance of a capitalist mode of production. Scientists represent one specialized segment of labor that is tasked with the production of knowledge (Peet \& Hartwick, 2009). As a result scientists are producing knowledge in order to maintain the status quo.

Max Weber sought to establish capitalism as the primary subject of social theory and made explicit the role religion should play in society. In order to demonstrate how society could be studied outside of economic relations he developed the concept of interconnected social spheres. These included: politics, law, economics, and religion; no one sphere could dominate the functions of society (Morrison, 1995). Central to his conceptualization of social phenomena 
was the idea of rationalization. Here Weber used this term to describe how nature, society, and individual action, throughout the process of historical development, became increasingly ordered by social organization, modernization, and accumulated knowledge (Weber, 1978). Weber applied his brand of rationalization to the analysis of capitalism as well. He viewed capitalism as a highly rational system that was effective as regulating economic transactions (Weber, [190405] 1958). Weber outlined a thesis in which the development of capitalism was tied with the moral, ethical, and industrious spirit of the Puritans. This led Weber to assume that there was a distinctly religious ethos that was at the root of capitalism, since Protestants were celebrated for their work ethic. The Protestant ethic led to a particular set of political, economic, and social relations, which were to guide the actions of human beings (Peet \& Hartwick, 2009). Thus, the Protestant way of life favored the development of a rational, bourgeois economic system.

The critical theoretical work of Marx, Durkheim, and Weber carried over into the academy during the turn of the $20^{\text {th }}$ century. Political ideology, faith in science, and capitalist social relations drove a majority of the critical theory being written about society in general and science in particular. The research of this period has not only come to represent a historiography of science, but has been incorporated into the broader framework of critical social theory as well (Morrison, 1995). Science was a specific form of citizenship, which placed the role of the scientist in the realm of social relations (Hamlin, 2007). By taking this view of science - a stance that implies a concrete history and dynamism - we can begin to tease out the very real material and social relations that have come to be embodied in the current ethos of science (Barber, 1952). We see scholars such as Marx, Durkheim, and Polanyi delivered abstruse, yet eloquent discussions of the social relations of science. What developed out of this was a 'sociology of science', which had a profound impact on the way we think about the social role of science, 
interpret the products of science, and view underlying foundations of science (Hamlin, 2007). This brought modern philosophers of science face to face with a contradiction that is still present today. How can we analyze science as a social pursuit and understand how social relations give rise to what is taken as knowledge and fact, while, at the same time, recognizing that science informs the society in which it develops? Scientific advancement simultaneously creates and is informed by modern scientific thought, and both are captured by the dominant productive forces of the capitalism (Peet, 1979).

The post-WWII period solidified this notion of captured science as it is aligned with Western ideals and pressed into service-in a very literal sense-in defense against Communism. Science and technology became the weapons and scientists became the soldiers on the front line during the Cold War (Conant, 1954). Science was seen as the purest form of reason and logic and thus stood as the antithesis of the perceived irrationality and ideology of the East (Hamlin, 2007). Science ceased to be the search for knowledge through observation and empirical research and became the duty of Western scholars as a form of dissent. Modern knowledge production became highly individualized and the new narrative suggested that those with the knowledge to help the poor or liberate the oppressed should be seen as exemplars of a free capitalist society (Polanyi, 1940). Scientists had to be free to pursue pure science and, in turn, this freedom can be brought to bear against problems that needed to be addressed. The scientific Right would not be the only group to take up this mantle of science as service. Leftist movements (i.e. Marxists, scientific humanists) also pushed for the application of reason and positivism to address major issues. Science was a progressive force that could be used for radical social change (Barber, 1952; Werskey, 2007). Yet, whatever a scientist's politics were, they internalized this sense of producing a social good; science could be used to solve problems. 
Through the meticulous nature of science scientists saw that their work was a fulfillment of their civic duty and the knowledge they produced belonged to the public (Hamlin, 2007).

As the $20^{\text {th }}$ century progressed, scientists ended their isolation as they began to participate in politics. Science and the scientist could not be fully removed from their social context (Latour, 1987). The norms and values come into play when we discuss the position science occupied in the broader context of society. Science, while perceived to be a value-neutral profession must be fully understood as a social activity and a cultural product. A great deal of thought has been given to the notion that science is a progressive force in society that can lead to the overall improvement in the quality of life. Yet, very little attention is paid to the internal contradictions that arise out of tensions that develop between science and society. The development of modern scientific thought is complex and cannot be separated from its social context. Citizen science captures this creative tension as it fights for recognition as a scientific tool with its more frontfacing goal of civic engagement and scientific learning.

Citizen science represents another stage of development in knowledge production. It is a research technique used by scientists to incorporate the public in the scientific process (Bonney, Cooper, Dickinson et al., 2009). The modern conceptualization of citizen science arose out of contradictions that resulted from a complex set of relations within science itself. Citizen scientists are volunteers that participate in research projects. The concept underlying citizen science is not new; what is new, however, is the scope of what volunteers are asked to do and the impetus for scientists to recruit volunteers (Miller-Rushing, Primack, \& Bonney, 2012). Historically, citizen science was used as a means to collect data, but over the last 20 years its role has shifted to include the use of structured guidelines, data screening, and the incorporation of learning objectives for citizen participants (Bonney, Cooper, Dickinson et al., 2009). 
Additionally, the ability of citizen science projects to collect and synthesize data that are necessary to analyze broad-scale issues such as global climate change will be crucial in the coming decades. Yet, the research objectives of these projects are not value neutral. Securing grant funding for scientists has become a professional necessity and with more researchers competing for fewer research dollars, citizen science has become a way to achieve programmatic goals while reducing costs. This is not to say, however, that all research objectives are inherently self-serving. Embedded within citizen science projects is the notion that science is a social activity and the outcomes of science belong to the public (Shirk et al., 2012). Contradictions arise when scientists try to fulfill their professional duties while implementing a more democratic form of science.

As scientists expand the scope of citizen science projects to address complex issues it becomes clear that broad-scale phenomena, such as climate change, are the result of many factors (Parmesan \& Yohe, 2003). The interactions between these factors, however, have been treated by the modern scientific enterprise as discreet and quantifiable. Modern science relies heavily on data that are used to inform complex models or support research hypotheses. Citizen scientists are being employed to provide more evidence for scientific questions while, at the same time, providing feedback on to the projects themselves. As contradictions come to the foreground each group must find a way to balance objectives so that volunteers are not exploited and researchers can produce high quality data. Marx's dialectic can be used to better understand how these contradictions can be resolved and how citizen science programs can adjust to competing objectives. The dialectic is excellent at focusing investigations on the changes taking place and offering complex, yet logical lines of evidence for the environmental, socioeconomic, and political dimensions for this change (Ollman, 2003). The examination of citizen science 
projects offers us insight into the evolution of scientific thought and offers a means to understand the relations that influence its development. While there is an acknowledgement that citizen science projects must be carefully planned, there is also a push to expand the complexity of these projects as well (Jordan et al., 2011). This model raises some contentious points and highlights the gap that still remains between the traditional conceptualization of science and the push for a more democratic science. Citizen science programs must be distilled through the filter of expertise, which represents a major obstacle to further development. The notion of expertise have become entrenched in the scientific enterprise over many decades and has been internalized to such an extent that it is difficult to see volunteers as capable of producing the same work as experts (Peet \& Hartwick, 2009). The development of citizen science projects, however, can be done in such a way that recognizes the political nature of science, transcends issues of experts versus non-experts, and yields knowledge that is recognized as both useful and partial in order to resolve our duality. Marx's dialectic is capable of generating this level of insight while making no claims of infallibility (Bhaskar, 1989). To resolve the contradictions inherent in modern citizen science programs it is necessary to refocus the understanding of what these projects can accomplish in order to engage the public in meaningful ways while producing knowledge from which they are no longer alienated.

\section{Methods}

This research project draws heavily from Marx's dialectic (see Chapter 4), which is a non-deterministic, non-teleological mode of thought and exposition that seeks to uncover the underlying relations that give rise to what people can observe (Ollman, 1993; 2003). The dialectic is rooted in the theory of historical materialism, which influenced Marx's assumptions about human consciousness. There is a link between the material basis of a society (i.e. the 
means of reproduction) and the social relations that influence transformations (Morrison, 1995; Ollman, 2003). Historical materialism suggests that every period of history has its own mode of production that directly shapes socioeconomic and political structures (Marx, [1867] 1990). Marx's dialectic helps us understand these complex transformations and the visible structures by delving deep into the social relations that account for the continued change.

Social relations link people and phenomena together in a complex relationship, but the transformations wrought through changes in these relations cannot be attributed to causative or deterministic powers. Rather, change occurs through the mediation, synthesis, resolution, and negation of various elements as a product of their continued interactions (Ollman, 1993; 2003). For this paper the social relations refer to the varying positions program developers and SATELLITES participants occupy within overarching structure of citizen science programs. The research was designed to temporarily stabilize the focus of investigation so that the unique vantage points each group has and how they reflect the development, implementation, and outcomes of citizen science projects. By examining these projects from different vantage points we obtain a better understanding of how each group's perspective is shaped by their situation and how their relations generate change within the broader context of citizen science programs. Scientists, in this case program developers, tend to privileged a positivist, empirical research agenda while ignoring socioeconomic and political phenomena that could change the underlying social relations (Levins \& Lewontin, 1985). Citizen science programs have grown out of the continued evolution of the modern scientific enterprise and there are complex relationships that produced the current form of citizen science (Jordan et al., 2011). By examining the vantage points of both program developers and participants we can gain a better understanding of how social relations can come to shape citizen science programs and generate change. Additionally, 
these interactions take place at multiple scales and varying durations of time, so a temporary boundary was set in order to make observations. Adopting Marx's dialectic as an epistemological device allows us to realize the dynamism of the scientific enterprise, the social relations that shape science, and the evolution of citizen science projects as a structurally embedded mode of knowledge production.

This analysis relied on two sources of information for examination. The first source was the Special Edition (Volume 10, Issue 6) of Frontiers in Ecology and the Environment (Frontiers), published in 2012. This issue is a collection of in-depth analyses on multiple aspects of citizen science from some of the leading scholars in the field. The issue was chosen because it provides a unique perspective of citizen science from the academic vantage point. The second source of information came from open-ended questions asked as part of an online survey distributed to educators partnered with the SATELLITES program. The open-ended questions provide the perspectives of people actual participating in citizen science programs. This analysis limited the extension of analysis to last $\sim 20$ years of development of citizen science programs and included only one specific program for analysis. Thus, two different vantage points were used to examine the role of the SATELLITES program in society as well as its situation modern scientific thought (Ollman, 2003). For an in-depth discussion of the SATELLITES program see Wixom (in prep b). A total of ten scholarly articles were analyzed from the Frontiers special edition. Each paper was treated as the sampling unit for investigation and was taken to represent the author or authors' position on the role of citizen science in academia and society (Silverman, 2005). Responses to open-ended questions were given by SATELLITES participants and collected online for a period of one year. A total of four questions were asked and 20 participants 
responded to all or a portion of the questions. Each question was treated as the sampling unit for investigation and was taken to represent the position of the participant.

Content analysis was used to uncover the underlying positions of the authors and participants to gain a better understanding of their thoughts on citizen science programs. Content analysis has been used since the early 1950s as a way to methodically analyze text data and ensure reproducibility (Berelson, 1952; Kerlinger 1986). Content analysis offers a way to reduce the inherent biases present in texts, which are often produced through ideological lenses (Bernard \& Ryan, 1998). Furthermore, the analysis of textual or written material offers a way to produce easily testable data (Krippendorff, 1989) and allows the researcher to draw inferences by identifying specific elements of messages through a highly organized approach (Holsti, 1969; Weber, 1985). This approach uncovers the influences that drive the authors and allows the researcher to understand the complex relations that give rise to positions and opinions on a given topic and allows for direct comparison of a given message across texts addressing the same or similar issues (Babbie, 1992; Krippendorff, 1989). Because language is inherently social, content analysis can help the researcher examine the complex relationships that exist between the producers of the text and their background (Fairclough, 2003). For scientists, these relationships are expressed in their writing, teaching, and presentations; for SATELLITES participants, these relationships are expressed in the way they engage with the program and teach their students. Each academic article and open-ended question was read in full to gain a high-level understanding of the author(s) purpose (Krippendorff, 1989). Notes were taken for each set of data and preliminary themes were recorded (Hsieh \& Shannon, 2005). Each set of data was set aside for one week and then reread and reanalyzed. The reanalysis was done twice and the results from the three rounds of examination were compared. This process was adopted, because there 
was no independent review of the reference materials (Krippendorff, 1989). After multiple close readings of the scholarly articles from the special edition of Frontiers, five major themes emerged that capture the current understanding of citizen science. These themes include: (i) scientific impacts, (ii) data quality and training, (iii) education, (iv) community-based program development, and (v) a focus on local outcomes as a democratizing force. These themes make it clear that the authors are well aware of the benefits and drawbacks of citizen science programs and recognize the need for continued programmatic evolution. There were three major themes for the open-ended questions: (i) scientific learning, (ii) student-centered outcomes, and (iii) role of citizen science in society.

\section{Results}

\section{Frontiers}

Scientific Impacts

Citizen science was developed as a methodological approach to better serve science in answering complex questions (Bonney, Cooper, Dickinson et al., 2009). As Bonter and Cooper (2012: 305) suggest, "[C]onducting research with assistance from the public, however, can be far more complex than a traditional scientist-led approach." All aspects of a citizen science project must be planned carefully to ensure that the objectives are met. Yet, the benefits of citizen science programs continue to push the development of this tool. Combining data and a broad network of volunteers have led to studies being conducted at broad geographic scales (Dickinson et al., 2012). Working across multiple scales, citizen science projects allow scientists to observe changes that have taken place in specific areas as well as develop baseline indicators to aid management programs. There was a change in the culture of science as it became highly professionalized, which limited the impact amateurs could have on scientific pursuits. We are 
now seeing a reversal back to a point-in-time when it was the norm to have amateurs participate in scientific endeavors (Miller-Rushing, Primack, \& Bonney, 2012). Following from that:

What distinguishes citizen science as an informal learning experience is its engagement in several aspects of authentic science (eg modeling, gathering evidence, testing ideas). Citizen science can foster ways of thinking in volunteers that are consistent with those of scientists, are crucial for decision making in modern society (Jordan, Ballard, \& Phillips, 2012, 307).

Through the use of citizen science programs and the continued evaluation of outcomes and learning objectives, program managers can ensure that their projects continue to evolve and meet their goals (Jordan, Ballard, \& Phillips, 2012). Scientists have turned to citizen science projects not only for their ability to produce data across large geographic areas, but also for their ability to respond to rising costs and shrinking programmatic budgets (Galloway, Tudor, \& Vander Haegen, 2006). Resources available to research agencies and scientists are often limited at the state and regional levels and preclude the kind of in-depth investigation needed to effectively address issues. In their study of plant monitoring activities, Havens et al. (2012) highlight the necessity of citizen scientists in the monitoring of at-risk plant species. Monitoring programs allow agencies access to real-time data that can be used to inform management decisions and policy prescriptions. "Volunteer monitoring reports also guide habitat management efforts by gauging the effectiveness of management (eg prescribed fire, invasive removal) in promoting the stability or growth of rare plant populations." (Havens, Vitt, \& Masi, 2012: 333). Thus, volunteers become fully engaged in the conservation process. In some instances, however, participation is transient and needs to rely on a continued sense of belonging and enthusiasm to meet project goals. Program managers must find a way to make reporting easy for participants as well as maintaining a level of commitment even when volunteers are not actively engaged (Marshall et al., 2012). As Newman et al. (2012: 298) put it: "the future of citizen science will 
likely be inextricably linked to emerging technologies." The broader program managers can make their reach the easier it will be for volunteers to participate and respond to program goals. Ultimately, the success of any citizen science program will depend on the quality of data they produce and how those data inform policy decisions (Schwartz, Betancourt, \& Weltzin, 2012).

\section{Data Quality \& Training}

Of particular importance for program organizers is the quality of data produced by volunteers. As Marshall et al. (2012: 332) suggest: "[D]ata validity is a potential problem for many citizen-science programs" and "our research indicates that volunteers are able to collect reliable data provided that the task is straightforward." While this point acknowledges a potential drawback to these projects, it stands in contradiction with the goals of many researchers who want to expand the scope of their projects and increase the responsibilities of their participants. As ecological studies are becoming more complex, however, increases in data collection, and the formulation of broader questions, the need for data pushes the boundaries of program objectives (Dickinson et al., 2012). Some citizen science projects have addressed the issue by adopting a more local approach where they conduct targeted recruiting campaigns for highly motivated people. The benefit of this approach is that the volunteers can receive in-depth training and will be motivated to maintain their participation given their interest. Regardless of the approach, "[T]raining by staff, and ongoing communication and interaction between staff and volunteers, helps to ensure data reliability" (Havens, Vitt, \& Masi, 2012: 332). Additionally, "it may be worth the time investment to engage long-term volunteers in more extensive training, given that such volunteers may have greater decision-making power" (Jordan, Ballard, \& Phillips, 2012: 307). Furthermore:

Principles for collaboration among network participants include mutually beneficial activities, shared vision about science and education, realistic demands 
on the capacities of partners, feedback to improve collaboration, and transparent data and information sharing policies (Schwartz, Betancourt, \& Weltzin, 2012: 327).

Citizen science programs need to evolve and adapt to changes to remain viable. By becoming more transparent and elaborating on the responsibilities being asked of participants program developers can create more inviting projects that reduce the level of intimidation to participants while improving the level of trust between managers and volunteers. If a volunteer feels comfortable and not overwhelmed by program objectives they are more likely to continue to engage in future data collection missions or other projects (Marshall, Kleine, \& Dean, 2012).

Ultimately, citizen science projects want to retain their volunteers and ensure the final data products are of high quality. Increasingly, citizen science programs have turned to new technologies to validate data and track participant performance. "Emerging technologies will broaden participation in citizen science in ways that were not previously possible and, if used appropriately, will allow data collection by communities who traditionally remained uninvolved in scientific projects" (Newman et al., 2012: 301). These technologies can track the performance of individuals and identify those who made need additional training. Finally, improvements in technology can offer almost real-time validation on data submitted by participants. As Bonter and Cooper (2012: 305) suggest: "improving data quality is critical for the success of such projects." The participants need to know that data validation is a core tenet of the scientific process and by having their data validated they can become accustom to the practice. Some programs have turned to automated data filters for their online submissions platforms.

\section{Education}

Scientific learning is a key tenet of citizen science projects. Citizen science is not just a research tool, but can also be viewed "as a method of engaging the public in the scientific 
process with the goal of improving scientific literacy" (Miller-Rushing, Primack, \& Bonney, 2012: 285). The benefits of promoting education during citizen science projects are epistemologically consistent with the principles of scientific though (Oberhauser \& LeBuhn, 2012). Citizen science projects rely on collaborative learning and collective intelligence, which can often lead to innovations and expanded knowledge production because a heterogeneous group of people brings with them multiple perspectives and specialized sets of training that amplify critical thinking (Dickinson et al., 2012). Thus, the more connections established between participants means that more learning can take place. "Regardless of the type of program, citizen-science practitioners should carefully consider and plan for quality evaluation of learning outcomes. After establishing learning goals, which tend to be broad and abstract, practitioners should focus on developing an evaluation plan" (Jordan, Ballard, \& Phillips, 2012: 307). Program developers must balance the needs of the researcher with those of the participants (Oberhauser \& LeBuhn, 2012). “[A] comparison of learning gains for individuals through citizen-science participation is critically important for understanding whether the program is meeting its educational and volunteer engagement goals" (Jordan, Ballard, and Phillips, 2012: 307). Citizen science projects need to take learning outcomes into account, even as researchers and participants alike are engaging with program objectives. These projects must be able to respond to changes in participant demographics, educational attainment, and personal interest. This offers a two-fold benefit for programs. On the one hand, researchers will be able to recruit and retain participants if program goals align with personal or local goals, and, on the other hand, participants will gain a sense of belonging and accomplishment when their needs are met (Zoellick, Nelson, \& Schauffler, 2012).

\section{Community-Based Program Development}


There has been a push within the sub-discipline of citizen science to move toward a community-based approach to building citizen science programs. Using a community-based approach allows program objectives to be formalized via both top-down institutional development and bottom-up grassroots effort on the part of communities in need of specialized services (Newman et al., 2012). The multi-scale and multidimensional aspects of current citizen science programs are focusing on community needs to better address local issues. Program managers and scholars are focusing on diversity and expanding the scope of what is considered for scientific analysis. Not only does diversity increase public understanding, but it can also contribute to the improved social well-being of at-risk communities (Dickinson et al., 2012). Collaboration from within at-risk communities can increase participation and lead to a sense that something can be done about persistent issues. "Participation in collaborative and communitybased monitoring has resulted in community-level outcomes, such as increased social capital" (Jordan, Ballard, \& Phillips, 2012: 308). Social capital is a collection of human interactions within a given space and societal norms of behavior governing these interactions (Adger, 2003). The complex relations that gave rise to observable elements within a community can be better understood as citizen science programs adopt a more local focus.

\section{Local Outcomes as a Democratizing Force}

When questions arise from local or even regional needs communities can be mobilized and citizen science can be used as a democratizing force (Dickinson et al., 2012). Unfortunately, the makeup of citizen science programs does not yet reflect the diversity found in the U.S. The groups that have historically been marginalized in the U.S. - African Americans, Women, Latinos, Hispanics, and Native Americans - do not participate at the same rate as White, middleclass Americans (Trumbull et al., 2000; Pandya, 2012). Thus, “[M]embers of certain ethnic, 
racial, and socioeconomic groups are therefore less likely to reap the benefits of citizen-science program" (Pandya, 2012: 314). This is of particular concern if program developers want to promote science learning and focus on local objectives. They must begin to engage with at-risk communities in order to be more inclusive. One way to achieve this goal to reframe the way citizen science projects are developed. Managers and participants must collaborate and come to a consensus about what matters to a community, what data are necessary, and how to implement the project (Pandya, 2012). There are, however, many factors that make participation by underrepresented groups a challenge. First, "[T]he challenge of balancing participation in citizen science against other responsibilities may be greater for low-income families" (Pandya, 2012: 314), which makes it virtually impossible for families in these communities to have the free time to volunteer in a citizen science project. Second, and equally troubling, is that many people in diverse communities cannot relate to these projects, because they are often led by demographically homogenous groups, which can make potential participants feel like outsiders. The demographics of science-based careers are not diverse, which serves as a signal to minority groups that citizen science program, and science, in general, are closed to them (Pandya, 2012). Finally, "to the extent that citizen science is the result of federal investment, lack of participation by specific racial, ethnic, or socioeconomic groups is not consistent with a democratic approach to science" (Pandya, 2012: 314). An inherent goal of science is to be a great socioeconomic leveler, but when investment excludes underrepresented, at-risk groups then structural barriers are set in place that preclude direct engagement in science. This, in turn leads to a less-informed electorate that simple cannot understand social, economic, or environmental issues that at-risk communities face.

\section{SATELLITES}




\section{Scientific Learning}

The first major theme to arise from an analysis of the open-ended questions focused on scientific learning. The participants were particularly concerned with the improvement of their student's learning and how the SATELLITES program helped. Respondent 1 suggested that by participating in the program students gained more in-depth knowledge of the topic they were studying. Respondent 34 said that the information made more sense to the students when they collected it themselves instead of only sitting through lessons and completing homework assignments. For respondent 13, SATELLITES made the science more real and students came to feel that they were part of the scientific process. This sense of being part of the process is effective at getting participants to continue working with programs and fueling their desire to learn. Respondent 13 went on to say that "it seems a bit more realistic to take part in real world data collection with students. More do-able." Effective participation on the part of educators and their students typically promotes continued engagement in future missions. Respondent 27 stated that "I am better able to understand it and therefore help students see the importance of student/citizen participation." Teaching efficacy is also improved through participation as practical skills reinforce classroom learning. The salience of student participation does, however, have its limits. For respondents 6 and 9, just participating in the SATELLITES program was not enough. Respondent 6 suggested students and educators needed more time to collect, interpret, and upload data. More time would ensure that students could learn about the different aspects of the tasks they were performing. Respondent 9 needed more support and help with their students. Working with larger classes can be difficult for one person, and overall learning can suffer. Finally, for respondent 8, participating to achieve learning objectives was just the beginning. Students need to know how to collect and use data throughout their lives. Wixom (in prep b) 
suggests that citizen science programs have the capacity to expand scientific literacy, which contributes to the overall understanding of the general populace. This, in turn, promotes engagement from the public in the democratic process. Respondent 1 added that student must be educated to care about complex issues facing society today. If they do not care or cannot communicate their position to others they will be less likely to have a positive impact on their communities (Brossard, Lewenstein, \& Bonney, 2005).

\section{Student-Centered Outcomes}

The second theme related to the outcomes participants felt were important for their students to learn from the SATELLITES program. One outcome focused on the role of students within the program in general. Respondent 14 stated that students could see the impact they had on science and how they fit into the scientific process. Situating their participation within a discussion of why they are doing it, what they can expect from their participation and its relevance to their daily lives can make students aware that scientific learning has a greater importance than just as a means of meeting basic requirements (Thomas \& Durant, 1987). Respondent 5 believed that project-based learning was crucial for student learning, but stressed that it took more time to accomplish. Unfortunately, this may prove to be a major hurdle for educators to overcome as they are pressed to prepare their students to meet rigorous state- and nationally-mandated standards. Those scholars seeking to develop citizen science programs need to be cognizant of this fact when engaging K-12 students. Despite being concerned with meeting educational requirements, many educators felt that the SATELLITES program improved their students' overall learning. Respondent 25 thought that the program's objectives made it clear to the students that the data they collected could be used to improve people's understanding of the world. 
Interestingly, four separate respondents recognized the benefits of their students' involvement in the program while acknowledging the limits to learning. Respondent 5 suggested that active participation by their students improved scientific learning, but was not truly necessary for a complete education. Respondents 8 and 9 thought that the data collected by their students benefited scientific problem solving because more data leads to a refinement of models and aids in testing hypotheses (Bonney, Cooper, \& Dickinson, 2009). Respondent 7, however, cautioned that there can be an issue with authenticating the data collected by volunteers, which is an issue with which all citizen science projects must contend. Additionally, two respondents recognized the future benefits to their students of program participation. Respondent 4 stated: "[M]y hope is that they will become environmentally responsible adults." This statement recognizes the need for students to be equipped with the necessary knowledge to respond to complex issues in the future. Project-based learning can improve students' scientific understanding by "teaching [them] to analyze information and misinformation. It prepares students to be skeptical and to look for more information beyond sound bites." This is particularly important because the predominant narratives delivered by media sources send mixed messages and promote debate over issues that are predicated on sound science (Wixom, in prep a). As these students become adults, they will need to interpret information in order to make informed decisions.

\section{Role of Citizen Science in Society}

The final theme to emerge from the open-ended questions focuses on how the respondents view the broader role of citizen science. Respondent 10 suggests that:

"[P]roject-based learning is a more engaging way for children to learn about their world. However, without the guarantee of similar investigations throughout the country, there is no way to determine whether the population in general will 
become more engaged and understanding of the scientific principles at work in our world."

Here we see an alignment of program and participant objectives. One of the fundamental elements of citizen science programs is their ability to capture broad-scale data. Program developers recognize this and attempt to exploit that benefit (Bonney, Brossard, \& Jordan, 2009). Respondent 10 is approaching the issue from a different vantage point. As more connections are established, participants come to fully appreciate that their work is contributing to a larger project that serves to validate program participation. Respondent 4 expands on this notion by adding that, as new data points are added, students begin to see the big picture; citizen science programs can link the local with the regional, national, and global. Additionally, respondent 4 states that "scientists can't be everywhere, but citizens are." This is significant realization by a program participant; as research questions become more complex, researchers need to expand their area of analysis and citizen science programs offer a way to achieve those goals (Dickinson et al., 2012). Respondent 28 goes on to add that governments do not have the resources to collect the vast amount of data necessary to monitor the environment properly. "More information and observations are critical to making better decisions and these science projects help fill that void." And, respondent 10 suggests that "we need a more enlightened society, in general, in order to be able to have a reasoned debate about topics like climate change." Finally, there is recognition by participants that citizen science programs take on a local focus. As respondent 14 points out: "providing different varieties of opportunities within their local community would benefit the student, giving them a chance to give back to their local community and seeing firsthand how they positively impacted their community" would improve these programs. After participating in the SATELLITES program, respondent 16 now "encourages everyone to get involved; they need 
us." Program participants recognize the impact SATELLITES has on their students' learning and its ability to produce an informed citizenry that seeks to address local issues.

\section{Discussion \& Conclusions}

Citizen science programs represent a new stage of development in the historical arc of the scientific enterprise as well as a unique tool that could serve to decentralize the current model of knowledge production. Citizen science is highly responsive to the needs of program developers and offers a means for volunteers to focus on local issues. Results of this study highlight the similarities and differences that were uncovered during analysis. Both sets of sample data have overlapping themes that illustrate the priorities of both program developers and program participants. Education is a fundamental principle of citizen science projects and the mission of the SATELLITES participants (Hedley et al., 2008; Bonney, Ballard, \& Jordan, 2009). Scientific learning was stressed by both groups as a necessary outcome for any project. SATELLITES instructors, however, had some concerns about using project-based learning to teach their students, but their overall attitudes toward the program were positive. Many participants (70\%) suggested that citizen science was capable of improving the overall learning of their students (Wixom, in prep b). Yet, a few participants stated that students needed more time to engage with the program in order to achieve this goal. Respondent 5 expressed concern that students needed more time in the field collecting data as well as classroom education in order to have a positive impact. Some participants felt that educational requirements made it more difficult to incorporate the SATELLITES program into their curriculum. The latter is a larger issue facing schools across the U.S. and needs to be explored in greater detail.

Next, both samples acknowledged the benefits to the scientific process itself. Educators participating with SATELLITES felt that the students could indeed contribute to science by 
collecting more data and adding them to existing datasets. Respondents 8 and 9 went further to say that the data could directly contribute the climate models and improve their overall accuracy. The authors of the Frontiers papers stressed the need to recruit volunteers to tackle issues that span multiple scales of time and space (Dickinson et al., 2012). Although there are shared goals between both samples there are nuanced differences as well. The developers of citizen science programs have specific objectives to meet in terms of answering research questions, publishing scholarly articles, and fulfilling grant requirements. One tenet of science that has always been sacrosanct is the necessity of collected data in order to support hypotheses or establish claims of truth. This of course is becoming even more of a necessity since technological advances have created the possibility of analyzing global datasets (Miller-Rushing, Primack, \& Bonney, 2012). Academic scholarship has become inextricably linked with procuring funding, which means that competition among scholars is high and requires innovation in project design (Greenberg, 2001). Citizen science programs offer a unique option for scholars because they can reduce costs associated with data collection, meet educational requirements, and engage the public. But they are still fundamentally tied to academia, which suggests that programmatic goals benefiting the researcher outweigh goals meant for the participant. As the scientific process is forced to respond to the requirements of the capitalist mode of production, creative tension presses the demands of research up against societal norms of education and literacy (Marx, [1867] 1990). This results in a contradiction in which citizen science programs must be brought into existence and expand is scope while being framed in a way that makes them beneficial for the general public.

According to the surveyed participants, they experienced and emotive effect by engaging with the SATELLITES program. Respondents 10 and 16 were inspired by their experiences and were motivated to engage with their community to get more people involved in this work. 
Respondent 16 was so inspired by their SATELLITES participation that they felt obliged to recruit people from their community. Respondent 10 also expressed hope that by using SATELLITES as a teaching tool for their students they would grow up to engage in complex debates. It is clear that the SATELLITES program had a substantial impact on some educators and their students. Respondent 4 suggested that this type of training can have long-lasting effects and produce adults that are capable of making informed decisions, particularly when it comes to environmental issues. Additionally, participants in the SATELLITES project felt that it contributed to their students' overall learning when paired with classroom activities (Wixom in prep b).

One of the key themes to arise out of this research was the realization by both groups that a community-level focus is necessary to strengthen citizen science programs and improve overall learning. As Jolly (2009) pointed out, there is a lack of participation by underrepresented and minority groups in these projects and the demographics for the SATELLITES program follow this trend as well (Wixom in prep b). There is a complex dialectic at work that may explain, at least to some extent, the reasons for this: underrepresented and minority groups are often financially insecure, which means that they often have to work multiple jobs to make ends meet. In turn, this often precludes these groups from participating because they do not have enough time. Furthermore, these groups often view themselves as outsiders, which can lead to a feeling of disconnectedness. Taken together, these factors lead to lower rates of learning and an exclusion of core groups from community planning (Jolly, 2009). The Frontiers authors and SATELLITES participants both recognized the need for a community-based approach to developing citizen science programs. By focusing on the local, communities get a say in issues that directly impact their lives and has the ability to engage more people and reduce the sense of 
exclusion felt by some. This can have a democratizing influence on science and social justice as well, since more people have input into the decision-making process. A more communal citizen science can serve simultaneously as a critique of modern scientific thought and become a lever of change to decentralize institutional power (Trumbull et al., 2000).

Finally, it appears that citizen science scholars are not as embedded with the academic superstructure as their peers. The outcomes of citizen science programs are continuously shaped by the same internal relations, but these scholars are also impacted by relations that align their goals closely to those of the participants. In theory, the expanded application of citizen science would remove some of the power and control that private and governmental institutions have over the scientific enterprise. This possibility would make science more democratic, increase public participation, and improve scientific literacy. Continued investigation of citizen science programs will be necessary in order to uncover the complex relations at work. Future work must rely on varying windows of time as well as expansions in scale to capture sub-national and global programs that were beyond the scope of this research. As this analysis has shown, there are complex relations at work that influence the development of citizen science projects as well as transform the structure of science itself. Expanding the scope and level of detail for analysis can provide us with a more comprehensive view of citizen science's role in both science and society. 


\section{Chapter 6: Conclusion}

The three constituent components of this dissertation produced a robust first pass at understanding the relationship between citizen science, scientific literacy, and the dissemination of scientific information. The content analysis for news articles and BO/Es yielded distinct patterns of the themes, key words, and experts used by supporters and opponents of the consensus on ACC. Confrontational voices produced counter-narratives that were designed to prolong public debate. Other studies have captured the level of consensus on ACC and Cook et al.'s paper represents the most comprehensive and most maligned paper published on the topic. Many detractors think that scientific facts are not open to a vote; this so-called post-modern science of gauging scientists' opinions and calling it evidence is a detriment to the scientific enterprise. Yet, consensus on any topic only comes about through meticulous study and validation. For climate science, consensus is not the end of the story, but rather the beginning since acknowledging the problem is the first step in combating the worst of the consequences. As Oreskes (2007) pointed out, the scientific consensus on ACC may be proven wrong in the future, but the likelihood diminishes as the body of evidence continues to mount.

Media representations of the consensus remain highly polarized with both proponents and opponents trying to convince the public that their position is right. This level of polarization precludes action and leads to confusion and distrust among the public. The results of this study show that the news coverage of the consensus is moving away from 'balanced' reporting, but this has not translated in broader public awareness. The results from $\mathrm{BO} / \mathrm{E}$ reporting were more complex. There is almost an even split between supporting and denialist coverage. The nature of online spaces makes the perpetuation of competing perspectives easier. Additionally, people's selective exposure to media narratives makes it more likely that they will never be convinced by 
conflicting evidence, even if that evidence is overwhelming. Selective exposure can also lead to an entrenchment of beliefs via disconfirmation bias. Oppositional groups understand this and their narratives target vulnerabilities in social perception. In general, scientists are well-respected in the U.S. and denialists play on public fears that scientific integrity could be corrupted by a political agenda. Supporting groups attempt to reify scientific evidence by portraying the process as robust and meticulous, and supporting pieces try to present the evidence and use rational thought to critique oppositional view points. Key word analysis showed that authors used specific words to convey meaning in their work. Words like denialist, alarmist, myth, and misinformation are used as signifiers for an author's perspective. The audience internalizes these words thus reinforcing their assumptions. The analysis of experts cited by the media reveals that authors rely on a small group of scientists to reinforce the validity of their arguments. The use of dueling experts makes judging the validity of an argument difficult to determine. Media narratives and their acceptance or rejection by the public are a direct challenge to the level of scientific understanding and literacy within the U.S. The dissemination of quality information is critical for people to make informed decisions.

Citizen science is a relatively novel form of scientific research that has the potential to increase scientific literacy and allow people to assess the information provided to them in order to make these informed decisions. There are concerns, however, that citizen science programs do not meet the educational needs of all communities. The SATELLITES program has a high rate of participation from a White, middle-class population, which has been observed with other citizen science programs. The lack of diversity poses some concerns that citizen science programs in general are missing at-risk minority groups (Pandya, 2012). Citizen science programs can be used to promote equality in science education, thus improving overall scientific literacy, but 
participation has to include all populations. The inclusion of underrepresented groups and a focus on community-level outcomes can promote a broader understanding of the various issues that impact people. Additionally, some of these issues remain hidden to broad segments of the U.S. population and bringing them to the foreground could be the first step in generating cultural, socioeconomic, and political cooperation across all communities.

Programs like SATELLITES are using community-level participation to engage a lot of children. SATELLITES' parent organization, GLOBE, is attempting to reach a diverse range of people at the global scale. The organizers of these programs recognize the need to be inclusive in order to achieve programmatic aims, which suggests that outreach efforts will continue to address the lack of diversity. Additionally, the creation of more localized neighborhood projects broadens the focus from solely education to include community-based engagement (Jordan, Ballard, \& Phillips, 2012). The SATELLITES program is effective at engaging students in basic scientific research. Respondents regarded the program as a useful teaching tool and acknowledged improvement their students' overall learning through their participation.

Citizen science programs provide a unique opportunity for educators to offer a hands-on educational experience for their students. However, science educators do not necessarily seek out citizen science programs; they have to be motivated to go beyond standard classroom-based instruction in order to introduce their students to hands-on application of scientific practices. Additionally, there is a concern that STEM education reaches male students at a disproportionate rate translates to fewer female students receiving science-based degrees (Ceci \& Williams, 2011). Yet, the SATELLITES program has a high rate of female student involvement, which is encouraging. 
Raising the awareness of the opportunities citizen science programs offer may increase their use both in the classroom and communities. This research project found mixed results in terms of the respondents' attitudes toward the SATELLITES program, but their overall opinion of its efficacy as a teaching tool was high. Yet, students did not receive program objectives equally and some respondents viewed the program as just another part of their curriculum. Thus, some students were not made aware that the science they learn in and out of the classroom could have a greater impact on their lives. Citizen science programs need to continue to stress the importance of the learning objectives so participants will develop a deeper connection and understanding of scientific inquiry in general. This will have the added benefit of promoting scientific literacy and creating generations of people that feel connected to science on a deeper level. The development and deployment of citizen science, however, is not value-neutral and should be examined through a critical lens. Citizen science programs are developed with specific academic objectives in mind, and, while program objectives include benefits to their participants, it is necessary to understand why researchers are using this form of research.

Citizen science programs represent a relatively new moment in the evolution of scientific thought. They are used by researchers as a method of data capture at broad geographic scales that span multiple time periods. Conversely, citizen science programs offer a means for people to improve their overall scientific literacy, which can allow them to become more actively involved in the decision-making process. An actively engaged citizenry has the potential to wrest control from corporate and special interests and promote a more democratic form of participation. Citizen science can serve as a model that is capable of responding to the modern needs of a technologically advanced society by allowing both scientists and volunteers to collaborate. Results of this study highlight the tension within citizen science programs as developers and 
participants seek to find common ground. Both groups have shared goals, but the implementation and focus often produce contradictions that make examination necessary.

Scientific learning was stressed by both groups as a necessary outcome for any project. SATELLITES instructors had some concerns about using project-based learning to teach their students, but their overall attitudes toward the program were positive. Yet, a few participants stated that students needed more time to engage with the program in order to achieve this goal. Some participants felt that educational requirements made it more difficult to incorporate the SATELLITES program into their curriculum. The latter is a larger issue facing schools across the U.S. and needs to be explored in greater detail. Program developers, on the other hand, stressed learning without specific objectives in mind. Particularly, there was no discussion of K12 educational requirements and how citizen science projects could help educators meet mandated standards. This is a complex issues that will take collaboration among educators and developers time to address.

Educators participating with SATELLITES felt that the students could indeed contribute to science by collecting more data and adding them to existing datasets. The authors of the Frontiers papers stressed the need to recruit and train volunteers properly to produce verifiable data. Although there are shared goals between both samples there are nuanced differences as well. The developers of citizen science programs have specific objectives to meet in terms of answering research questions, publishing scholarly articles, and fulfilling grant requirements. Educators want to see the science fit into a broader context. Academic scholarship has become inextricably linked with procuring funding, which means that competition among scholars is high and requires innovation in project design (Greenberg, 2001). Citizen science programs offer a unique option for scholars because they can reduce costs associated with data collection, meet 
educational requirements, and engage the public. This has the potential to skew the goals of citizen science in favor of the program developers and take away the volunteer- or communitylevel focus that seems to be emerging at present.

According to the surveyed participants, they experienced an emotive effect by engaging with the SATELLITES program. It is clear that the SATELLITES program had a substantial impact on some educators. Citizen science has the ability to impart practical knowledge on their students. Respondent 4 suggested that this type of training can have long-lasting effects and produce adults that are capable of making informed decisions, particularly when it comes to environmental issues. Additionally, participants in the SATELLITES project felt that it contributed to their students' overall learning when paired with classroom activities (Wixom in progress $\mathrm{B})$.

Finally, a key theme to arise out of this research was the realization that a communitylevel focus is necessary to strengthen citizen science programs and improve overall learning. As Jolly (2009) pointed out, there is a lack of participation by underrepresented and minority groups in these projects and the demographics for the SATELLITES program follow this trend as well (Wixom in progress b). Underrepresented groups often view themselves as outsiders, which can lead to a feeling of disconnectedness and exclusion (Jolly, 2009). Program developers also recognized the need for a community-based approach citizen science programs. By focusing on the local, communities get a say in issues that directly impact their lives and has the ability to engage more people and reduce the sense of exclusion felt by some. This can have a democratizing influence on science and social justice as well, since more people have input into the decision-making process. A more communal citizen science can serve simultaneously as a critique of modern scientific thought and become a lever of change to decentralize institutional 
power (Trumbull et al., 2000). Despite the readily apparent contradictions between program developer and participant goals, it appears that the shared goals among both groups outweigh the institutional goals of the academic superstructure. This suggests that, as citizen science projects grow in scope and popularity, these programs could generate real change and equity within communities. This has the combined effect of making science work for all people, improving scientific literacy, and promoting an actively engaged citizenry. 


\section{References}

Adger, W.N. (2003). Social capital, collective action, and adaptation to climate change. Economic Geography. 79(4): 387-404.

Agrawala, S. (1998). Structural and process history of the Intergovernmental Panel on Climate Change. Climatic Change, 39: 621-642.

Agresti, A. and Kateri, M. (2011). Categorical Data Analysis. In Lovric, M. (Ed.). International Encyclopedia of Statistical Science, pp. 206-208. Springer: London, UK.

Aikenhead, G.L. (1996). Science education: border crossing into the subculture of science. Studies in Science Education, 27: 1-52.

397.

Alexander, L.V. et al. (2013) Summary for policy makers. IPCC.

Anderegg, W.R.L, et al. (2010). Expert credibility in climate change. PNAS, 107(27): 1210712109.

Antilla, L. (2005). Climate scepticism: US newspaper coverage of the science of climate change. Global Environmental Change, 15: 338-352.

Anonymous. (9/25/13). What-If Anything-Should Be Done About Global Warming. Wall Street Journal. Accessed 5/16/15.

Anonymous. (4/5/14). Climate change: In the balance. The Economist. Accessed 8/29/15 from http://www.economist.com.

Archer, T.M. (2008). Response rates to expect from web-based surveys and what to do about it. Journal of Extension, 46(3).

Arrhenius, S. and Holden, E.S. (1897). On the influence of carbonic acid in the air upon the temperature of the earth. Publications of the Astronomical Society of the Pacific, 9(54): 1424.

Babbie, E. (1992). The practice of Social Research. Macmillan: New York, NY.

Banerjee, N., Song, L., and Hasemyer, D. (9/16/15). Exxon's Own Research Confirmed Fossil Fuels' Role in Global Warming Decades Ago. Inside Climate News. Retrieved 12/19/15 from http://insideclimatenews.org/news/15092015/Exxons-own-research-confirmed-fossil-fuelsrole-in-global-warming.

Barber, B. (1952). Science and the Social Order. The Free Press: Glencoe, IL.

Bast, J. and Smith, T. (5/14/14). The myth of a global warming consensus. Heartland Institute. Accessed 1/13/15 from http://www.heartland.org.

Becker, C.D. (2005) Community-based monitoring of fog capture and biodiversity at Loma Alta, Ecuador enhance social capital and institutional cooperation. Biodiversity and Conservation, 14: $2695-2707$.

Beisner, E.C. (7/16/14). Climate Consensus? Nonsense! Watts Up With That? Accessed 6/13/15 from http://www.wattsupwiththat.com.

Berelson, B. (1952). Content Analysis in Communicative Research. Free Press: New York.

Bernard, H.R. and Ryan, G. (1998). Text analysis: qualitative and quantitative methods. In. H. Russell Bernard (Ed.) Handbook of Methods in Cultural Anthropology, pp. 585-644. Rowman \& Littlefield: Lanham, MD.

Bhaskar, R. (1989). Reclaiming reality. Verso: London, UK.

Blaikie, N. (2003). Analysing Quantitative Data. Sage Publications: London, UK.

Bohm, D. (1983). Wholeness and the implicate order. London. 
Bonney, R. Cooper, C, Dickinson, J.L. et al. (2009). Citizen science: a developing tool for expanding science knowledge and scientific literacy. BioScience. 59(11): 977-984.

Bonter, D.N. and Cooper, C.B. (2012). Data validation in citizen science: a case study of Project FeederWatch. Frontiers in Ecology and the Environment. 10(6): 305-307.

Boykoff, M.T. (2007a). Flogging a dead norm? Newspaper coverage of anthropogenic climate change in the United States and United Kingdom from 2003 to 2006. Area, 39(4), 470-481.

Boykoff, M.T. (2007b). From convergence to contention: United States mass media representations of anthropogenic climate change science. Transactions of the Institute of British Geographers, 32(4): 477-489.

Boykoff, M.T. and Boykoff, J.M. (2007). Climate change and journalistic norms: a case-study of US mass-media coverage. Geoforum, doi:10.1016/j.geoforum.2007.01.008

Burnett, H.S. (4/6/15). The 97 Percent Climate Change Consensus That Wasn't. Heartland Institute. Accessed 5/23/15 from http://www.heartland.org.

Brossard, D., B. Lewenstein, and R. Bonney. (2005). Scientific knowledge and attitude change: the impact of a citizen science project. International Journal of Science Education. 27(9): 1099-1121.

Carvalho, A. (2007). Ideological cultures and media discourses on scientific knowledge: rereading news on climate change. Public Understanding of Science, 16: 223-243.

Ceci, S.J. and Williams, W.M. (2011). Understanding current causes of women's underrepresentation in science. PNAS, 108(8): 3157-3162.

Cohn, J.P. 2008. Citizen science: can volunteers do real research? BioOne. 58(3): 192-197.

Collinge, C. 2008. Positions without negations? Dialectical reason and the contingencies of space. Environment and Planning. 40(11): 2613-2622.

Collins, H.M. and R. Evans. 2002. 'The third wave of science studies: studies of expertise and experience'. Social Studies of Science. 32(2): 235-296.

Comte, A. (1908). A General View of Positivism. Routledge: London.

Cook, J. et al. (2013). Quantifying the consensus on anthropogenic global warming in the scientific literature. Environmental Research Letters, 8: 1-7

Cooper, C. et al. (2007). Citizen science as a tool for conservation in residential ecosystems. Ecology and Society. 12(2): 11.

Corbett, J.B. and Durfee, J.L. (2004). Testing public (un)certainty of science: media representations of global warming. Science Communication, 26: 129-151.

DeBoer, G.E. (2000). Scientific literacy: another look at its historical and contemporary meanings and its relationship to science education reform. Journal of Research in Science Teaching, 37(6): 582-601.

Demeritt, D. (2001). The construction of global warming and the politics of science. Annals of the Association of American Geographers. 91(2): 307-337.

(2006). Science studies, climate change and the prospects of constructivist critique. Economy and Society, 35(5): 453-479.

Dickinson, J.L. and R. Bonney eds. (2012). Citizen Science: Public Participation in Environmental Research. Comstock Publishing: Ithaca.

Dickinson, J.L. et al. (2010). Citizen science as an ecological research tool: challenges and benefits. Annual Review of Ecology, Evolution, and Systematics. 41: 149-172.

Dickinson, J.L. et al. 2012. The current state of citizen science as a tool for ecological research and public engagement. Frontiers in Ecology and the Environment. 10(6): 291-297. 
Dispensa, J.M. and Brulle, R.J. (2003). Media's social construction of environmental issues: focus on global warming - a comparative study. International Journal of Sociology and Social Policy, 23(10): 74-105.

Doran, P.T. and Zimmerman, M.K. (2009). Examining the scientific consensus on climate change. Eos, 90(3), 22-23.

Dos Santos, W.L. (2009). Scientific literacy: a Freirean perspective as a radical view of humanistic science education. Science Education, 93(2): 361-381.

Duffy, B., et al. (2005). Comparing data from online and face-to-face surveys. International Journal of market Research, 47(6): 615-639.

Dunlap, R.E. and McCright, A.M. (2010). A widening gap: Republican and Democratic views on climate change. Environment: Science and Policy for Sustainable Development, 50(5): 2635.

Dunlap, R.E. and McCright, A.M. (2011). Organized Climate Change Denial. In J.S. Dryzek, R.B. Norgaard, \& D. Schlosberg (Eds.), The Oxford Handbood of Climate Change and Society, pp. 144-160. Oxford University Press: Oxford, UK.

Dunlap, R.E., Xiao, C., and McCright, A.M. (2001). Politics and environment in American: Partisan and ideological cleavages in public support for environmentalism. Environmental Politics, 10(4): 23-48

Dunwoody, S. and Peters, H.P. (1992). Mass media coverage of technological and environmental risks: a survey of research in the United States and Germany. Public Understanding of Science, 1: 199-230.

Durant, J.R. (1993). What is scientific literacy? In J.R. Durant \& J. Gregory (Eds.), Science and Culture in Europe, pp. 129-137, London: Science Museum.

Durkheim, E. [1893] 1933. The Division of Labor in Society. The Free Press: New York . ([1895] 1982). The Rules of Sociological Method. The Free Press: New York.

Edwards, D. (2000). Can we trust the media on the environment? The Ecologist, 30(4): 22.

Einsiedel, E.F. (1992). Framing science and technology in the Canadian press. Public Understanding of Science, 1: 89-101.

Eisenhart, M., E. Finkel, and S.F. Marion. (1996). Creating the conditions for scientific literacy: a re-examination. American Educational Research Journal. 33(2): 261-295.

Evans, J.R. and Mathur, A. (2005). The value of online surveys. Internet Research, 15(2): 195219.

Fairclough, N. (2003). Analysing discourse: Textual analysis for social research. Routledge: London, UK.

Fan, W. and Yan, Z. (2010). Factors affecting response rates of the web survey: A systematic review. Computers in Human Behavior, 26: 132-139.

Farrell, J. (2016). Corporate funding and ideological polarization about climate change. PNAS, 113(1): 92-97.

Feldman, L., Maibach, E.W., Roser-Renouf, C. and Leiserowitz, A. (2011). Climate on cable: the nature and impact of global warming coverage on Fox News, CNN, and MSNBC. The international Journal of Press/Politics. Doi: 10.1177/1940161211425410.

Feldman, L., Myers, T.A., Hmielowski, J.D., and Leiserowitz, A. (2014). The mutual reinforcement of media selectivity and effects: testing the reinforcing spirals framework in the context of global warming. Journal of Communication, 64: 590-611. 
Field, D.R. et al. (2003). Reaffirming social landscape analysis in landscape ecology: a conceptual framework. Society \& Natural Resources: An International Journal, 16(4): 349361.

Fitzpatrick, M.C. et al. (2009). Observer bias and the detection of low-density populations. Ecological Applications, 19(7): 1673-1679.

Foran, C. (12/8/14). The Plan to Get Climate-Change Denial Into Schools. The Atlantic. Accessed 8/29/15 from http://www.theatlantic.com.

Freudenburg, W.R. and Muselli, V. (2010). Global warming estimates, media expectations, and the asymmetry of scientific challenge. Global Environmental Change, 20(3): 483-491.

Funk, C. and Rainie, L. (2015). Chapter 2: Climate change and energy issues. In C. Funk, L. Rainie, and D. Page (Eds.). Americans, Politics and Science Issues: The general public's views are strongly linked to their attitudes on climate and energy issues. But politics is a less important factor on biomedical, food safety, space issues, pp. 36-75. Pew Research Center: Washington, DC.

Galloway, A.W.E, Tudor, M.T., and Vander Haegen, W.M. (2006) The reliability of citizen science: a case study of Oregon white oak stand surveys. Wildlife Society Bulleting, 34(5): $1425-1429$.

Gans, H. (1979). Deciding What's News. Pantheon: New York.

Gelbspan, R. (1998). The Heat is On: The Climate Crisis, the Cover-Up, The Prescription. Perseus Press: Cambridge.

Gliem, J.A. and Gliem, R.R. (2003). Calculating, interpreting, and reporting Cronbach's alpha reliability coefficient for Likert-type scales. Midwest Research to Practice Conference in Adult, Continuing, and Community Education.

Greenberg, D.S. (2001). Science, Money, and Politics: Political Triumph and Ethical Erosion. University of Chicago Press.

Hamlin. C. (2007). STS: Where the Marxist critique of capitalist science goes to die? Science as Culture. 16(4): 467-474.

Harvey, D. (1982). Limits to Capital. University of Chicago Press: Chicago.

Oxford.

. (1996). Justice, Nature, \& the Geography of Difference. Blackwell Publishing:

. (2003). The New Imperialism. Oxford University Press: Oxford, UK.

. 2008. On the deep relevance of a certain footnote in Marx's Capital. Human Geography. 1(2): 26-31.

Havens, K., Vitt, P., and Masi, S. (2012). Citizen science on a local scale: the Plants of Concern program. Frontiers in Ecology and the Environment. 10(6): 321-323.

Hedley, M.-L., K. et al. (2008). SATELLITES: A geospatial technology program for teachers and students. The Earth Scientist. 27: 11-13.

Hegel, G.W.G. [1816] 1929. Science of logic. Allen and Unwin: London.

Henderson, S. et al. 2012. Project BudBurst: Citizen Science for All Seasons. In Citizen Science: Public Participation in Environmental Research. Eds J.L. Dickinson and R. Bonney. Comstock Publishing: Ithaca.

Hmielowski, J.D., Feldman, L, Myers, T.A., Leiserowitz, A, and Maibach, E. (2014). An attack on science? Media use, trust in scientists, and perceptions of global warming. Public Understanding of Science, 23(7): 866-883.

Holsti, O.R. (1969). Content Analysis for the Social Sciences and Humanities. Addison-Wesley: Reading, MA. 
Hosmer, D.W. and Lemeshow, S. (2000) Applied logistic regression. 2nd ed. Wiley: New York Howard, W. (8/13/14). Appeals to the climate consensus can give the wrong impression. Climate Etc. Accessed 2/7/15 from http://judithcurry.com.

Hsieh, H.-F. and Shannon, S.E. (2005). Three approaches to qualitative content analysis, 15(9): 1277-1288.

Huff, T.E. 2003. The Rise of Early Modern Science: Islam, China, and the West. $2^{\text {nd }}$ ed. Cambridge University Press: Cambridge.

Hutten, E.H. (1962). The Origins of Science: An inquiry into the foundations of Western thought. Allen and Unwin: London.

Hurd, P. (1958). Science literacy: its meaning for American schools. Science Education, 16: 1313.

(1998). Scientific literacy: new minds for a changing world. Science Education, 82(3): 407-416.

IPCC (2014). Climate Change 2014: Synthesis Report. Contribution of Working Groups I, II and III to the Fifth Assessment Report of the Intergovernmental Panel on Climate Change. Core Writing Team, R.K. Pachauri and L.A. Meyer (Eds.). IPCC, Geneva, Switzerland, 151 pp.

Iverson, L.R. et al. (2011). Lessons learned while integrating habitat, dispersal, disturbance, and life-history traits into species habitat models under climate change. Ecosystems. 14: 10051020.

Jacques, P.J., Dunlap, R.E., and Freeman, M. (2008). The organisation of denial: Conservative think tanks and environmental scepticism. Environmental Politics, 17(3): 349-385.

Jasanoff, S. and Wynne, B. (1998). Science and decisionmaking. In E. Malone and S. Rayner (Eds.). Human Choice and Climate Change, Vol 1: The Societal Framework, pp. 1-87. Battelle Press: Ohio.

Jasper, W.F. (6/5/13). Cooking climate consensus data: "97\% of Scientists Affirm AGW" debunked. The New American. Accessed 10/30/15 from http://www.thenewamerican.com.

Jamieson, S. (2004). Likert scales: how to (ab)use them. Medical Education. 38: 1217-1218.

Johnson, T.J. and Kaye, B.K. (2004). Wag the blog: how reliance on traditional media and the internet influence credibility perceptions of weblogs among blog users. J \&MC Quarterly, 81(3), 622-642.

Jordan, R.C. et al. 2011. Knowledge gain and behavioral change in citizen-science programs. Conservation Biology. 25(6): 1148-1154.

Jordan, R.C., Ballard, H.L., and Phillips, T.B. (2012). Key issues and new approaches for evaluating citizen-science learning outcomes. Frontiers in Ecology and the Environment. 10(6): 307-309.

Kahan, D.M. et al. (2011). The tragedy of the risk-perception commons: culture conflict, rationality conflict, and climate change. Temple University Legal Studies Research Paper No. 2011-26; Cultural Cognition Project Working Paper No. 89; Yale Law \& Economics Research Paper No. 435; Yale Law School, Public Law Working Paper No. 230.

Kelling, S. et al. 2009. Data intensive science: a new paradigm for biodiversity studies. BioScience. 59(7): 613-620.

Kerlinger, F.N. (1986). Foundations of behavioural research. $3^{\text {rd }}$ ed. Holt, Rrinehart and Winston: New York, NY.

Krippendorff, K. (1989). Content analysis. In E. Barnouw, G. Gerbner, W. Schramm, T.L. Worth, \& L. Gross (Eds.), International Encyclopedia of Communication. Vol. 1, pp. 403- 
407. New York, NY: Oxford University Press. Retrieved November 17, 2014 from http://repository.upenn.edu/asc_papers/226.

Lahsen, M. (2005). Technocracy, democracy, and U.S. climate politics: the need for demarcations. Science, Technology, \& Human Values, 30(1): 137-169.

Latour, B. 1986. Science in Action. Harvard University Press: Cambridge.

Laugksch, R.C. (2000). Scientific literacy: a conceptual overview. Science Education, 84(1): 7194.

Legates, D.R., W. Soon, W.M. Briggs, and C. Monckton of Brenchley. (2013). Climate Consensus and 'misinformation': a rejoinder to Agnotology, scientific consensus, and the teaching and learning of climate change. Science \& Education, 1-20.

Leiserowitz, A.A. et al. (2013). Climategate, public opinion, and the loss of trust. American Behavioral Scientist, 57(6): 818-837.

Levins, R. and Lewontin, R. (1985). The Dialectical Biologist. Harvard University Press: Cambridge.

Lewandowsky, S. Gignac, G.E., and Vaughan, S. (2012). The pivotal role of perceived scientific consensus in accepting of science. Nature Climate Change, 3: 399-404.

Lewenstein, B.V. (2011). Changing our ideas. International Journal of Science Education, 1(1): $17-21$.

Lewis, M. (10/16/13). Balance is not bias - Fox News critics mislead public on climate change. Fox News. Accessed 10/30/15 from http://www.foxnews.com.

Lynch, S.M. (2013). Using Statistics in Social Research: A concise approach. Springer: New York.

Maessen, C. (9/16/13). 97\% Climate consensus 'denial': the debunkers again not debunked. Real Sceptic. Accessed 9/9/15 from http://www.realsceptic.com

Maessen, C. (5/19/14). Richard Tol Versus Richard Tol On the 97\% Scientific Consensus. Real Sceptic. Accessed 9/9/15 from http://www.realsceptic.com

Maessen, C. (4/6/15). Using The Tactics of The Merchants Of Doubt To Combat Science Denial. Real Sceptic. Accessed 6/6/15 from http://www.realsceptic.com.

Mandel, E. (1990) Introduction. In Capital vol. I. Penguin Classics: London.

Mansvelt, J. and L.D. Berg. (2005). Writing qualitative geographies, constructing geographical knowledges. In Qualitative research methods in human geography $2^{\text {nd }} \mathrm{ed}$. Ed. I. Hay. Oxford University Press: Melbourne.

Marcuse, H. 1954. Reason and Revolution: Hegel and the Rise of Social Theory. Humanities Press: New York

Marshall, N.J., Kleine, D.A., and Dean, A.J. (2012). CoralWatch: education, monitoring, and sustainability through citizen science. Frontiers in Ecology and the Environment. 10(6): 332334.

Marx, K. 1859. A contribution to the critique of political economy. C.H. Kerr: Chicago. [1867] 1990. Capital Vol. I. Penguin Classics: London. ([1872] 1990). Letter to Maurice La Châtre. Preface to the French Edition in Capital Volume I. Penguin Classics: London.

Marx, K. and F. Engels. (1945). The Communist Manifesto. Chicago

Marx, K. and F. Engels. (1981). The German Ideology. International Publishers: New York.

McCluskey, M. and Hmielowski, J. (2012). Opinion expression during social conflict: Comparing online reader comments and letters to the editor. Journalism, 13(3): 303-319. 
McGuirk, P.M. and O’Neill, P. (2005). Using questionnaires in qualitative human geography. In . I. Hay ed. Qualitative Research Methods in Human Geography. $2^{\text {nd }}$. Ed. Oxford University Press: Melbourne.

McMillan, S.J. (2000). The microscope and the moving target: the challenge of applying content analysis to the world wide web. Journalism \& Mass Communication Quarterly, 77: 80-98.

Memarsadeghi, N. (2016). Overview. Retrieved 4/16/2016 from https://globe.gov/about/overview.

Miles, M.B. and A.M. Huberman. (1994). Qualitative Data Analysis: An Expanded Sourcebook. Sage: Thousand Oaks, CA.

Miller, J.D. (1983). Scientific literacy: a conceptual and empirical review. Daedalus, 112(2): 2948.

Miller, J.D. (2004). Public understanding of, and attitudes toward, scientific research: what we know and what we need to know. Public Understanding of Science. 13: 273-294.

Miller-Rushing, A, Primack, R., and Bonney, R. (2012). The history of public participation in ecological research. Frontiers in Ecology and the Environment. 10(6): 285-290.

Monckton of Brenchley, C. (9/9/13). 97\% Climate consensus 'denial': the debunkers debunked. Watts Up With That? Accessed 9/12/15 from http://www.wattsupwiththat.com.

Monroe, Rob (2015). What does the number mean? Scripps Institute of Oceanography, University of California San Diego. Retrieved 12/12/2015 from https://scripps.ucsd.edu/programs/keelingcurve/.

Morano, M. (4/17/15). Climatologist Dr. Judith Curry rips 'manufactured consensus'-Human influence is NOT 'dominant over natural climate variability'. Climate Depot. Accessed 6/13/15 from http://www.climatedepot.com.

Morrison, K. (1995). Marx, Durkheim, Weber: Formations of Modern Social Thought. SAGE Publications: London.

NASA. (8/28/15). Consensus: 97\% of climate scientists agree. Retrieved 9/19/2015 from http://climate.nasa.gov/scientific-consensus/.

Nelkin, D. (1987). Selling Science: How the Press Covers Science and Technology. W.H. Freeman: New York.

Newman, G., et al. (2012). The future of citizen science: emerging technologies and shifting paradigms. Frontiers in Ecology and the Environment. 10(6): 298-304.

Nisbet, M.C. and Myers, T. (2007). The polls-trends: Twenty years of public opinion about global warming. Public Opinion Quarterly, 71(3): 444-470.

Nuccitelli, D. (1/6/15). Scientists connect the dots from identifying to preventing dangerous climate risks at the AGU 2014 fall meeting: Climate and social scientists gathered to share their latest research. The Guardian. Accessed 5/16/15 from http://www.theguardian.com.

Oberhauser, K. and LeBuhn, G. (2012). Insects and plants: engaging undergraduates in authentic research through citizen science. Frontiers in Ecology and the Environment. 10(6): 318-320.

O'Hara, P.A. (2009). Political economy of climate change, ecological destruction and uneven development. Ecological Economics. 69: 223-234

Ollman, B. (1976). Alienation: Marx's conception of man in capitalist society. $2^{\text {nd }}$ ed. Cambridge University Press: Cambridge. . (1993). Dialectical Investigations. Routledge: New York. (2003). Dance of the Dialectic; Steps in Marx's Method. University of Illinois Press: Urbana. 
Oppenheimer, M. O’neill, B.C., Webster, M. and Agrawala, S. (2007). The limits of consensus. Science, 317: 1505-1506.

Oreskes, N. (2004). Beyond the Ivory Tower: the scientific consensus on climate change. Science, 306: 1686.

Oreskes, N. (2007). The scientific consensus on climate change: How do we know we're not wrong. In. J. DiMento and P. Doughman (Eds). Climate Change: What it means for you, your children, and your grandchildren, pp. 105-148. Cambridge, MA: The MIT Press.

Pandya, R.E. (2012). A framework for engaging diverse communities in citizen science in the US. Frontiers in Ecology and the Environment, 10(6): 314-317.

Parmesan, C. and G. Yohe. 2003. A globally coherent fingerprint of climate change impacts across natural systems. Nature, 421: 37-42.

Peet, R. (1979). Societal contradiction and Marxist Geography. Annals of the Association of American Geographers. 69(1): 164-169. (2007). Geography of power: making global economic policy. Zed Books: London.

Peet, R. and E. Hartwick. (2009). Theories of Development: Contentions, Arguments, Alternatives. The Guilford Press: New York.

Place, F, Adato, M., and Hebinck, P. (2007). Understanding rural poverty and investment in agriculture: an assessment of integrated quantitative and qualitative research in Western Kenya. World Development, 53(2): 312-325

Plait, P. (9/9/14). 97 Percent, 97 Hours, 97 Climate Scientists. Bad Astronomy. Accessed 6/13/15 from www.badastronomy.com.

Polanyi, M. 1940. The Contempt of Freedom: the Russian Experiment and After. Watts \& Co.: London.

Price, D.K. 1965. The established dissenters. Daedalus. 94(1): 84-116.

Price, C.A. and Lee, H.-S. (2013). Changes in participants' scientific attitudes and epistemological beliefs during an astronomical citizen science project. Journal of Research in Science Teaching, 50(7): 773-801.

Root, T.L. et al. (2003). Fingerprints of global warming on wild animals and plants. Nature. 421: 57-60.

Shackley, S. and Wynne, B. (1996). Representing uncertainty in global climate change science and policy: boundary-ordering devices and authority. Science, Technology, \& Human Values. 21(3): 275-302.

Silvertown, J. (2009). A new dawn for citizen science. Trends in Ecology \& Evolution, 24(9): 467-471.

Redfearn, G. (6/6/13). The Campaigns That Tried to Break the Climate Science Consensus. Desmog Blog. Accessed 2/7/15 from desmogblog.com.

Ritter, L.A. and Sue, V.M. (2007). Introduction to using online surveys. New Directions for Evaluation, 115: 5-14.

Robbins, N.B. and Heiberger, R.M. (2011). Plotting Likert and other rating scales. Proceedings of the 2011 Joint Statistical Meeting. 1058-1066.

Rosenberg, S., A. Vedlitz, D. Cowman, and S. Zahran. (2010). Climate change: a profile of U.S. climate scientists' perspectives. Climatic Change, 101(3-4) 311-329.

Roth, W.-M. \& Barton, A.C. (2004). Rethinking scientific literacy. Routledge Falmer: New York, NY.

Samenow, J. (9/25/13). The climate change consensus: a call for care in interpretation. The Washington Post. 
Schulte, K.-M. (2008). Scientific consensus on climate change? Energy \& Environment, 19(2): 281-286.

Schwartz, J. (1/14/15). West Virginia Withdraws Altered Climate Curriculum. The New York Times. Accessed 8/22/15.

Schwartz, M.D., Betancourt, J.L., and Weltzin, J.F. (2012). From Caprio's lilacs to the USA National Phenology Network. Frontiers in Ecology and the Environment. 10(6): 324-327.

Shirk, J.L. et al. (2012). Public participation in scientific research: a framework for deliberate design. Ecology and Society, 17(2): 29.

Silverman, D. (2005). Doing Qualitative Research. $2^{\text {nd }}$ ed. SAGE: London.

Smith, A. ([1776] 1910). The Wealth of Nations. Dent \& Sons: London.

Smith, N. (2008). Uneven Development: Nature Capital, and the Production of Space. University of Georgia Press: Athens.

Stemler, S. (2001). An overview of content analysis. Practical Assessment, Research, \& Evaluation. 7, 17. Retrieved 11/17/2014 from http://PAREonline.net/getvn.asp?v=7\&n+17.

Tamny, J. (3/15/15). Global Warming Hype Is Mocked By The World's Most Powerful Market Signal. Forbes. Accessed 6/13/15 from http://www.forbes.com.

Taylor, J. (5/30/13). Global warming alarmists caught doctoring '97-Percent Consensus' Claims. Forbes. Accessed 2/7/15 from http://www.forbes.com.

Tesch, R. (1990). Qualitative Research: Analysis Types and Software Tools. Bristol, PA: Falmer. Thomas, G. and Durant, J. (1987). Why should we promote the public understanding of science? Scientific Literacy Papers, edited by M. Shortland. Oxford: Department for External Studies.

Tisdale, B. (3/26/15). Richard Tol's excellent summary of the flaws in Cook et al. 2013. Watts Up With That? Accessed 9/12/15 from http://www.wattsupwiththat.com.

Timmer, J. (9/4/14). Scientific consensus has gotten a bad reputation - and it doesn't deserve it. Ars Technica. Accessed 9/15/14 from http://www.arstechnica.com.

Tol, R.S.J. (2014). Quantifying the consensus on anthropogenic global warming in the literature: a re-analysis. Energy Policy, 73: 701-705.

Tremayne, M. (2012). Introduction: Examining the blog-media relationship. In M. Tremayne (Ed.). Blogging, Citizenship, and the Future of Media, pp. ix-xix. Routledge: New York, NY.

Trumbull, D.J. et al. (2000). Thinking scientifically during participation in a citizen-sicnec project. Science Education, 84(2): 265-275.

Wainwright, J. (2010). Climate Change, capitalism, and the challenge of transdisciplinarity. Annals of the Association of American Geographers, 100(4): 983-991.

Wainwright, J. and Mann, G. (2012). Climate leviathan. Antipode, 45(1): 1-22.

Waitt, G. (2005). Doing Discourse Analysis. In Qualitative research methods in human geography $2^{\text {nd }}$ ed. Ed. I. Hay. Oxford University Press: Melbourne.

Watts, A. (9/4/14). How 'scientific consensus' ended up with a bad reputation. Watts Up With That? Accessed 9/15/14 from http://wattsupwiththat.com.

Weber, M. [1904-1905] 1958. The Protestant Ethic and the Spirit of Capitalism. Scribner's Press: New York.

Weber, R.P. (1990). Basic Content Analysis, $2^{\text {nd }}$ ed. SAGE Publications, Inc: Newbury Park, CA.

Weber, M. (1978). Economy and Society. Vols. 1 \& 2. G. Roth and C Wittich eds. University of California Press: Berkeley.

Werskey, G. (2007). The Marxist critique of capitalist science: a history in three movements? Science as Culture. 16(4): 397-461. 
White, H. (2002). Combining quantitative and qualitative approaches in poverty analysis. World Development, 30(3): 511-522.

Whitehead, A.N. (1925). Science and the Modern World. Macmillan

Wilkins, J.S. (2008). The roles, reasons, and restrictions of science blogs. Trends in Ecology \& Evolution, 23(8), 411-413.

Williams Woolley, A. et al. (2010) Evidence for a collective intelligence factor in the performance of human groups. Science, 330: 686-688.

Wixom, J.A. (In prep a). Arguing over agreement: media coverage of the consensus on anthropogenic climate change. To be submitted to Science Communication. . (In prep b). Citizen science and environmental learning: a case study of the

SATELLITES program. To be submitted to Ecology \& Society.

W.W. (6/20/13). Climate change: A cooling consensus. The Economist. Accessed 8/29/15.

Vernant, J.-P. (1988). Myth and Society in Ancient Greece. The MIT Press: Cambridge, MA.

Zoellick, B., Nelson, S.J., and Schauffler, M. (2012). Participatory science and education: bringing both views into focus. Frontiers in Ecology and the Environment. 10(6): 310-313. 